


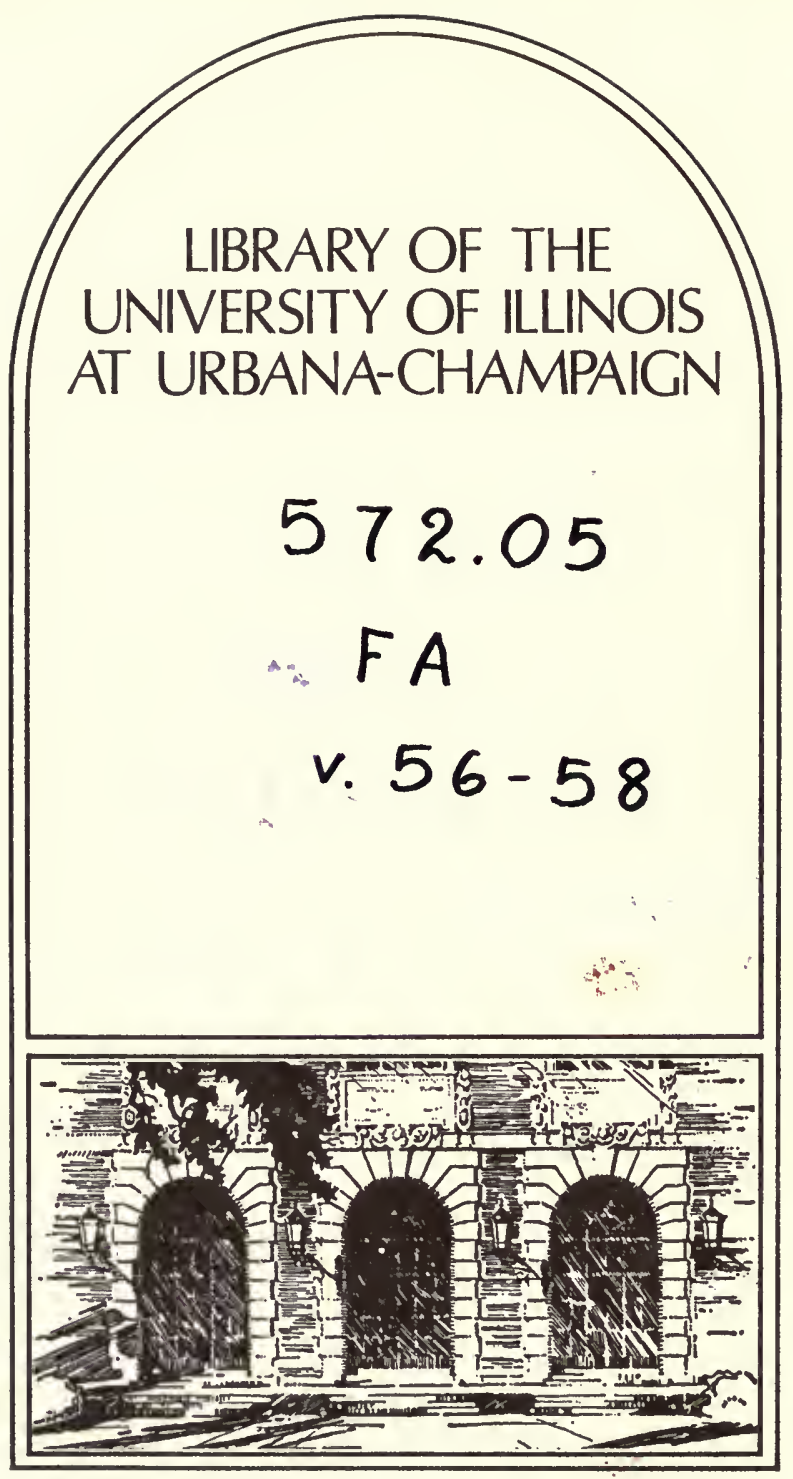


The person charging this material is responsible for its return to the library from which it was withdrawn on or before the Latest Date stamped below.

Theft, mutilatlon, and underlining of books are reasons for disciplinary action and may result in dismissal from the University.

To renew call Telephone Center, 333-8400

UNIVERSITY OF ILLINOIS LIBRARY AT URBANA.CHAMPAIGN

al

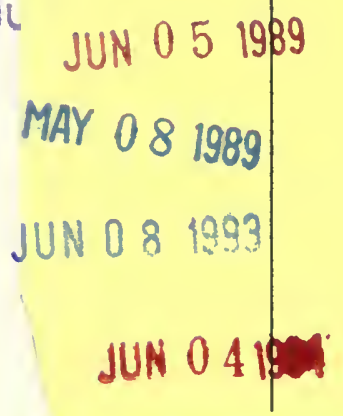







\title{
TIKCHIK VILLAGE
}

A NINETEENTH CENTURY RIVERINE COMMUNITY

IN SOUTHWESTERN ALASKA

\author{
by \\ JAMES W. VANSTONE
}

University of Illinois

JAN $5 \quad 1970$

Lurng

FIELDIANA: ANTHROPOLOGY

VOLUME 56, NUMBER 3

Published by

FIELD MUSEUM OF NATURAL HISTORY OCTOBER 14, 1968 






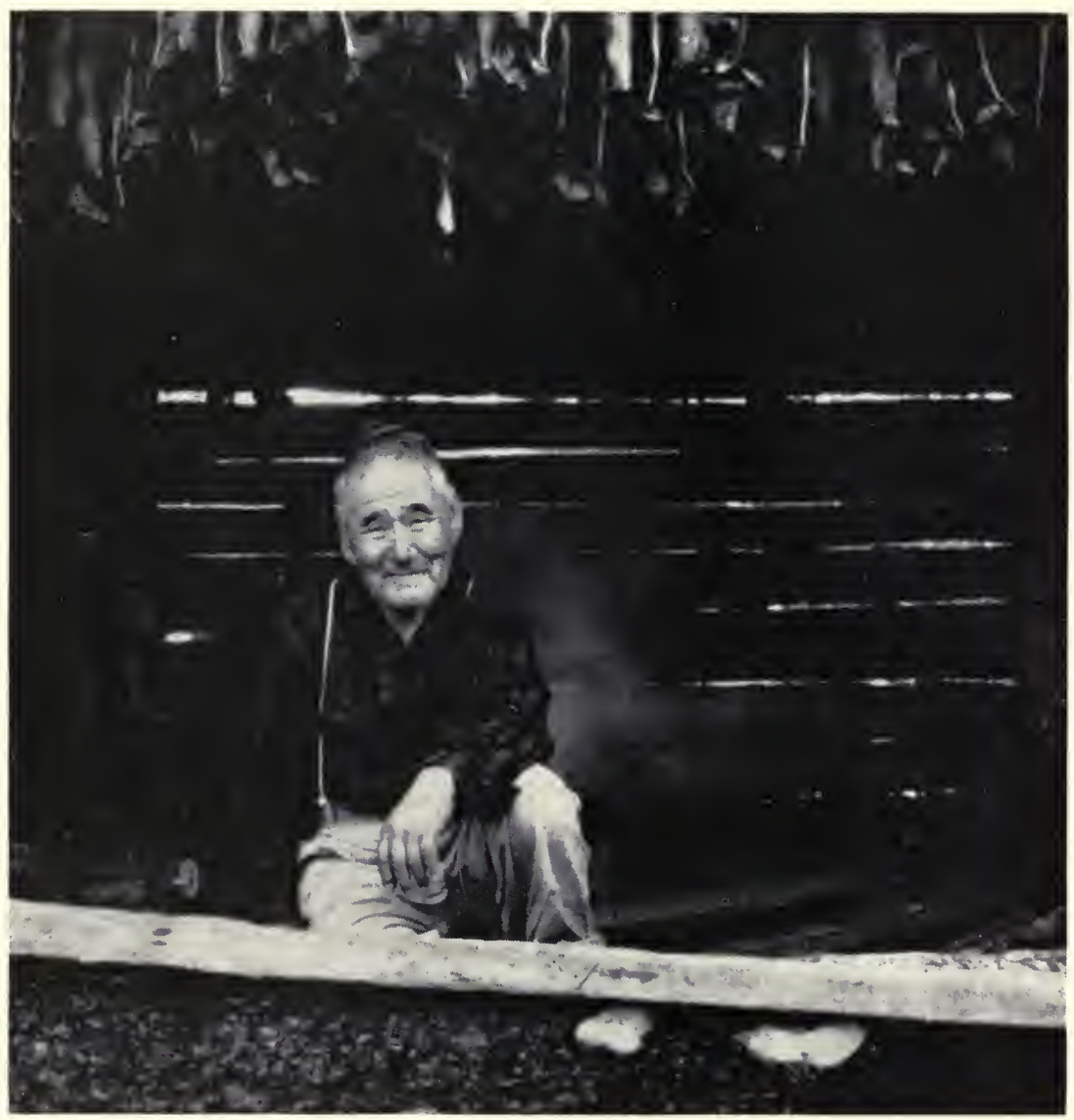

Ivan Ishnook, the last Tikchik survivor. 


\title{
TIKCHIK VILLAGE
}

\section{A NINETEENTH CENTURY RIVERINE COMMUNITY}

\section{IN SOUTHWESTERN ALASKA}

\author{
$b y$ \\ JAMES W. VANSTONE \\ Associate Curator, North American Archaeology and Ethnology
}

FIELDIANA: ANTHROPOLOGY

VOLUME 56, NUMBER 3

Published by

FIELD MUSEUM OF NATURAL HISTORY

OC'TOBER 14,1968 
Library of Congress Catalog Card Number. 68-31884

PRINTED IN THE UNITED STATES OF AMERICA BY FIELD MUSEUM PRESS 


\section{Contents}

LIST OF ILLUSTRATIONS

ACKNOWLEDGEMENTS . . . . . . . . . . . . . . . 215

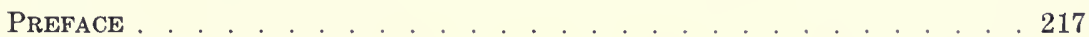

TiKCHIK Village IN History . . . . . . . . . . . . . . . . . . . . 222

Excavations . . . . . . . . . . . . . . . . . 231

Houses . . . . . . . . . . . . . . . . . . 233

Kashgees . . . . . . . . . . . . . . . . . . . . . . . . . . . 252

Middens and test trenches . . . . . . . . . . . . . . 258

Burials . . . . . . . . . . . . . . . . . . 260

Collections

Locally manufactured goods . . . . . . . . . . . . . . . . . . . . 265

Chipped stone . . . . . . . . . . . . . . 265

Ground stone . . . . . . . . . . . . 266 26

Bone and antler . . . . . . . . . . . . . . . 272

Clay . . . . . . . . . . . . . . . 279

Bark and root . . . . . . . . . . . . . . . 283

Glass . . . . . . . . . . . . . . . . 284

Non-Eskimo pottery . . . . . . . . . . . . . . . 284

Leather . . . . . . . . . . . . . . . . 284

Metal . . . . . . . . . . . . . . . . 284

Imported manufactured goods . . . . . . . . . . . . . . . . 288

Non-Eskimo pottery . . . . . . . . . . . . . . . . 288

Glass . . . . . . . . . . . . . . . . . 292

Clay . . . . . . . . . . . . . . . 296

Textile . . . . . . . . . . . . . . . 296

Metal . . . . . . . . . . . . . . . 296

CONTINUITY AND INNOVATION . . . . . . . . . . . . . . . 306

Time and Change . . . . . . . . . . . . . . . . . 324

$1829-1866$. . . . . . . . . . . . . . 324

$1867-1900 \ldots . \ldots 331$

INTERPRETATIONS AND CONCLUSIONS . . . . . . . . . . . . . . . . . 341

REFERENCES . . . . . . . . . . . . . . . . . . 352

Appendix, Tikchik trait list . . . . . . . . . . . . . . . . 358 


\section{List of Illustrations}

Ivan Ishnook, the last Tikchik survivor

Frontispiece

\section{TEXT FIGURES}

1. Map of Alaska showing places mentioned in the text . . . . . . . . 218

2. Map of the Nushagak River region showing places mentioned in the text

3. Map of the Tikchik village site . . . . . . . . . 232

4a. Air photograph of Tikchik in early June, 1965 before excavation . . . 234

4b. Tikchik in August after excavation . . . . . . . . . . . . . . . . 235

5. House 1. . . . . . . . . . . . . . . . . . . . . . 238

6. House 2. . . . . . . . . . . . . . . . . . . . . . . . . . 240

7. House 3 . . . . . . . . . . . . . . 241

8. House 4 . . . . . . . . . . . . . . . . . . . . . . . . . 242

9. House 5 . . . . . . . . . . . . . . . . . . . . . . . . . . . 243

10a. Collapsed roof timbers in house 5 . . . . . . . . . . . . . . . . 245

10b. A reconstruction of the living area of house 5 . . . . . . . . . . 245

11. House 6. . . . . . . . . . . . . . . . . . . . 246

12. House 7 . . . . . . . . . . . . . . . . . 247

13. House 8 . . . . . . . . . . . . . . . . . . . . . . . . . . . 248

14. House 9 . . . . . . . . . . . . . . . . . . . . . . . . . . . . 249

15. House 10 . . . . . . . . . . . . . . . . . . . . . . . . 251

16. Kashgee 1 . . . . . . . . . . . . . . . . . . . . . . . . . . . .

17. Reconstruction of a wall in kashgee 1 . . . . . . . . . . . . . . 254

18. Kashgee 2 . . . . . . . . . 256

19. Bead types according to shapes, showing cross sections of each . . . 294

\section{TABLES}

1. House construction features . . . . . . . . . . . . . 250

2. Distribution of tempering material in Tikchik pottery . . . . . . . . 282

3. Surface treatment and temper comparison of Tikchik pottery . . . . 283

4. Animal bones recovered from the Tikchik site . . . . . . . . . . . 310

\section{PLATES}

1. Chipped and ground stone artifacts . . . . . . . . . . . . 264

2. Ground stone artifacts . . . . . . . . . . . . . . 268

3. Ground stone and antler artifacts . . . . . . . . . . . . . . . . 269

4. Bone and antler artifacts . . . . . . . . . . . . . . . . . . . . 273

5. Bone and antler artifacts . . . . . . . . . . . . . . . . . . . . 276

6. Bone, antler, bark and leather artifacts and locally-made pottery . . . 277

7. Metal artifacts . . . . . . . . . . . . . . . . . 286

8. Metal, glass and imported pottery artifacts . . . . . . . . . . . 291

9. Metal artifacts . . . . . . . . . . . . . . . . . . . . . . . . . 299

10. Metal artifacts . . . . . . . . . . . . . . . . . . . . 301

11a. Locally-made pottery . . . . . . . . . . . . . . . . . . . . . . 314

11b. Locally-made pottery . . . . . . . . . . . . . . . . . . . . . . 315

11c. Locally-made pottery . . . . . . . . . . . . . . . . . . . . . 316 


\section{Acknowledgements}

The archaeological field work on which this study is based was financed by the Canada Council; the National Museum of Canada provided additional financial support so that related ethnographic information could be collected. I am grateful to Dr. David J. Damas, Human History Branch, National Museum of Canada, for his interest and encouragement. Able assistance in the field was provided by Mr. David Lumsden and Mr. Douglas Smith, at that time undergraduate students in anthropology at the University of Toronto.

In the field, the following individuals were particularly helpful because of their interest in the work and their willingness to contribute time and effort to help me solve the many logistic problems that are associated with archaeological excavations in Alaska: Mr. and Mrs. Charles Lucier of Anchorage, Mr. and Mrs. C. J. Stovall, and Mr. and Mrs. Alfred Andree of Dillingham. Most of the ethnographic information in this study was obtained with the willing assistance of Mr. Ivan Ishnook, Mr. Blunka Ishnook, Mr. Antoine Johnson, and Mr. Charles Nelson, all of New Koliganek.

The author is also grateful for the help and advice of many people during his study of the collections from the Tikchik site. Expert assistance in the laboratory was provided by Miss Kathleen Lynch, then an undergraduate student in anthropology at the University of Toronto. Her skill and careful work are apparent in the pottery reconstructions illustrated in Plate 11. Dr. Walter Tovell of the Royal Ontario Museum identified lithic materials from the site and Dr. R. M. Organ of the same institution gave the author much valuable advice concerning the cleaning and preservation of metallic specimens. Assistance in identifying and describing trade goods was provided by Professor Kenneth E. Kidd of Trent University, Peterborough, Ontario, and Mr. D. S. Weaver of Waterloo, Ontario. Dr. Don E. Dumond of the University of Oregon kindly examined the Tikchik pottery and offered valuable advice concerning its relationship to pottery from other sites in southwestern Alaska. Dr. Dumond also made available his detailed knowledge of pottery sequences on the Alaska Peninsula and, at a considerable sacrifice of his own 
time, corresponded frequently with me on Alaskan pottery problems in general. The skeletal material was examined by Dr. Robert E. Dailey, Florida State University, who provided data on age and sex. The text figures and maps were drawn by Mr. Gustaf Dalstrom of Field Museum of Natural History and, finally, the excellent photographs are the work of Mr. John Glover, Photographic Department, Faculty of Arts and Sciences, University of Toronto.

For critical comments and helpful suggestions during the preparation of this study I wish to express my appreciation to Dr. Wendell $\mathrm{H}$. Oswalt of the University of California, Los Angeles. Nearly every phase of the description and analysis of the Tikchik collections was discussed with Dr. Oswalt who is, however, in no way responsible for any errors either of fact or interpretation. 


\section{Preface}

The present study is the result of my interest in the culture history of the Nushagak River region in southwestern Alaska and my attempts to gather information about the population of the river system from the time of earliest historic contact until the present (Fig. 1). The area has been occupied in historic times by a coastal Eskimo population combining fishing with sea mammal hunting and by interior Eskimos who emphasize fishing and land hunting but make frequent trips to the coast, particularly during the summer months. During the contact period, however, the cultural distinction between the two groups has gradually been obliterated by the depradations of epidemics and by migrations into the area, mostly from the Alaska Peninsula to the south and the Kuskokwim River to the north.

The Nushagak River region is a particularly suitable area for the study of nineteenth century culture change. The region was penetrated by the Russians early in that century, and the mouth of the river was the site of the first Russian trading post north of the Alaska Peninsula, constructed in 1818. A mission of the Russian Orthodox Church was established at the post in 1842 and the Moravian Church entered the mission field in the area in 1886. The fur trade was well developed throughout the period of contact and miners, the commercial fishing industry in Bristol Bay, the reindeer herding program, health and education services have all at various times been instrumental in bringing about change in the culture of the population of the region. Of particular importance in this regard has been the commercial salmon fishing industry which began in the 1880 's and has, since that time, been the major economic factor influencing the lives of the Eskimos of the Nushagak River and Nushagak Bay.

As might be expected, all these agents of contact have provided a rich store of published and archival information on the Eskimos of the region, information that covers most of the nineteenth and early twentieth centuries. In 1963 I began a detailed study of these published and unpublished source materials and prepared an annotated ethnohistorical bibliography on the region (VanStone, 1968) for my own use and the use of others who might become interested in the area. In addition to their value for the study of early phases of con- 
tact between Eskimos and Europeans, these materials provide a firm foundation for the consideration of contemporary Nushagak Eskimo culture.

During the summer of 1964, I conducted an archaeological survey along the Nushagak River and three of its major tributaries, the Wood, Nuyakuk, and lower Mulchatna rivers (Fig. 2). A total of 45 sites belonging to the period of historic contact were located and many of them were mapped. My familiarity with historical source materials for the area made it possible for me to know the names and locations of many sites prior to the beginning of the survey. The names of others, together with some population estimates and much ethnographic information, were obtained from informants at the present-day villages of New Koliganek, Ekwok, and New Stuyahok and at various bay locations. Additional ethnographic data and information on nineteenth century settlements were obtained from informants at New Koliganek and Dillingham after the completion of archaeological work during the summer of 1965 . The material from historic sources and the ethnographic data form the basis of a recently published monograph on the ethnohistory of the Nushagak River region (VanStone, 1967). I also intend to prepare a detailed report on nineteenth and early twentieth century settlement patterns throughout the river system, but this study will require additional field work.

The archaeological survey of the Nushagak and Nuyakuk (which included the lower Tikchik) rivers in 1964 revealed two centers of population during the period of historic contact; an upper and a middle river center. Nushagak Bay, of course, constituted a third and somewhat more populous center. As a result of the survey, it was decided to begin intensive excavations in the region with one of the upriver sites and then continue with the excavation of one or more middle river settlements and one on Nushagak Bay. Of the severai upriver sites, only two were considered large and important enough to warrant extensive excavation; the Old Koliganek site near the mouth of the Nuyakuk River and Tikchik located approximately two kilometers above the mouth of the river of that name. Old Koliganek is mentioned frequently in the historical sources and it seems likely that it was occupied in the 1840's and perhaps earlier. It was as large as Tikchik but had the disadvantage, from the standpoint of my interests, of not having been totally abandoned until

FIG. 1. Map of Alaska showing places mentioned in the text. 


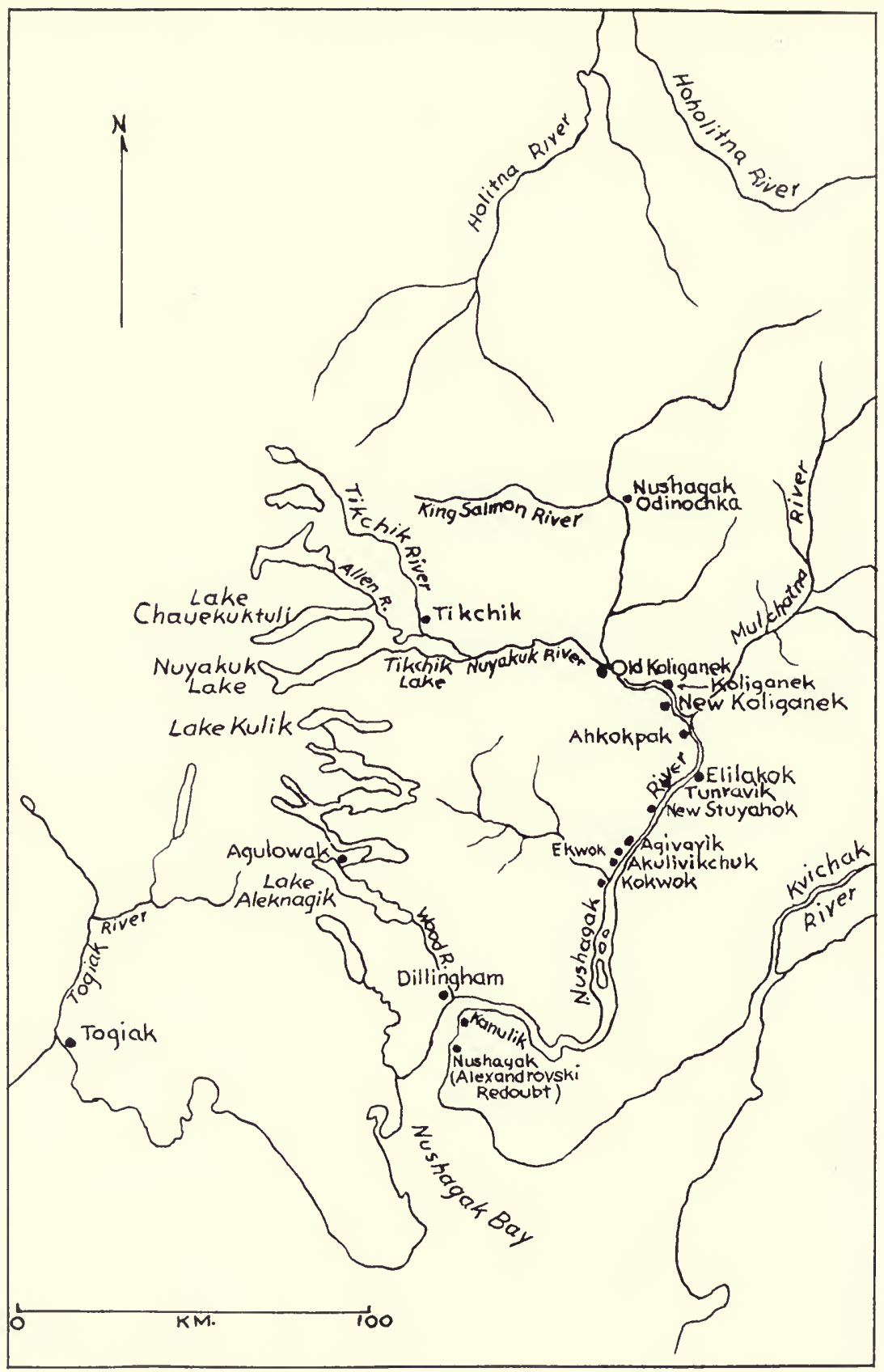

FIG. 2. Map of the Nushagak River region showing places mentioned in the text. 
around 1940. The Tikchik site, on the other hand, while being just as old or older, although not mentioned as frequently in the historical sources, was abandoned at the turn of the century. Thus, it could be expected to represent a segment of a period of rapid change, one which is increasingly difficult for informants to bring to mind. It is nearly as large as any site in the interior region and the survey appeared to indicate that it represented a continuous, relatively uncomplicated occupation. Small test pits put down in the summer of 1964 showed that midden deposits, except in one or two places, were thin and that there would probably be no preservation of organic material. It was not expected, however, that frozen sites would be encountered in this area. Most important of all, perhaps, was the availability of a single informant, resident at New Koliganek, who had been born in the village and a number of other elderly people who might be able to provide data about the site and its dwellers.

Excavations at the Tikchik site were begun on June 17, 1965 and completed on August 17. In retrospect, there were both advantages and disadvantages in selecting this site. It proved to be less rich in recovered materials than had originally been hoped and, most disappointing of all, no clearly separate levels representative of Russian and American influences were established. This latter problem had been encountered before in the excavation of an historic site in southwestern Alaska and it may be that such an ideal stratigraphic separation and the consequent isolation of short term exotic influences is not possible in this area (Oswalt and VanStone, 1967, pp. 101-102). However, the Tikchik site proved to be extremely rich in information concerning house and kashgee construction and informants provided much valuable information about the period of occupation.

Although the artifact collection from Tikchik is not extensive, it is sufficiently varied, particularly in trade goods, to provide valuable data about the immediate effects of material change in a small community when the agents of change are from a technologically advanced western society. The Tikchik excavations constitute a useful base line for future excavations along the Nushagak River and in Nushagak Bay. They also provide valuable data for comparison with recovered materials from the growing number of historical sites being excavated in various parts of Alaska and particularly in southwestern Alaska. The time is rapidly approaching when it may be possible, with the aid of archaeological, historical, and ethnographic data, to make broad generalizations about the mutual impact of whites and Eskimos upon each other during the early contact period. 


\section{Tikchik Village in History ${ }^{1}$}

The meaning of the word Tikchik as applied to the site, the river, and to the large lake in the immediate vicinity is difficult to determine. According to the late Mr. Frank Waskey, a long time resident of the Nushagak River region, it is a corruption of an Eskimo word which means stink and was applied to the river because each summer, for a long time after the red salmon had spawned, the water tasted and smelled bad (Bower, 1927, p. 25). Informants in Nushagak River villages that I questioned, however, could not confirm this. Some of them insisted that the word was just a place name. Throughout its recorded history the settlement was occupied by Eskimoan speakers of the Western Eskimo language stock. This linguistic grouping is separated into three major dialect clusters, Yuk, Cux, and Suk (Hammerich, 1958, pp. 632-639); the Tikchik people spoke Yuk (plural, Yuit). This dialect was limited distributionally to an area extending north to St. Michael and south to Bristol Bay and the western end of Iliamna Lake. The inland range of Yuk was to the village of Paimiut on the Yukon River and the vicinity of Aniak on the Kuskokwim River. The Yuk-speaking Eskimos think of themselves as Yupik or "real people" and some authors have referred to the language by this designation. The Eskimos of the Nushagak River region have the ethnic name of Kiatagmiut. This sub-group of Yuk speakers occupied, at the time of historic contact, the entire Nushagak River and the area to the west as far as and including the Wood River Lakes and the Tikchik Lakes (Oswalt, 1967; VanStone, 1967). Nushagak Bay was inhabited by the Yuk-speaking Aglegmiut. There is some doubt, however, as to whether Tikchik was ever occupied exclusively by Kiatagmiut.

The cultural center of Yupik-speaking peoples was along the central Bering Sea coast of Alaska. In this area the people were oriented toward a maritime economy in which the seal was the most important animal killed. On the adjacent tundra there was some caribou hunting, and fishing for salmon was significant at the mouths of rivers and in certain bays. The Yupik penetration of the Nushagak River sys-

${ }^{1}$ Much of this chapter has been summarized from VanStone, 1967. 
tem, as well as other river systems in southwestern Alaska, took place at some unknown time during the prehistoric period when the people presumably moved inland from the Bering Sea coast. It was their already-acquired salmon fishing technology and the variety and abundance of these fish that made the Eskimos able to exploit effectively an inland environment like that along the Nushagak River and its tributaries.

The first well-documented contact between Yupik-speaking peoples and Europeans took place in 1818 when a Russian party was dispatched from Kodiak Island to make a thorough exploration of the territory to the north of Bristol Bay. The party appears to have been under the direction of Petr Korsakovski, an employee of the Russian-American Company, and its major aim was to establish a redoubt at the mouth of the Nushagak River. Most of the expedition proceeded from Kodiak to Cook Inlet and traveled overland to Iliamna Lake in the spring of 1818. From there the route led down the Kvichak River to Bristol Bay and along the coast to the mouth of the Nushagak. Some of the party, including Fedor Kolmakov, of mixed Russian and aboriginal Siberian ancestry, were left there to construct a fortification while the rest, under Korsakovski himself, went on to explore the mouth of the Kuskokwim River with the aid of another section of the expedition which had proceeded to that point by boat. When they returned, Korsakovski found that the work had been completed. The redoubt was named Alexandrovski, perhaps in honor of the Tsar, and Kolmakov, who had been put in charge, had already established trade relations with the Eskimos living in the neighborhood (Berkh, 1823, pp. 46-48; Tikhmenev, 193940, pt. I, pp. 300-302; Chernenko, 1967, p. 16).

Since Kolmakov was an energetic trader, he was extremely useful in spreading the Russian-American Company's influence in the general area of Alexandrovski Redoubt. However, information about the people of the interior was very difficult to obtain. Consequently, the company decided to send an overland expedition under the leadership of Ivan Filippovich Vasiliev to explore the country north of the redoubt, to make geographical and ethnological observations, and to establish trade relations with the Eskimos. Vasiliev set out from the redoubt in June of 1829 and ascended the Nushagak River. He was accompanied by three Russians, six Aleuts from Kodiak Island, and ten "baptized Aglegmiuts" whose loyalty was seemingly assured by keeping their families as hostages at the redoubt (Zagoskin, 1967, p. 280). 
Vasiliev's route beyond the lower river is partly conjectural, but he appears to have followed a western tributary of the Nushagak, probably the Nuyakuk, and explored Tikchik Lake and Lake Chauekuktuli. The Aglegmiut, who had accompanied him to act as guides, became fearful as they neared the territory of the Kuskowagamiut and eventually refused to proceed further. Although the journals of Vasiliev were never published, a letter in the Russian-American Company records mentions that the explorer stopped at a Kuskowagamiut settlement called "Tuksa" and attempted to persuade some of the inhabitants to guide him across the mountains to the Kuskokwim River. This they refused to do and the party was forced to return to Alexandrovski (Tikhmenev, 1939-40, pt. I, pp. 339-341; Russian-American Company Records: Communications Sent, vol. 6, no. 244, folios 478).

It seems virtually certain that the village referred to as "Tuksa" was actually Tikchik. It is described as being in approximately the correct location, and it is logical to assume that when Vasiliev was thwarted in his efforts to proceed beyond Lake Chauekuktuli, he would proceed to the nearest sizeable settlement in an attempt to obtain assistance. If the identification is correct, then, this meeting in the summer of 1829 was undoubtedly the first between the people of Tikchik and a European at the village.

The following summer, in 1830, Vasiliev again attempted to reach the Kuskokwim River by way of the Nushagak and this time he was successful. Leaving Alexandrovski Redoubt on June 19, his party ascended the river to its headwaters, crossed over to the Holitna in an "agonizing five-day march," and descended that stream to the Kuskokwim. Two years later, in 1832, Fedor Kolmakov and Semen Lukin, mixed-blood assistant to Kolmakov at the redoubt and an interpreter for the Vasiliev party, made a similar trip with a party of Eskimos and founded the first trading station on the Kuskokwim, a single barabora built at its confluence with the Holitna. This post was abandoned after a year and still another location was tried before Kolmakovski Redoubt was built in 1841 opposite the mouth of the Kwik River, approximately 16 kilometers above Aniak. It remained an important trading center until abandoned by the Russian-American Company in 1866 (Tikhmenev, 1939-40, pt. I, p. 341; VanStone, 1959 , p. 46, footnote 28; Zagoskin, 1967, pp. 80, 252; Russian-American Company Records: Communications Sent, vol. 7, no. 257, folio 269$)$. 
Since the expeditions of 1830 and 1832 traveled by way of the upper Nushagak, it is probable that they had no direct contact with Tikchik. More important than any isolated meetings, however, is the fact that the exploration of Bristol Bay and the Nushagak River, together with the founding of Alexandrovski Redoubt, later to be called Nushagak by Anglo-Americans, played a vital role in opening up the interior regions of southwestern Alaska to the fur trade. Kolmakovski Redoubt continued to be supplied from Alexandrovski until 1845, and the route from the headwaters of the Nushagak River, across the divide and down the Holitna or Hoholitna to the Kuskokwim became a heavily traveled route with supplies going upriver into the Kuskokwim country and furs proceeding in the opposite direction (see Oswalt, 1963, chap. 1; Chernenko, 1967). Although Tikchik was not on the direct route of these regular journeys between the Kuskokwim and Alexandrovski Redoubt, the settlement could not fail to have been brought within the influence of the trading post and to have been drawn increasingly into the flourishing fur trade that was rapidly developing throughout southwestern Alaska.

In 1841 the first Russian Orthodox Church north of the Alaska Peninsula was established at Alexandrovski Redoubt and missionaries began to penetrate the Nushagak River country. Although little is known concerning the exact nature of their contacts with the Eskimos of the interior regions, an early reference to Tikchik occurs in the vital statistics of the church at the redoubt. In 1847 two Tikchik men, one 35 years old and the other 50 , probably visitors to Alexandrovski, are listed as having been baptized. Residents of the settlement continue to be mentioned more or less regularly in the statistics until 1882 and there is some indication that it may have been visited by a missionary as early as 1850 (Alaska Russian Church Archives, vital statistics, Nushagak, 1843-1931). Aside from comments concerning Vasiliev's probable visit to Tikchik in 1829, these are the only references to the village during the Russian period that have come to light.

The significance of Russian activities in the lives of the inhabitants of Tikchik may be determined only within the general framework of Russian expansion into interior Alaska. It is clear from the sources that the primary purpose of Russian penetration was the extension of the fur trade. We have assumed that the Tikchik Eskimos were rapidly drawn into this trade and it is likely that shortly after initial contact they began making annual trips to the mouth of the Nushagak River to exchange their furs for trade goods at Alexandrovski Redoubt. 
From the records of the Russian-American Company it is possible to extract some scanty information concerning the methods by which the manager of Alexandrovski Redoubt dealt with the Eskimos of the surrounding area for furs. When new contacts were established with remote villages like Tikchik, an attempt was made to determine the community leaders, or toyons as the Russians called them. These individuals were given silver medals, called "United Russia," with the Tsar's picture on one side, a certificate designating the leader as a person of authority recognized by the company, and occasional incentive gifts. The general manager frequently warned Fedor Kolmakov and his successors at Alexandrovski against handing out the medals indiscriminately. The post manager was supposed to keep a careful account of those medals he did distribute and even to try to retrieve them from the families of toyons who died so that they might be awarded once again. The toyons were supposed to be individuals who were held in respect by the people and whose friendly relations with the Russians would be of definite benefit to the company. They encouraged their fellow villagers to hunt and bring their furs to the redoubt. It is doubtful whether the toyons ever actually had as much power and authority in their communities as the company's officials thought they had. Nevertheless, in one way or another, a faithful toyon could encourage the hunters in his village to expend more energy in the company's behalf than they might otherwise have been inclined to do (Russian-American Company Records: Communications Sent, vol. 8 , no. 322 , folio 247 ; vol. 9 , no. 460 , folio 350 ; vol. 16 , no. 467 , folios $178-179$; vol. 17 , no. 387 , folios $370-371$ ).

Although this was the traditional manner of dealing for furs with the inhabitants of southwestern Alaska, the Russians did not hesitate to try other methods if they gave promise of being successful. For example, in the summer of 1839 a party of hired Eskimos went out from Alexandrovski Redoubt to hunt beavers. The hunters were paid a specific wage and all fur taken belonged to the company. This hunt was not only highly successful, but the Eskimos seemed to approve of the new type of arrangement (Russian-American Company Records: Communications Sent, vol. 18, no. 335, folios 314-317).

It is not known for certain, but we can assume that the Eskimos of this general area, as in other parts of Alaska, were encouraged to become indebted to the company in order to insure that they would have to trade with or work for the local post. The more closely the Eskimos were bound to the company and the more they relied on the trader for supplies and items of European manufacture, the less likely 
they were to pursue traditional subsistence activities. It is certain that many aboriginal hunting techniques began to be forgotten at this time. The company assumed a paternal role, not only controlling the goods which the Eskimos could obtain, but also carefully regulating how much they were to receive.

It appears that Alexandrovski Redoubt, after an initial short period of importance as the only company post north of the Alaska Peninsula, lapsed into relative obscurity with the emergence of other posts in southwestern Alaska. In 1846 it was reduced to an odinochka, or trail house, and subordinated to Nikolaevski Redoubt on Cook Inlet. From this time on until the end of the Russian period, Kolmakovski was supplied through Mikhailovski Redoubt near the mouth of the Yukon River (DRHA, ${ }^{1}$ vol. 1, pp. 365-366; Tikhmenev, 1939-40, pt. II, p. 218; Russian-American Company Records: Communications Sent, vol. 27, no. 267, folio 387).

The center of fur trade activity in southwestern Alaska may have shifted farther north, but Alexandrovski continued to maintain its influence in the Nushagak River region. The number of Russians and creoles actually occupied in trading activities was probably always small but they maintained control over desirable products, and the Eskimos could obtain these only through the exchange of fur. This simple fact explains more than anything else the amazing rapidity with which the Eskimos of southwestern Alaska were exposed to the fur trade. Between 1818 and 1840 the entire region was opened up and trading contacts were established throughout the heavily populated Yukon and Kuskokwim river systems, as well as along the Nushagak and its tributaries.

For a long time after the transfer of Alaska from Russia to the United States, no attempt was made to explore the Nushagak River region. At the end of the nineteenth century the vast inland region north of Bristol Bay still remained comparatively unknown although it was penetrated by occasional trappers and traders, none of whom has left specific accounts of visits to Tikchik. The assets of the Russian-American Company were purchased by Hutchinson, Kohl \& Company of San Francisco. This firm, which apparently ran the Nushagak post for at least a year and possibly two, was soon reorganized to form the Alaska Commercial Company which dominated

1 This is a reference to "Documents Relative to the History of Alaska," 15 typewritten volumes, copies of which are located in the University of Alaska Library and the Library of Congress. These volumes, the first four of which contain most of the Russian era materials, were compiled as part of the Alaska History Research Project (1936-1938) of the University of Alaska. 
trade in southwestern Alaska throughout the rest of the nineteenth century and well into the twentieth. It is possible that American traders at Nushagak abandoned the paternalistic credit system of the Russian-American Company, but whatever may have been the effect of this policy shift on the Eskimos, the post maintained a moderately flourishing trade with the people of the area at least throughout the remainder of the nineteenth century.

Unfortunately, Tikchik village does not appear in any of the census enumerations for Alaska in the late nineteenth century, nor are there any textual references to the village in the known contemporary reports by missionaries, government officials, or travellers. Apparently the settlement was too far inland to be easily accessible, especially since it was not located on an important and heavily populated river. Most of the villages along the Nushagak itself were enumerated in the Federal Census of 1880 (Petroff, 1884) or 1890 (Porter, 1893). Tikchil is incorrectly located on Petroff's map (1884, map 1) and there is no reference to it in the text. The only population listing for the village was obtained by G. W. Bailey, a government official who visited Nushagak in October, 1879 and collected census data from church records. A population of 31 "Kuskoquims" was recorded for Tikchik (Bailey, 1880, pp. 26-27).

The interesting thing about this statement is the reference to the village having been occupied by "Kuskoquims," people from the Kuskokwim River. The earliest historical sources mention relations between the people of the Nushagak River region and those from other parts of southwestern Alaska, particularly the Kuskokwim. It seems likely that the mixture of population in the Nushagak area began in the prehistoric period but the newly established Alexandrovski Redoubt served as an additional attraction for peoples both from the north and south. So the distinction between the coastal Aglegmiut of Bristol Bay and the inland Kiatagmiut may already have been in a state of flux by the time the Russians appeared on the ssene. This trend continued throughout the nineteenth century and into the twentieth, with movements of peoples from the Kuskokwim being particularly common. Therefore, it is altogether possible that Tikchik may have been occupied by Kuskowagamiut at the time Bailey collected his census data. His information would seem to be reliable since it was collected by Russian Orthodox missionaries who spoke the Yupik dialect and specifically gathered information on the places of birth of their parishioners. It may even be that Tikchik was established by Eskimos from the Kuskokwim River sometime 
early in the nineteenth century and may never have been occupied exclusively or even primarily by Kiatagmiut.

Bailey's population listing of 31 for Tikchik seems low in light of the appearance of the site today. However, as will be noted later, there is no reason to believe that all the house pits presently visible were occupied at the same time. An informant at New Koliganek reported that her father, who had lived at Tikchik as a young man, often told her that many residents had died from illnesses before he was born. Since periodic epidemics swept the Nushagak River region after the initial arrival of the Russians, it is likely that the residents of Tikchik would have been affected just as were those of the more accessible villages along the Nushagak River and in Bristol Bay.

The period around the turn of the century at Tikchik was vaguely recalled by Ivan Ishnook, an elderly male resident at New Koliganek in 1965, who is reportedly the last surviving person born at the settlement. He was born in 1889 and told me that he moved from the village with other members of his extended family when he was "just old enough to remember." When Ivan was a small boy the people of Tikchik would leave their village in early summer not long after the ice had gone out of the rivers and lakes and travel down the Nuyakuk and Nushagak rivers to the Alaska Commercial Company post at Nushagak to trade their furs. They travelled in large skin boats that were covered with caribou skins or sometimes brown bear hides. At the post they would sell their furs and obtain tea, flour, sugar, tobacco, gun powder, crackers, and other items in exchange. A brisk trade with peoples of the bay area would also take place as a result of which the Tikchik residents would acquire seal oil and other coastal products. When it came time for the return trip, the big boats would be traded or abandoned and skin-covered kayaks acquired for the return trip which was made by way of the Wood River and the lakes. By this route it was possible to avoid the arduous ascent of the Nushagak and Nuyakuk rivers. By the lakes route there was only the one long portage from Lake Kulik into Nuyakuk Lake.

Ivan Ishnook remembers little about the physical appearance of Tikchik at the time he lived there. Nor is he able to estimate the number of people who were in residence when he was a small boy. He does remember clearly, however, that his own family was the last to leave. The population of the settlement had been virtually wiped out by the "great sickness," as the influenza and measles epidemic of $1899-1900$ is termed locally. Apparently the last survivors were 
Ivan's father's family and his father's brother's family. At Tikchik they lived in one house and it may have been house 7 as designated in this report, although the informant could not be completely certain. Ivan's father had wanted to stay, but the other members of the family were lonely and did not want to remain where there had been so much sickness and death.

And so Tikchik village joined the silent ranks of abandoned settlements in southwestern Alaska. Parenthetically, it is interesting to note the movements of Ivan Ishnook and his family after their departure from Tikchik. Most of Ivan's youth was spent at Agulowak, a large settlement at the mouth of the river of that name on Lake Aleknagik. When he was a young man he moved back inland to the upper Nuyakuk where his first children were born and where the family successfully survived the influenza epidemic of 1918-1919. This was just a summer residence where the young family lived with two others and put up dried fish. In winter they moved to the mouth of the Tikchik River not far from the old Tikchik settlement. Nearly 40 years ago they settled permanently at Old Koliganek where the family continued to live until that village was abandoned for another location a few miles down the river. In 1964 Ivan, now living with his son, moved with the rest of the Koliganek residents to New Koliganek still farther down the Nushagak River. 


\section{Excavations}

The Tikchik village site is located on the east bank of the Tikchik River about two kilometers above its mouth (Fig. 3). The old settlement appears as a cleared area roughly $90 \mathrm{~m}$. long by $38 \mathrm{~m}$. wide on a low bluff about $41 / 2 \mathrm{~m}$. above the level of the river. In the general area of the site, the river bank is relatively high only at the location of the village and for about one-half a kilometer to the south. Below that point the land is low and a heavy growth of willows borders the river on both sides. Just at the site the river makes a sharp turn to the west, a turn which constitutes the downriver side of a large horseshoe bend. This feature appears to be relatively recent, for the old river bank, on the side where the site is located, continues toward the northwest. Below this bank at the upriver end of the site is a marshy area with a slough in early summer. A dense growth of willows covers the bank itself at this point, extends on up the rise, and forms the northwest border of the site. Directly opposite the site the river bank is also very low and there is dense willow growth. Thus, in the general area, the place where the village was located is the only area suitable on either side of the river.

The Tikchik River is relatively deep near the site since the bank is cutting at this point and for a distance of approximately half a kilometer down stream. The cutting is more extensive below the site, although at no point can the banks be said to be cutting back very rapidly. It is likely that the sloping, grass-covered bank in front of the settlement presents roughly the same general appearance today as it did at the time of occupation.

The land on which the village was located rises gradually to a crest at the very rear of the site which is approximately $101 / 2 \mathrm{~m}$. above the level of the river rising to $15 \mathrm{~m}$. in the eastern corner. Then there is a gradual drop down again suggesting that at one time a slough of the river may have extended into the area behind the site. Four house pits are located near the front of the site not far from the river bank, while the other six and the two kashgees are clustered toward the rear near the crest of the rise (Fig. 4, a and b). The gentle rise which characterizes the whole site is most pronounced at the extreme southeastern corner and it is here that the larger of the two 


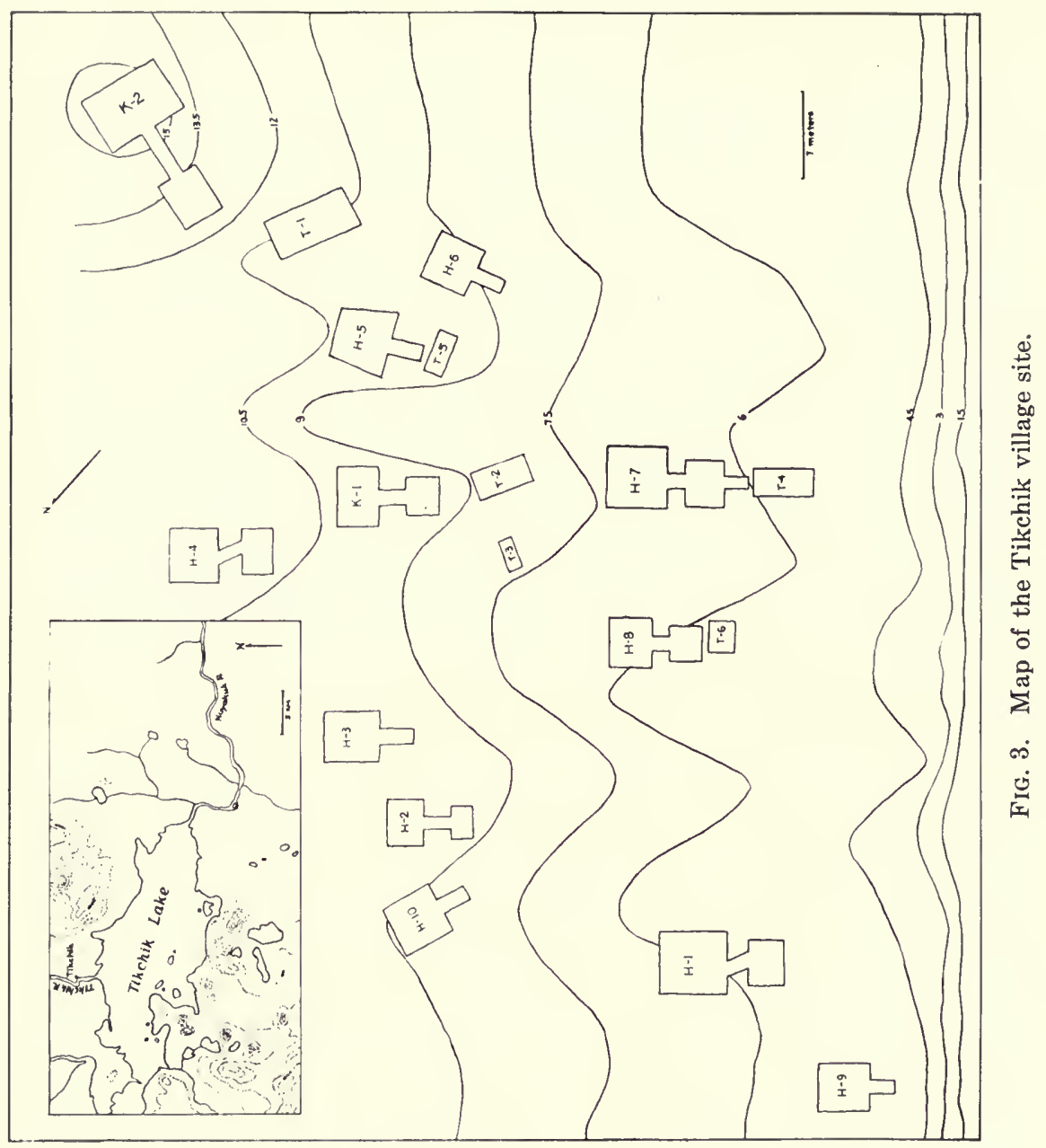


kashgees is situated. This was by far the largest structure in the settlement and its prominent location on the highest point in the general area adds to its impressiveness.

The village was situated so as to afford a good view down the river toward Tikchik Lake. Behind and at some distance from the settlement the land again rises gently but almost immediately Tikchik Mountain begins and eventually rises to a height of more than $800 \mathrm{~m}$. This spectacular feature gains in impressiveness because it is the only really high ground in the immediate vicinity. Vegetation in the area of the Tikchik site consists for the most part of spruce, birch, willows, and alders. The latter two virtually surround the site; even along the river bank a small stand of willows is growing up. Behind the willows around most of the site is an extensive stand of spruce which, at the time the settlement was occupied, may have been thicker and more extensive than it is at present. The trees, which extend back to the base of Tikchik Mountain, are widely spaced and there is even growth. But the forest is not of uniform density. In places there are open meadow-like areas, particularly to the southeast of the site, which in summer are marshes where water continually stands. Birch are not plentiful in the vicinity of the site today, there being only an occasional small tree in the spruce forest, notably on the higher ground.

Both willows and spruce are slowly encroaching on the site. The willows come first and behind them are small spruce trees. Willows are very close to the largest kashgee (K-2) and there is a large clump between houses 2 and 3 and house 9 . Sixty-five years after abandonment, this willow-spruce encroachment has made no real progress, and yet it is not difficult to imagine that within another 200 years or so, the site may be completely covered with these trees.

The purpose of the 1965 field season was to excavate the site as fully as possible. The first step was to strip the sod layer from each of the ten house pits and the two kashgees. An obvious midden deposit was found in front of K-2 and here the sod was stripped from an area measuring $9 \mathrm{~m}$. by $3 \mathrm{~m}$. In addition, five test pits, four of them in front of houses, were opened up at various times during the summer for the purpose of locating, if possible, additional midden material and to determine the maximum thickness of the cultural debris at several places on the site.

\section{THE Houses}

Excavation of the houses posed none of the problems that sometimes confront archaeologists who work in arctic and subarctic re- 


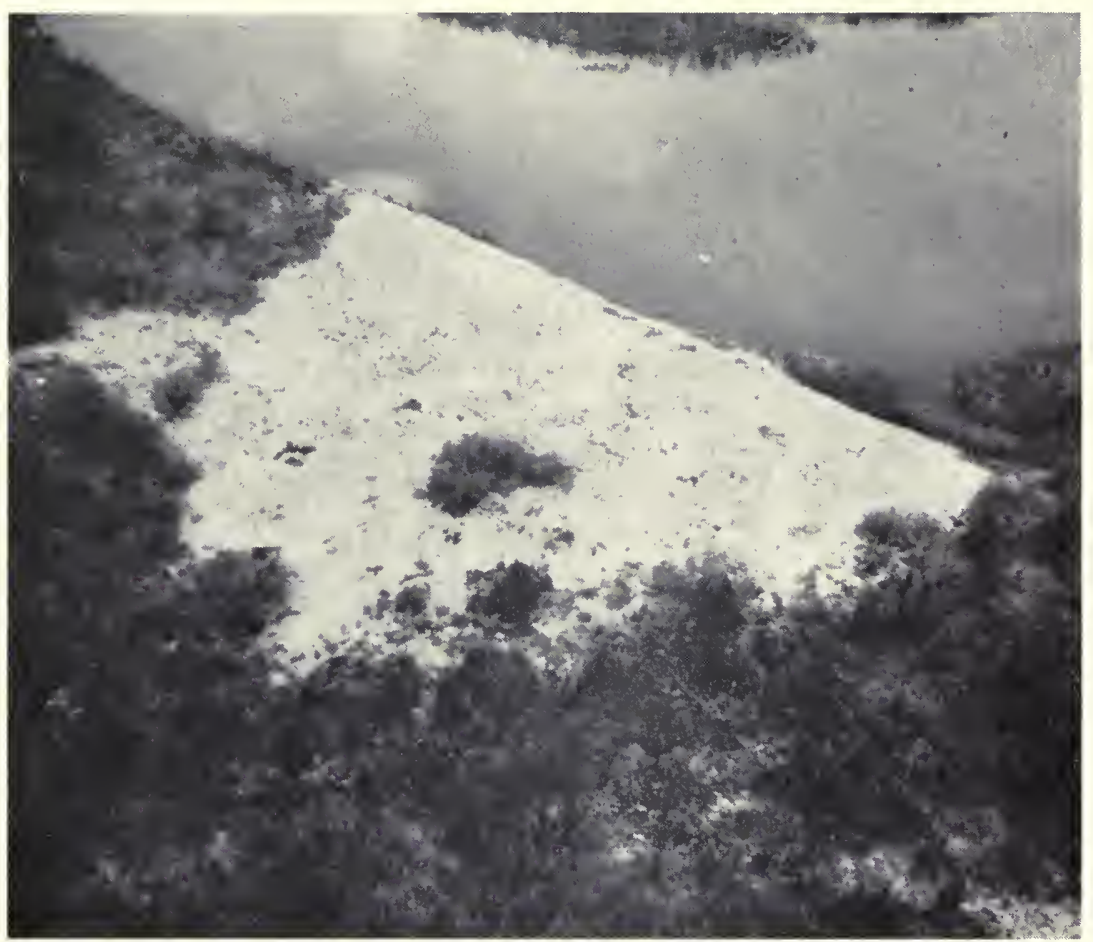

FIG. 4a. Air photograph of Tikchik in early June, 1965, before excavation.

gions. At the time excavations were begun on June 17 the sod was almost completely thawed and only occasionally was frost encountered in any of the house pits. In general, it was found that three individuals could remove the sod from one house per day. Thus, nearly two weeks were spent at this rather unrewarding task. Once the sod was removed, a single excavator worked in each house and the time required to complete the excavation varied from two days to a week depending on the size of the structure. Since frost was not a problem, drainage from the excavations was always good in spite of the fact that the summer was an unusually wet one.

Certain generalizations about the ten houses at Tikchik are appropriate before discussing the details of each one in particular. First of all, it is by no means certain that all the houses were occupied simultaneously. In fact, I am fairly certain that this was not the case. In a later chapter this problem will be dealt with in some detail. Here it is sufficient to say that since the total period of occupancy at Tikchik was not great and since the dwellings are all 
structurally similar, we can deal with them as though they did represent a cluster of contemporary residences. It would be well to keep in mind, however, that there may have been no time during the period of occupation when all ten houses were occupied.

In constructing the houses, the builders in each instance made an excavation in the ground slightly larger than the proposed house before the wood construction was begun. Thus, all the houses were semi-subterranean dwellings. The species of wood employed were spruce and cottonwood. Spruce was utilized for all wall logs and uprights, while spruce and some cottonwood were used for roof timbers. The roof beams in all but two houses $(\mathrm{H}-3,5)$ had disappeared. At the level of the roof of one of these structures (H-5) badly decayed sheets of birch bark were recovered. This sheeting was clearly above the roof logs and doubtless served as a protective layer. It is very likely that on the roofs of at least several of the houses, and perhaps all of them, sod or dirt was placed on top of sheets of birch bark to

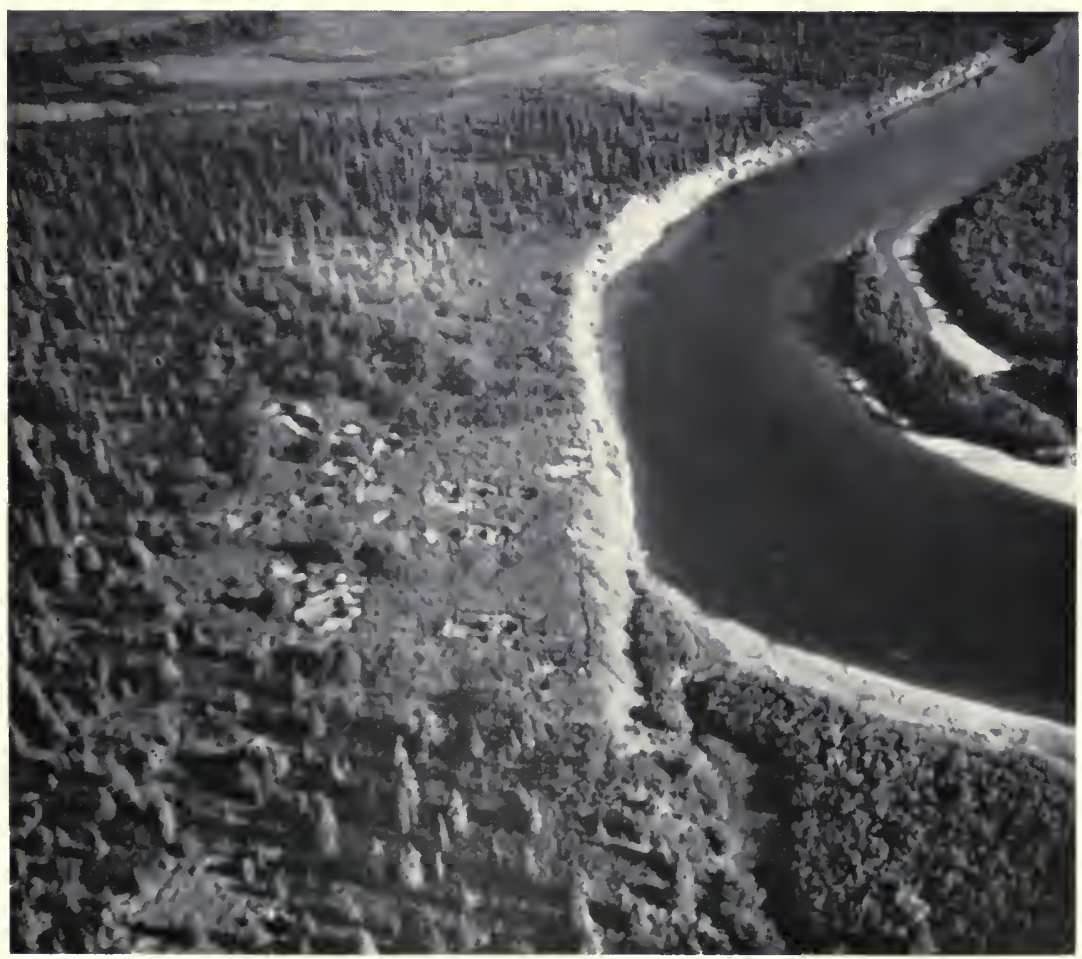

FIG. 4b. Tikchik in August after excavation. 
form a more substantial and waterproof protective cover. In six houses $(\mathrm{H}-1,3,4,6,9,10)$ there was evidence that at least some of the construction timbers had been removed prior to the collapse of the dwelling. Timbers from an abandoned house would, of course, provide a ready supply of firewood or seasoned construction timbers. The removal of logs from some of the houses is one indication that not all the dwellings were occupied simultaneously. The removal of logs naturally increases the difficulties in determining certain features of house construction.

Entrance tunnels are common features of Eskimo dwellings and they are found in all the Tikchik houses. The tunnels of seven houses ( $\mathrm{H}-1,2,3,4,7,8,9)$ opened directly toward the river bank, while one $(\mathrm{H}-10)$ faced slightly downstream and two $(\mathrm{H}-5,6)$ slightly upstream. The floors of the tunnels of all houses were lower than the house floors, thus forming a cold trap and necessitating a step up into the residential area. The tunnels are projected into the main body of the house, although the amount of projection varied considerably. At the inner ends of the tunnels there were usually planks which served to shore up the end and at the same time formed an entrance. In six houses $(\mathrm{H}-1,2,3,4,7,8)$ this took the form of a row of horizontal planks and in two cases $(\mathrm{H}-2,3)$ the top planks formed a rounded sill at the floor level. A row of vertically placed planks served a similar purpose in one house (H-5), the top of the planks forming the sill. In three houses $(\mathrm{H}-6,9,10)$ so little wood remained that it was impossible to determine the construction at the inner end of the tunnel. However, in one of these (H-6) the presence of small rocks in the area suggests that these might have been used.

Tunnel construction in seven houses $(\mathrm{H}-1,2,3,4,5,7,8)$ consisted of a series of parallel horizontal logs held in place by short vertical supports, while in three $(\mathrm{H}-6,9,10)$ there was no wood preservation in the tunnels at all. Short, split logs were consistently placed horizontally on top of the tunnel wall logs and at right angles to these to form the tunnel roofs. As a rule, the tunnels do not seem to have been robbed of logs prior to their collapse except possibly in three structures $(\mathrm{H}-2,3,6)$. In all houses with tunnel log preservation, the tunnel walls had been compressed somewhat by pressure from the earth.

Five of the Tikchik houses had entryrooms or stormsheds at the outer end of the tunnels $(\mathrm{H}-1,2,4,7,8)$. With one exception (H-7), most of the logs had been removed before the structures collapsed and therefore it is possible to make only general remarks about their 
features. In each instance, the outer end of the tunnel extended into the entryroom and terminated in a step up consistent with the one at the opposite end. A curious feature of two houses $(\mathrm{H}-1,4)$ was the fact that the tunnels left the residential areas and entered the entryrooms at a decided angle. Wall logs were preserved in only two house entryrooms $(\mathrm{H}-4,7)$ and these suggest that horizontal timbers held in place by vertical supports may have been the rule. A consistent feature of all the entryrooms was irregular floors that seemed to be nothing more than the natural well-trodden ground surface. Thus, the entryroom "floors" tended to be low in the middle and rise gradually toward the side walls. It would seem, then, that the entryroom was, as a rule, not as carefully constructed as the rest of the house. A marked exception to this can be noted in the case of one house (H-7) which had a carefully constructed entryroom characterized, apparently, by a four-post-center type of roof construction. From this, led a second tunnel similar in every way to the one connecting the residential area with the entryroom.

In over-all plan the houses ranged from virtually square $(\mathrm{H}-4,6$, $7,8,9)$ to rectangular with the longer sides at right angles to the tunnel (H-2), to rectangular with the longer sides parallel to the tunnel $(\mathrm{H}-1,3,10)$. A single house (H-5) was similarly rectangular but was narrower at the back than at the front. At least some trace of horizontal wall logs, presumably always held in place by vertical posts, was found in all houses except two $(\mathrm{H}-6,10)$. Cribbed corners occurred in three dwellings $(\mathrm{H}-4,7,8)$, although in none was this structural feature consistently carried out in all four corners. The horizontal cribbing logs were held in place by narrow vertical posts. The floors of all the houses were of hard packed, darkened earth from which the over-lying material usually separated easily. Near the center of each house a hearth was located. Each fireplace was characterized by discolored earth and a wood ash concentration. In three houses $(\mathrm{H}-2,3,8)$ one or more fire-darkened stones found in or near the fireplace suggested that at one time those hearths may have been clearly delineated by stone borders. A single structure (H-7) had two clearly defined floor levels suggesting that the occupants had spread fresh earth over the first surface in order to obtain a clean floor.

Wall benches, never more than $15-20 \mathrm{~cm}$. above the floor, were a characteristic feature of the Tikchik houses. In three dwellings $(\mathrm{H}-2,6,10)$ only side wall benches were present while in seven others $(\mathrm{H}-1,3,4,5,7,8,9)$ benches occurred along the back as well as the side walls. Horizontally-laid split planks covered the benches 
in two houses $(\mathrm{H}-3,6)$, while in six $(\mathrm{H}-1,2,4,5,7,9)$ the surfaces were of darkened, hard packed earth. One structure (H-8) had grasscovered benches and in another $(\mathrm{H}-10)$ they were too poorly defined to determine the covering. In three houses $(\mathrm{H}-2,5,7)$ the benches had split retaining logs or hewn planks along the outer edges.

Roof form was the most consistent feature of the Tikchik houses. All structures had the remains of vertical posts almost equidistant from the side walls. These four posts presumably supported four horizontal beams, and short roof posts stretched from the beams to the uppermost log in the walls on all four sides. This is the typical four-post-center type of roof construction that is characteristic of Eskimo houses in many parts of Alaska.

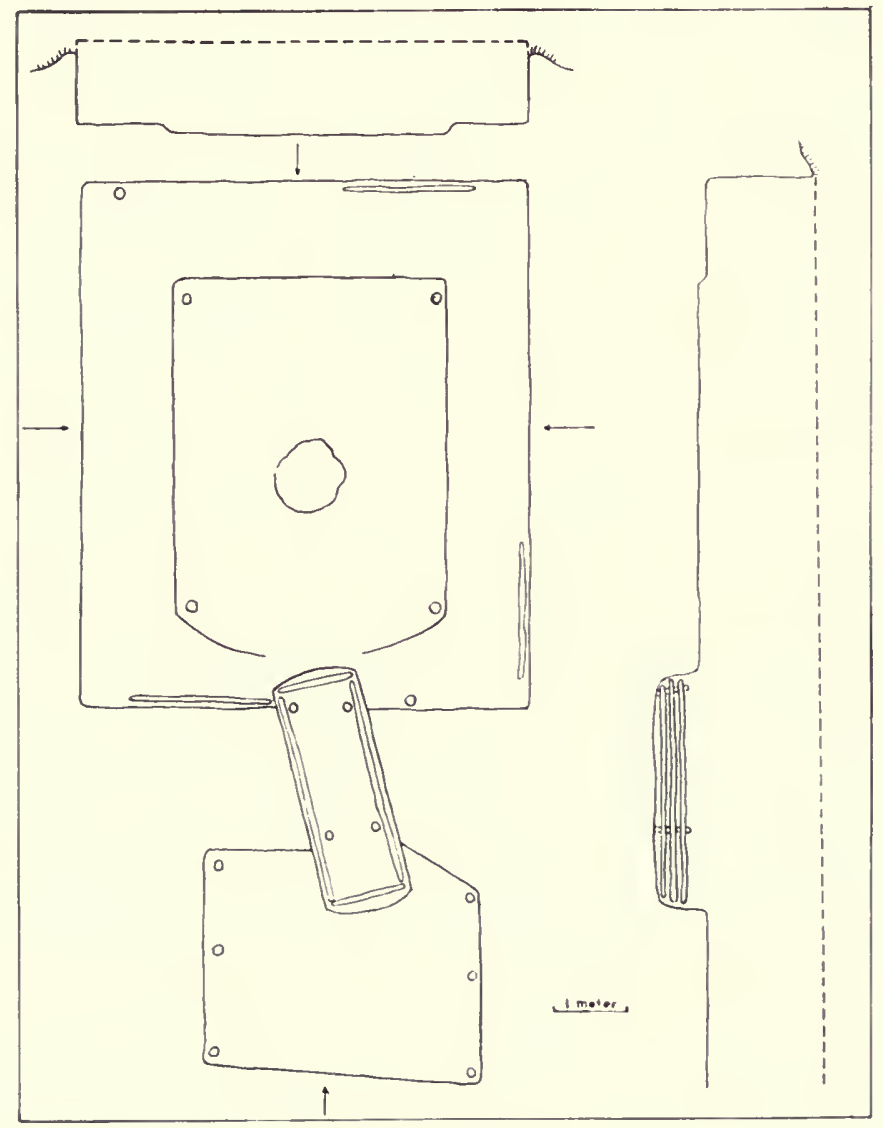

Fig. 5. House 1. 


\section{House 1 (Fig. 5)}

This was the second largest house on the Tikchik site, but very little wood was preserved. The presence of almost all the logs used in tunnel construction suggests that the more accessible timbers of the main chamber were removed prior to the collapse of the structure. Because of the almost total absence of wood in the main body of the house, the walls and corners were very difficult to determine. In places it was necessary to locate the bench surface and then extend the excavation outward until the level terminated. A few spongy sections of wall logs were noted. The long axis of this dwelling was parallel to the tunnel and there were low benches on three sides. The bench surfaces and floor consisted of a dark, compact, scaly layer which was easy to follow. The hearth area was a dark reddish color and very extensive. Although no roof timbers were recovered, the post holes for four-post-center construction were clearly visible. The tunnel of this structure, which extended well into the living area at one end and the entryroom at the other, was a pronounced angle to these two units. At either end of the tunnel were short, horizontal, retaining planks set into the earth. The tunnel floor was a hard, compact layer containing gravel and charcoal, and the step-up at either end was 46 to $51 \mathrm{~cm}$.; seemingly, an intermediate step would have been required to provide access to the living chamber and the entryroom. As is typical for most of the Tikchik houses, the entryroom is difficult to describe. There was no preserved wood and the floor was uneven and poorly defined. The presence of six post holes, three on each side, suggests vertical supports for horizontal log construction or perhaps a framework against which vertical side planks were fastened. It may have been that the front of the entryroom was open and that the structure was intended only to provide protection for the tunnel and a certain amount of storage space. Around two of the post holes was a wide area of very soft, unconsolidated dirt suggesting fill material put in around the logs when they were set. The floor of the entryroom is very uneven but tends to be low in the center and higher around the sides. In other words, not a prepared floor but simply a trampled surface.

\section{House 2 (Fig. 6)}

The characteristic features of this structure were reasonably good wood preservation, a long, deep tunnel, and a small but well-defined entryroom. The main chamber was virtually square and wall construction consisted of horizontal logs held in place by vertical supports. There were three such logs along one wall and this seems to 


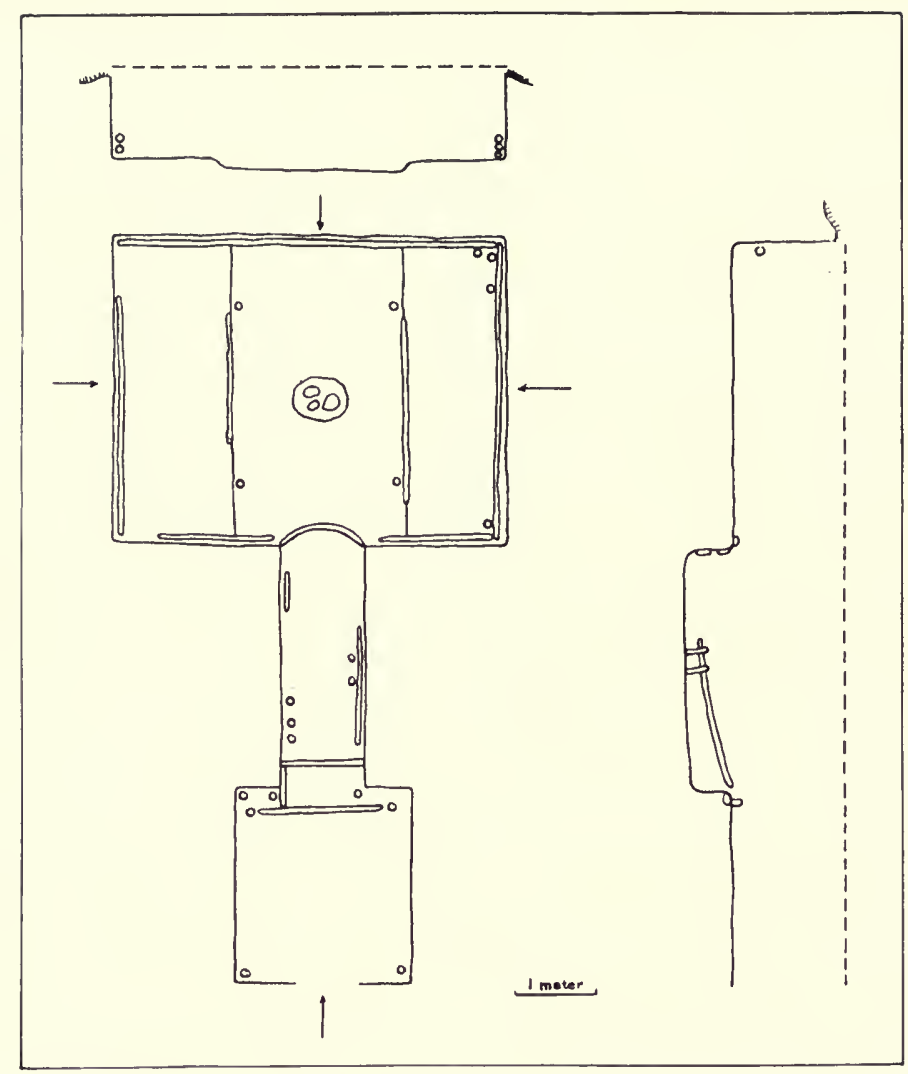

FIG. 6. House 2.

have been the maximum number. The roof beams took off from this log. Four-post-center construction was noted and there were low benches on two sides only. These ran to the front and back walls, had a dark, hard surface, and were characterized by retaining planks along the inner edges. The center floor was a compact dark area and the central hearth had three large, fire-cracked rocks within it. At the front where the tunnel entered the main chamber there was a semi-circular wooden sill at the level of the floor. The step-up from the tunnel floor was extremely steep and two horizontal retaining planks could be seen at this point. The step-up into the entryroom at the other end of the tunnel occurred about $45 \mathrm{~cm}$. preceding this room. Tunnel construction resembled house 1 and the entryroom had a well-defined, even floor with post molds visible in the four corners. 


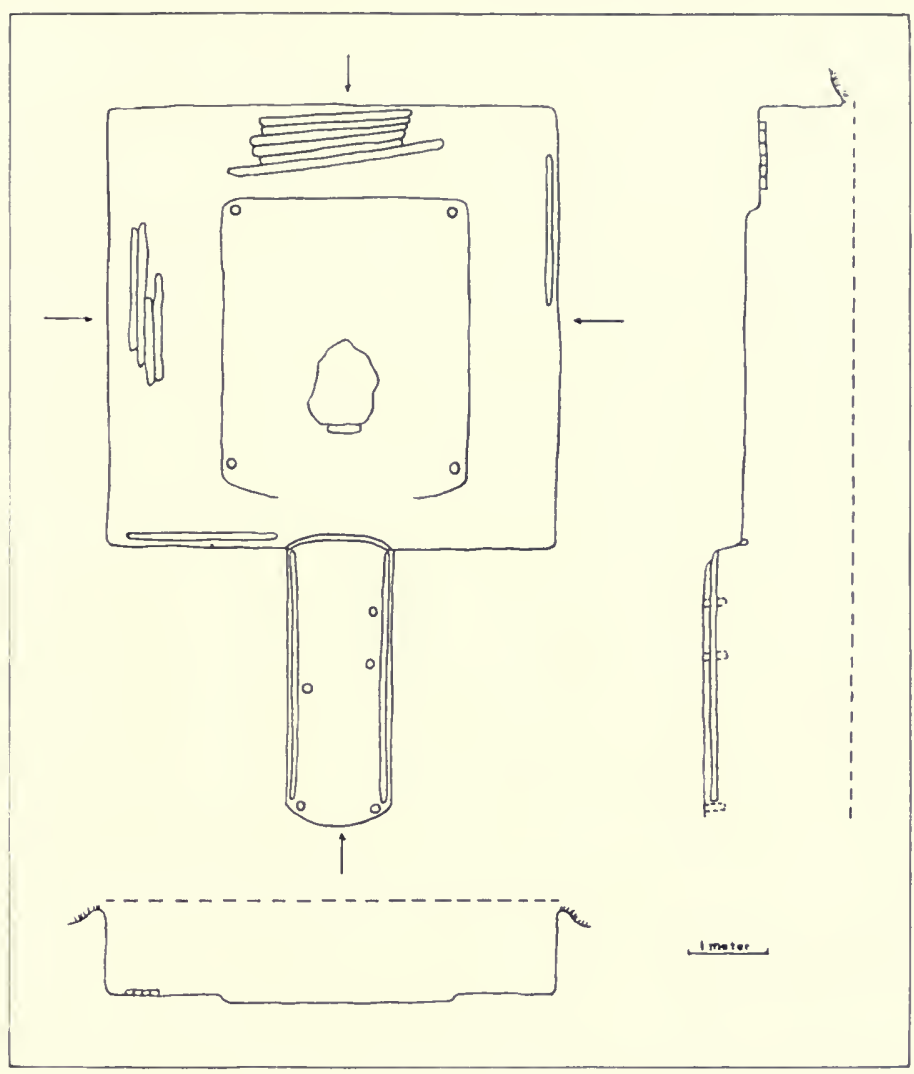

Fig. 7. House 3 .

House 3 (Fig. 7)

Before excavation this house appeared to be shallower and less distinct than most of the others. And the floor turned out to be no more than $65 \mathrm{~cm}$. below the level of the ground. The soil was sandier here than at most places on the site and wood preservation was very poor. However, the few sections of spongy wall logs remaining indicated the usual type of wall construction. The long axis of the structure was parallel to the tunnel, and there was four-post-center construction with low benches on three sides. On either side of the entrance to the tunnel the benches sloped inward until they reached floor level just opposite the tunnel. The benches were covered with very thin, narrow planks and the hearth area, large and diffuse, was reddish brown. The spongy remains of a semi-circular wooden sill were found at the floor level where the tunnel entered the main body 


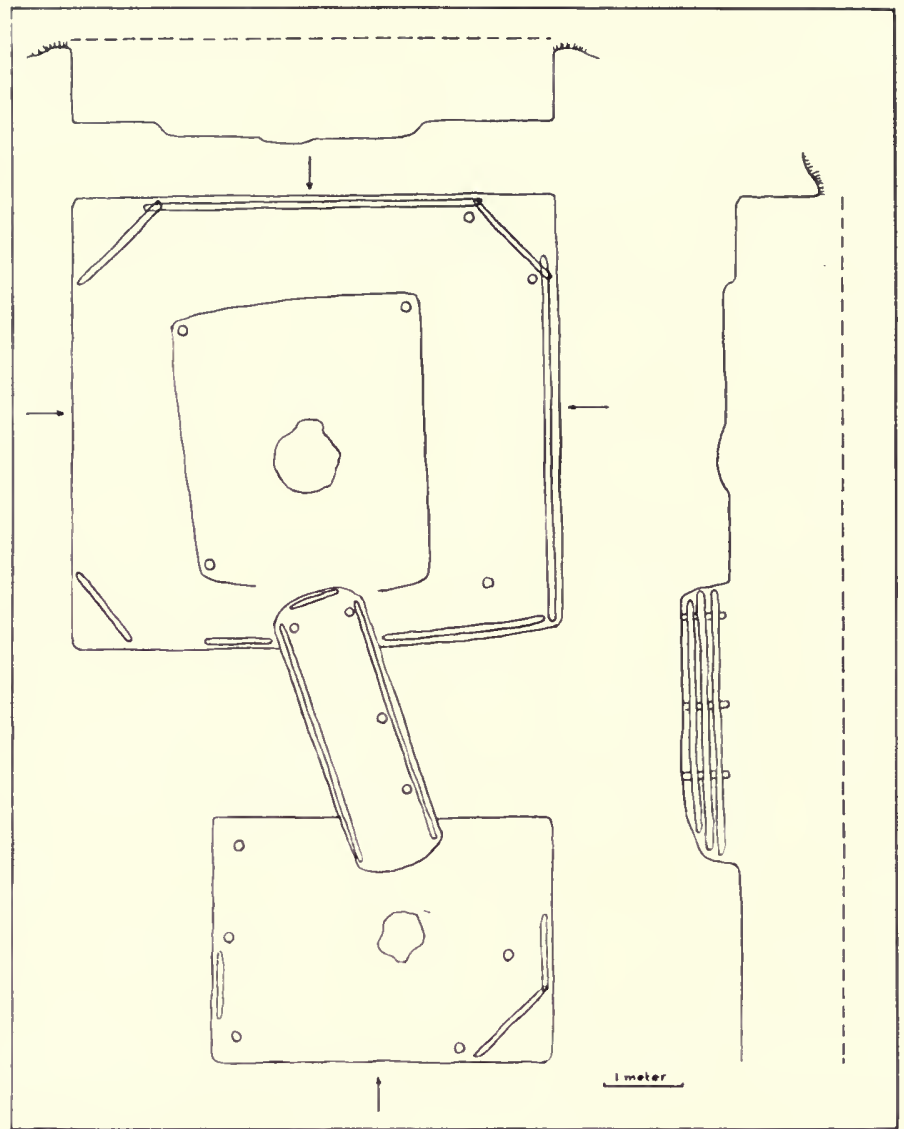

FIg. 8. House 4.

of the house. Tunnel construction resembled the previously described houses and the outer end was clearly visible in the form of a semi-circular discoloration of the soil. There was no entryroom.

\section{House 4 (Fig. 8)}

An interesting feature of this house was that prior to excavation, difficulty was experienced in determining the outlines of the structure. As a result, a much larger area than necessary was stripped of sod. The excavation was actually begun at some distance behind the back wall. The deceptive size of the outline was apparently due to the manner in which the roof logs collapsed, drawing with them an area of sod from in back of the walls which, when the sod had settled and grass grown up, gave the appearance of the walls them- 
selves. The most distinctive feature of house 4 was the cribbing of short, horizontal logs which was found in three corners of the residential area. Wood preservation was fair and the remains of horizontal logs were found along three walls. These wall logs extended just to the cribbing, suggesting that this type of corner construction was used because it enabled the builder to utilize shorter logs for the walls. The cribbing appears to have been supported by two vertical posts placed at either end in such a way that they also served as supports for the wall timbers. Although four-post-center construction is indicated for this dwelling, the arrangement of the posts was rather haphazard and the whole interior appeared oriented in the direction of the slanted tunnel. The benches were also unusual in that they were raised much higher above the center floor than in any of the

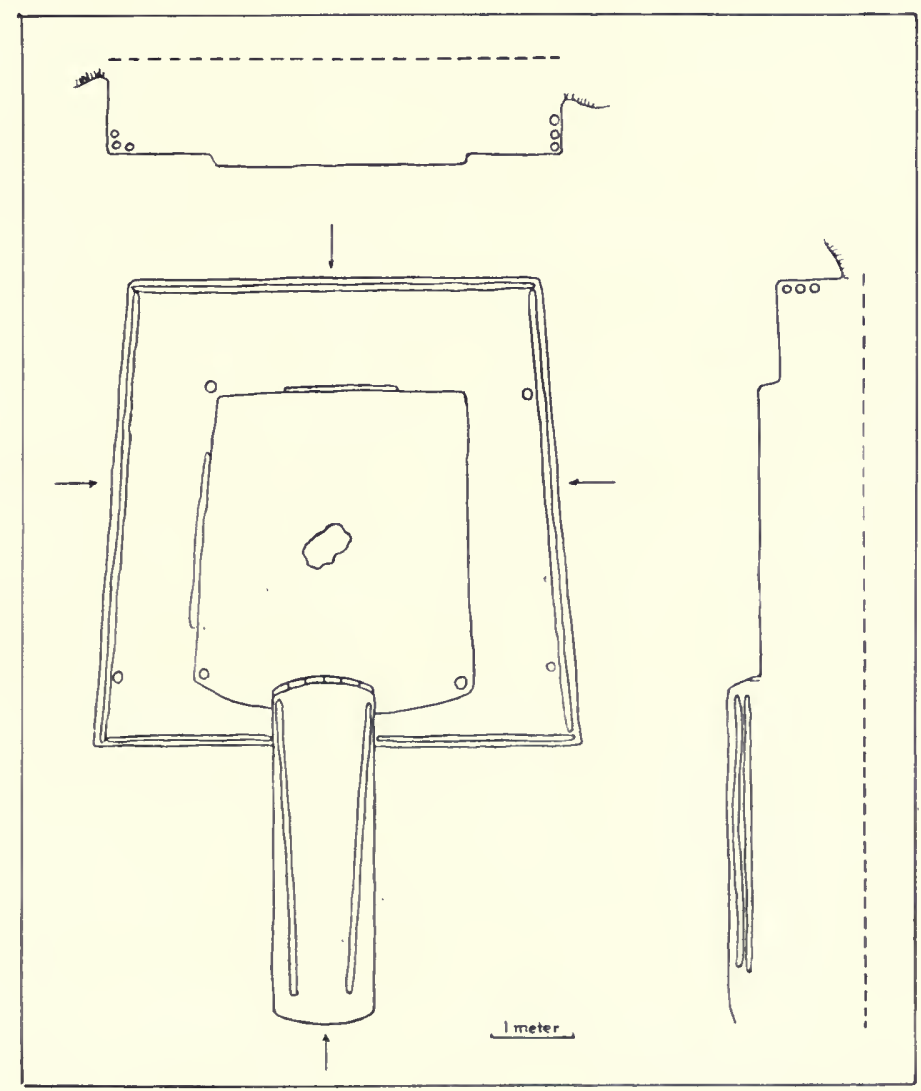

Fig. 9. House 5. 
other houses. The back bench was somewhat lower than those at the two sides. The central hearth layer was larger than in most houses and traces of burned materials extended well below the floor level. The tunnel was typical except for being extremely deep and the entryroom exhibited the usual poorly defined floor level and general absence of construction features. A small hearth appeared to be located directly in front of the tunnel which was a unique feature. The presence of spongy log sections suggested cribbing in one corner.

\section{House 5 (Fig. 9)}

This house was the best preserved of those without entryrooms and one of the more productive in terms of artifacts recovered. It was also the only structure on the site where the position of the roof poles could be determined with some degree of accuracy. When the sod was stripped it was apparent that there were extensive burned areas just below the sod level and it was at first thought that the house had burned. However, no trace of burning could be noted on any of the preserved timbers. The burned area extended into the tunnel fill, but again the timbers were not affected. Perhaps the grass and debris on top of the structure burned, or there may even have been an unsuccessful attempt to set fire to it at the time of abandonment. An interesting feature of the house was that it was nearly $60 \mathrm{~cm}$. wider at the front than at the back; the long axis was parallel to the tunnel. The appearance of the interior of this structure was noteworthy only for the very complete preservation of the wall logs which apparently never numbered more than three on each side. Also, the back bench was 5 to $8 \mathrm{~cm}$. higher than those at the sides. Only the bottom logs remained in the tunnel and these had been pushed well toward the center.

As previously noted, roof timbers were particularly evident in house 5 and the accompanying drawing (fig. 10a) indicates how they appeared at the time of excavation. It will be noted that these timbers, which were split planks, started from just above the top or third wall log. A single center post measuring $229 \mathrm{~cm}$. was found lying across the house floor. This made it possible to determine with some degree of accuracy the height of the roof and to make a reconstruction of the appearance of the dwelling before its collapse (fig. 10b). It is interesting to note the steep slope of the roof, the very low area toward the back of the benches, and the shallow excavation for the entire structure. 
House 6 (Fig. 11)

This structure was, with one possible exception, the most poorly defined on the site as there was virtually no preserved wood. The long axis of this house was at right angles to the tunnel, but the only structural feature that could be determined with certainty was four-

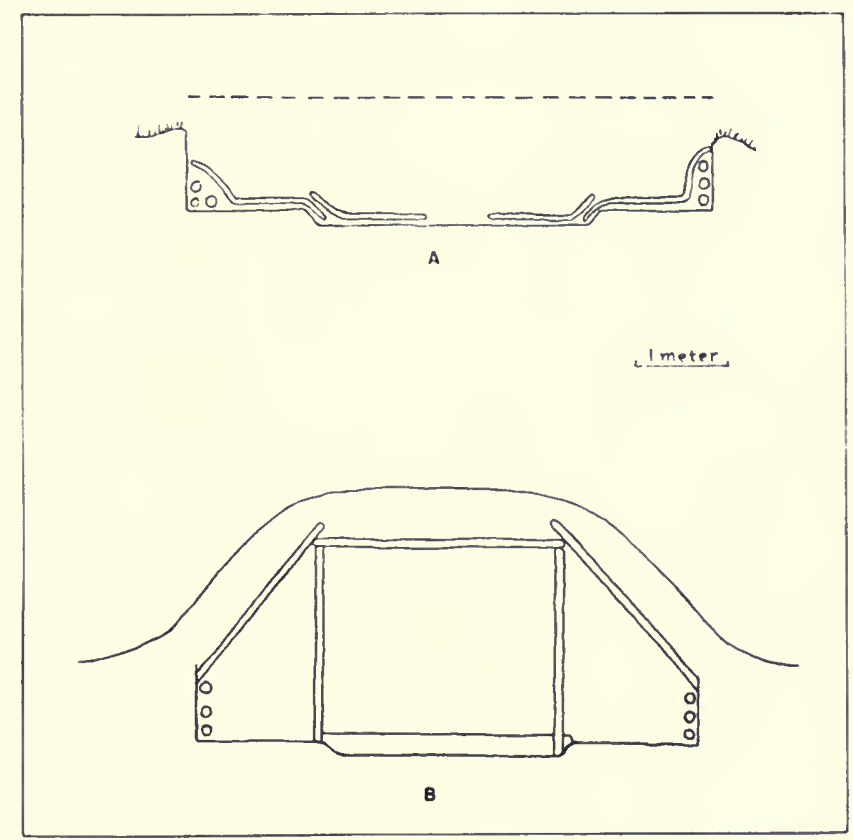

FIG. 10a. Collapsed roof timbers in house 5.

FIG. 10b. A reconstruction of the living area of house 5 .

post-center construction, indicated by post molds. There were low benches on either side, at least one of which seems to have been covered with thin, horizontal planks. The tunnel contained no preserved wood at all with the exception of a series of short parallel planks near the outside entrance that may or may not have been associated with the house. Two sizeable stones found at the step-up into the main body of the house may have served as retainers at this point. It should be noted that except in a few places, bench and floor levels were extremely thin and poorly defined. Obviously, much wood was removed from this structure prior to collapse and a short, possibly seasonal, occupation may also be indicated. 


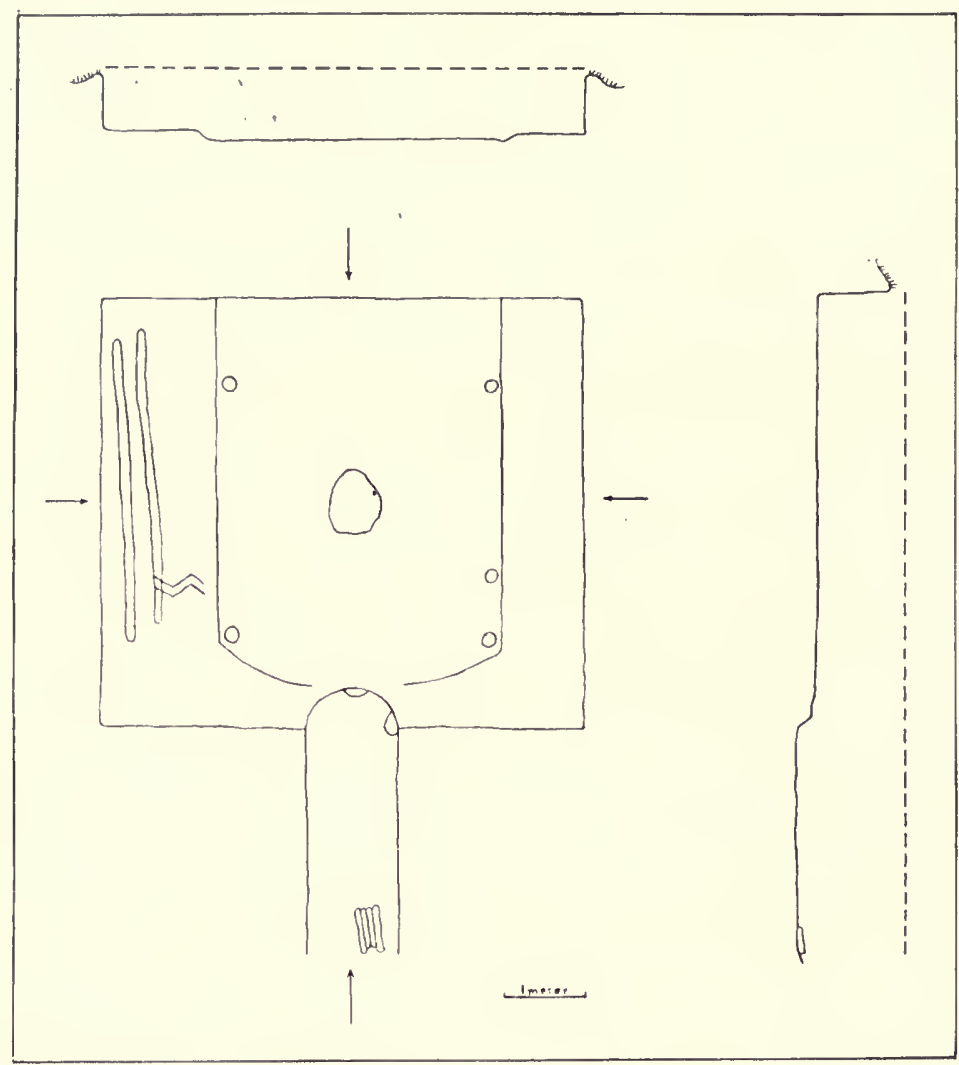

Fig. 11. House 6.

\section{House 7 (Fig. 12)}

This was the largest of the dwellings on the site and more artifacts were recovered from it by far than from any other. The main chamber appeared to be badly disturbed. So much so, in fact, that it was difficult to determine the outlines and the initial stripped area proved to be much larger than the actual house. Since many of the logs were apparently removed from the residential area after abandonment, it may have been this activity that disturbed the original outlines of the structure. Fortunately, the rest of the house was well preserved and no logs had been removed. The main body of the dwelling, in spite of the disturbance, can be seen to have been characterized by four-post-center construction with benches on three sides, the back bench being considerably higher than the other two. 


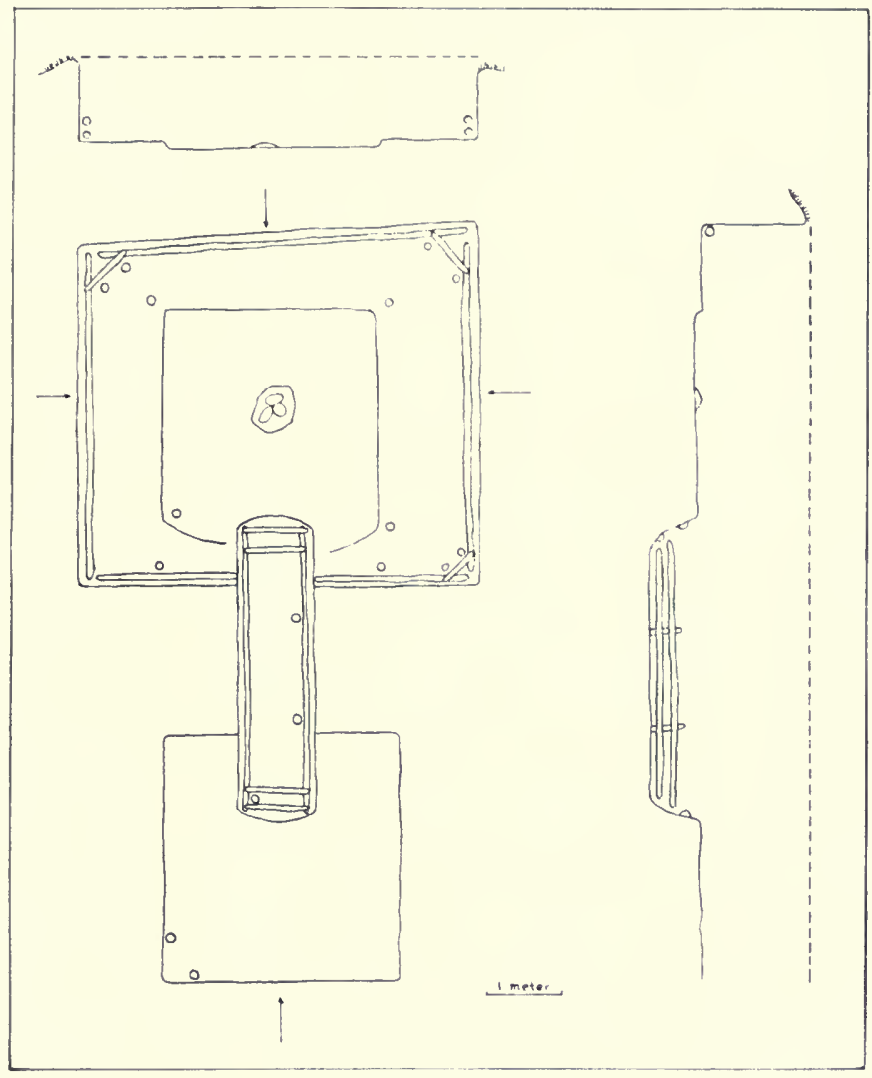

Fig. 12. House 7 .

At least one corner appears to have been cribbed in the same manner as previously described for house 4 . One side bench continued to the front wall, while the other ended just beyond the south corner allowing for a continuation of the center floor in this area. There proved to be a second occupation surface about $5 \mathrm{~cm}$. below the top one on both side benches and the center floor. Gravel and sand had been thrown in upon the first floor to provide a new and clean surface. The benches were further characterized by horizontal retaining planks along their outer edges.

The tunnel which led to the entryroom extended into the main chamber about $60 \mathrm{~cm}$. It was very deep and had six horizontal logs on each side but otherwise was not distinctive. The entryroom was the largest of any on the site, was the best preserved, and had a num- 


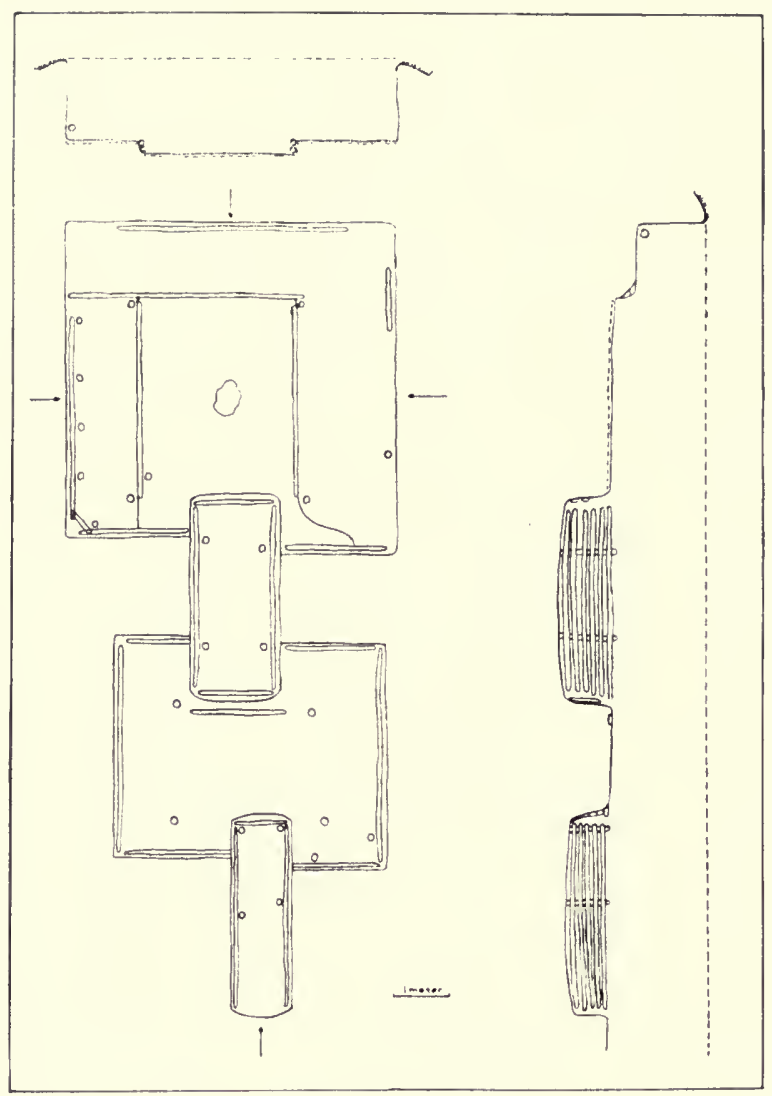

Fig. 13. House 8 .

ber of other unique features. Horizontal wall logs were evident on all four sides and the occurrence of posts set equidistant from the four walls suggested four-post-center construction. The floor, however, was poorly defined and uneven; a narrow plank was set into it just in front of the trunnel entrance. Unlike other entryrooms, this one had an entrance tunnel which in every way resembled the one connecting the residence area and the entryroom except that there were five horizontal logs on each side instead of six, and it was somewhat narrower. The presence of this second tunnel and the carefully constructed entryroom itself might have made one suspect that this was a double house. However, there were no benches in the entryroom and no hearth. The uneven floor further suggests that this structure was simply a carefully constructed entryroom. 


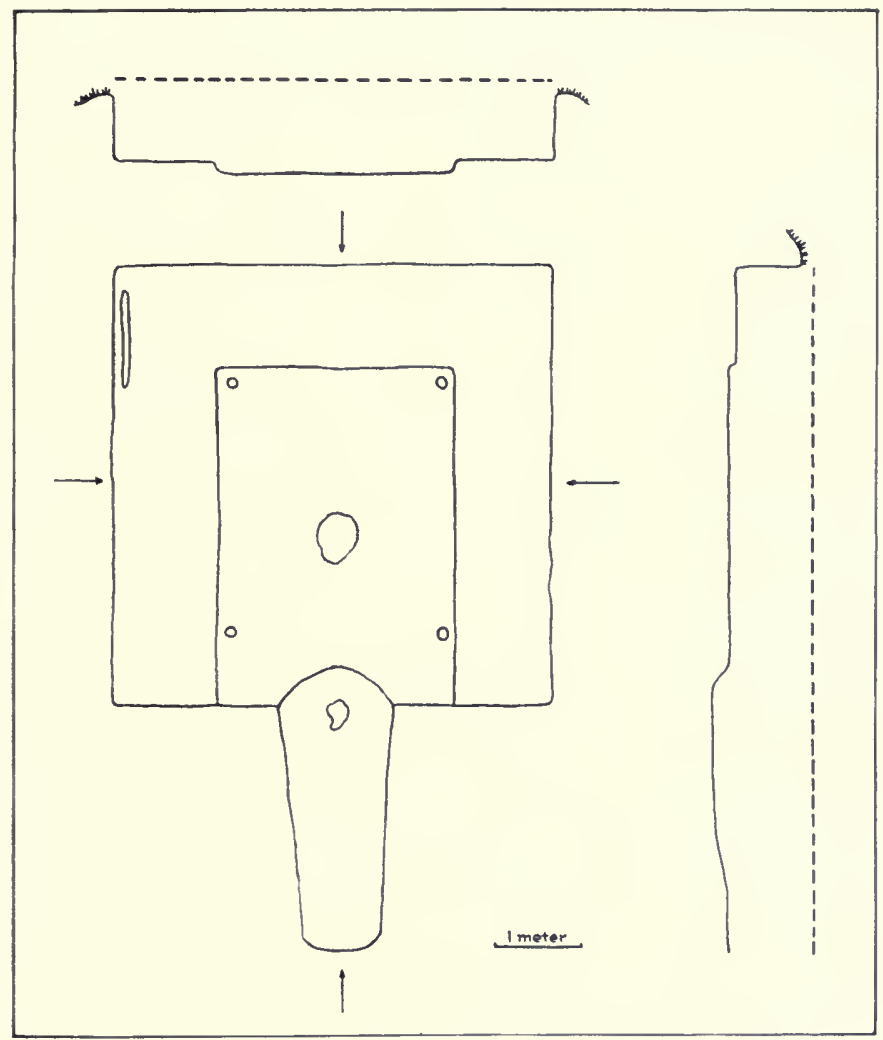

FIg. 14. House 9.

House 8 (Fig. 13)

The main body of this structure was virtually square and wood preservation was good. Horizontal wall logs and cribbed corners were characteristic, although in this case the cribbing was not intended to make possible the use of short logs since the wall timbers extended beyond the cribbing right into the corners. Four-post-center construction was indicated and there were three benches, none of which extended more than $15 \mathrm{~cm}$. above the center floor. The bench surfaces were covered with a compressed layer of grass. The center floor was ill defined and difficult to follow in places. Pockets of occupational debris occasionally extended well below what was thought to be the floor level. In the central fireplace there were three large rocks badly cracked and splintered from the heat. The tunnel in every way resembled those previously described except that the floor 
TABLE 1.-House Construction Features.

House

\section{Feature}

Excavated foundation

Spruce wall logs

Spruce or cottonwood roof beams

Birch bark sheets at

fallen roof level

Logs removed before collapse of house

Tunnel

shallow floor

deep floor

wall logs horizonta]

short, split tunnel roof logs

horizontal planks at inner end of tunnel vertical planks at inner end of tunnel

Tunnel entryrooms

House

dimensions square $\stackrel{0}{\mathrm{x}}$ dimensions rectangular $\mathrm{X}$ horizontal wall logs cribbed corners central hearth

\section{$\mathrm{H} 1 \mathrm{H} 2$}

$\underset{\mathrm{X}}{\mathrm{X}} \mathrm{X} \underset{\mathrm{X}}{\mathrm{X}}$

$\mathrm{H} 4$

H5

$\mathrm{H} 6$

$\mathrm{H}^{7}$

$\mathrm{X} \quad \mathrm{X} \quad \mathrm{X} \quad \mathrm{X}$

? $\mathrm{X}$ ?

$\begin{array}{lll}0 & 0 & \mathrm{X}\end{array}$

$\mathrm{X} \quad \mathrm{X} \quad \mathrm{X}$

$\begin{array}{cccccccccc}0 & 0 & \mathrm{X} & 0 & \mathrm{X} & \mathrm{X} & 0 & 0 & \mathrm{X} & 0 \\ \mathrm{X} & \mathrm{X} & 0 & \mathrm{X} & 0 & 0 & \mathrm{X} & \mathrm{X} & 0 & 0 \\ \mathrm{X} & \mathrm{X} & \mathrm{X} & \mathrm{X} & \mathrm{X} & ? & \mathrm{X} & \mathrm{X} & ? & ?\end{array}$$$
\text { ? }
$$$$
? \quad \mathrm{X}
$$

000

$\mathrm{x}$

$\mathrm{X}$ X 
vator. Wood preservation was practically non-existent but the presence of well-defined post holes revealed four-post-center construction. Low benches on three sides were covered with a very thin, dark gray

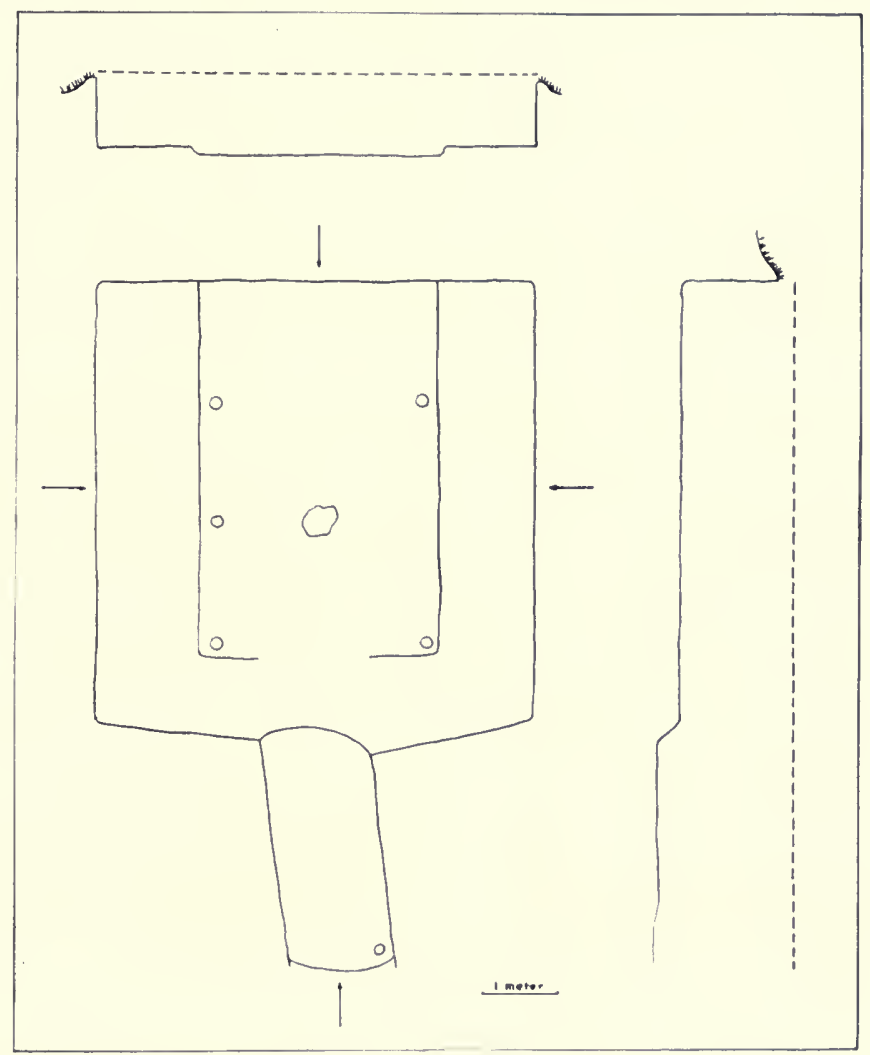

FIg. 15. House 10.

occupation layer as was the floor. The hearth area in the center was very diffuse and indistinct. At the point where the tunnel entered the main body of the house there was a short step-up of less than $30 \mathrm{~cm}$. and a shallow, semi-circular depression which extended into the house for about $36 \mathrm{~cm}$. A large, flat rock lay directly in front of the step-up. Construction features in the tunnel could not be determined; the floor sloped up markedly at both ends. The two most notable features of this house were the virtual absence of artifacts and the shallowness of the excavation. Everything about this structure suggests a very brief occupation. 


\section{House 10 (Fig. 15)}

This structure was the least distinct of all from the surface and there was even some doubt at the beginning of the field season as to whether it was a house or just a natural depression that somewhat resembled one. This doubt persisted throughout the early phases of the excavation and it was not until structural features, such as they were, began to appear that it was removed. This was a dwelling entirely without preserved wood, the long axis of which was parallel to a tunnel which ran out slightly at an angle. Very thin traces of wood were found in two places along the southeast wall, but for the most part the walls of this house could be delineated only by following the bench levels to their furthest extent. Even at that, the lines representing walls in the figure should be considered very tentative at best. Bench areas were noted on two sides and the post hole pattern was fairly clear indicating four-post-center construction. The step-up from the tunnel to the house floor was quite steep and the tunnel floor was the most clearly defined surface in the house. At the outside entrance a semi-circular shaped soil discoloration and a single post hole were noted. House 10 was located very close to house 2, so much so that it is almost inconceivable that the two structures could have been built at the same time. If house 2 was built after house 10 was abandoned, it is possible that the disturbance during construction could have affected preservation in house 10 or the new builders may purposely have destroyed the older dwelling after first taking many logs from it.

\section{KASHGEES}

When I first saw the Tikchik site in the late summer of 1964, my attention was immediately drawn to the impressive and obvious kashgee, or ceremonial house, ruin in the southeastern corner of the site. Excavations were begun the following summer and for most of the season I was under the impression that my crew and I were excavating only the one kashgee, even though another structure appeared to be very deep and exhibited other peculiar features when compared with the houses that were being dug. Finally, toward the end of the season, when the construction of this structure became evident and it closely resembled that of the obvious kashgee, my suspicions were aroused. These suspicions were confirmed when, at the close of the field season, Ivan Ishnook, the last surviving former resident at Tikchik was interviewed at New Koliganek. He stated immediately that there had been two kashgees in the village and he identified both of these on my map of the site. So that the structure which had ten- 
tatively been given a house number was labeled kashgee 1 and the obvious kashgee on the rise in the southeast corner became kashgee 2 . The informant was certain that kashgee 1 was the most recent of the two structures, but it was not altogether clear whether they had been in use at the same time. He seemed to think that kashgee 2 had been abandoned partly because it was located too far back on the site to be convenient for the villagers of his time and partly because it had begun to fall into disrepair. He remembered taking steam baths in kashgee 1 when he was a small boy so presumably this structure was in use right up until the site was totally abandoned.

\section{Kashgee 1 (Fig. 16)}

The wood preservation in this structure was truly remarkable when compared with that in the houses. Virtually the entire walls

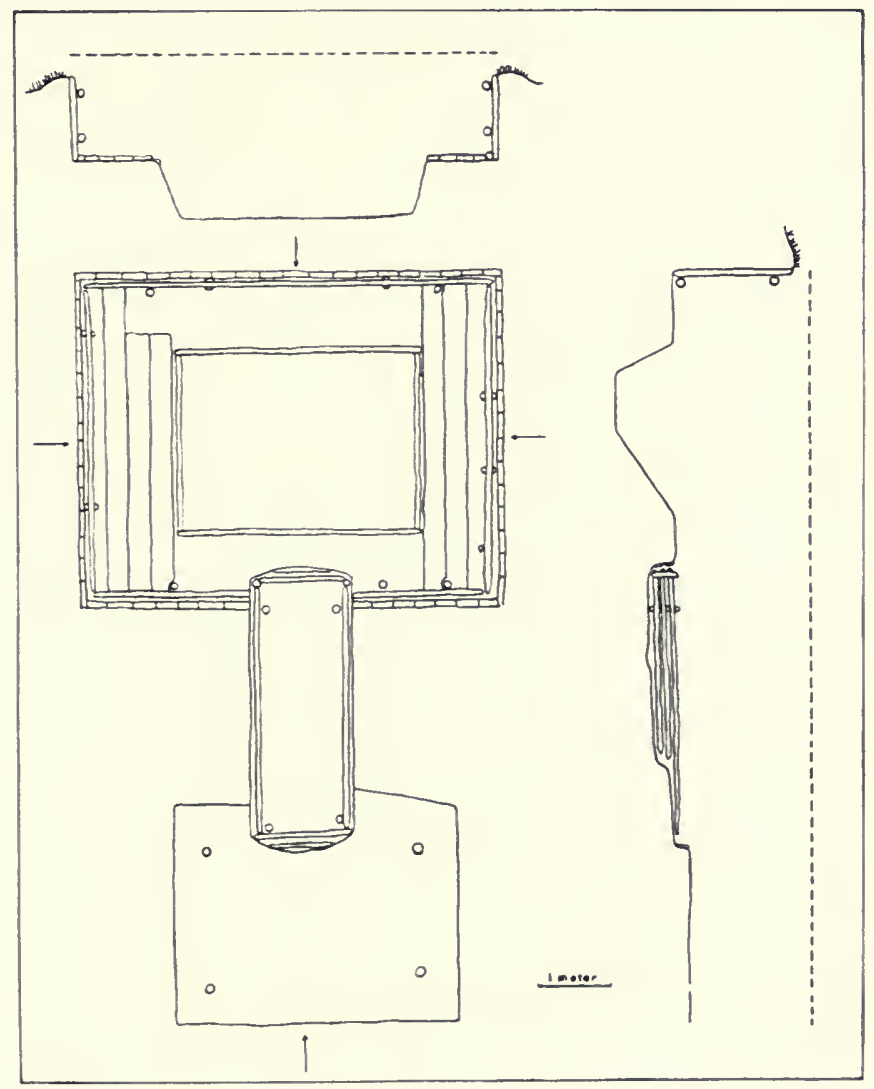

FIG. 16. Kashgee 1. 
were intact, as was the tunnel. Roof logs were a tangled mass that overlaid everything and made excavation slow and tedious. Even before the sod was stripped, roof logs and other debris were visible. Only the entryroom was bereft of timber and in that way resembled those attached to the dwelling units. Kashgee 1 was by far the most distinct and therefore the most recent looking structure on the site prior to excavation.

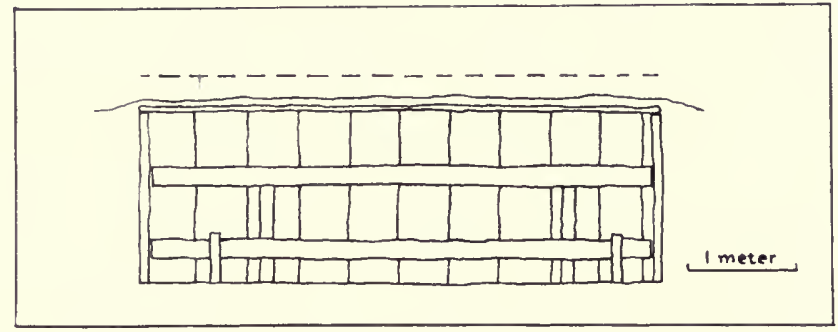

FIG. 17. Reconstruction of a wall in kashgee 1.

The construction of kashgee 1 is different in many respects from that of any of the dwelling units. To begin with, the walls consisted of vertical-hewn spruce planks that extended almost from the sod level to the tops of the benches. The lower ends of these planks rested on a solid foundation of split logs which apparently had been laid, flat surface up, as soon as the excavation for the structure was completed and which outlined the main chamber at the bench level. The vertical wall planks, some of which were as much as $46 \mathrm{~cm}$. wide, had been carefully beveled along the edgés to obtain a closer fit. They were held in place by two horizontal logs, one of which stretched the entire length of each wall near the sod level, and the other near or at the bench floors. The upper horizontal logs were held in place by short vertical supports set at intervals flat against the vertical wall planks; the upper logs rested on these. The lower logs were held in place by short vertical supports which were driven into the bench floors and wedged the horizontal logs against the vertical wall planks. Since all these structural features were intact, or virtually so, along all four walls, it was possible to reconstruct the wall approximately as it must have appeared at the time the kashgee was in use (Fig. 17).

There were benches on all four sides of this structure and those on the sides were covered with hewn spruce planks. Under these planks, and on the surface of the other two benches, was a concentrated dark 
layer containing considerable charcoal. Retaining planks lined the outer edges of all the benches. The center area, or hearth pit, of the kashgee was extremely deep with sloping sides, particularly on the tunnel side. The actual floor was approximately $92 \mathrm{~cm}$. square and covered with charcoal fragments. The vertical wall planks were dark with soot suggesting that the kashgee had been used extensively as a bath house.

The tunnel, which in construction resembled those in a number of houses already described, extended into the front bench for a distance of $61 \mathrm{~cm}$. In entering the main chamber, a person would step up directly onto the bench. An unusual feature of the tunnel was a step about one meter from the actual entrance to the entryroom. The entryroom itself, as previously noted, contained no preserved wood. Like the house entryrooms, it appears to have been a very crude affair, perhaps just enough construction to protect the tunnel entrance.

Although many roof logs were found during excavation of the main chamber, it is not possible to say with certainty what method of roofing was actually used. As there were no center posts the type of roof that was characteristic of all the houses would definitely be ruled out. Concentrations of collapsed short logs at the corners definitely suggests that this kashgee may have had a cribbed roof. Such a method of roof construction for ceremonial houses has been reported elsewhere in southwestern Alaska (Nelson, 1899, p. 250; Lantis, 1946, fig. 5).

Among the impressions gained during the very instructive excavation of this kashgee, the ones that seem worthy of mention here are the large size of the logs used in construction and the careful workmanship that was evident at every turn. Reference has already been made to the wide vertical planks which lined the walls. Some of the roofing timbers and wall support logs were also of impressive size, much thicker and larger than any trees now growing in the immediate vicinity of the site. The amount of work that must have gone into the construction of kashgee 1 is truly amazing. The hewing of the vertical wall planks, with the type of implements available, in itself must have been a laborious and time-consuming chore.

Kashgee 2 (Fig. 18)

It cannot be over emphasized that the most significant thing about this kashgee was its commanding position with reference to the rest of the site. It is this and not its size that first strikes the 


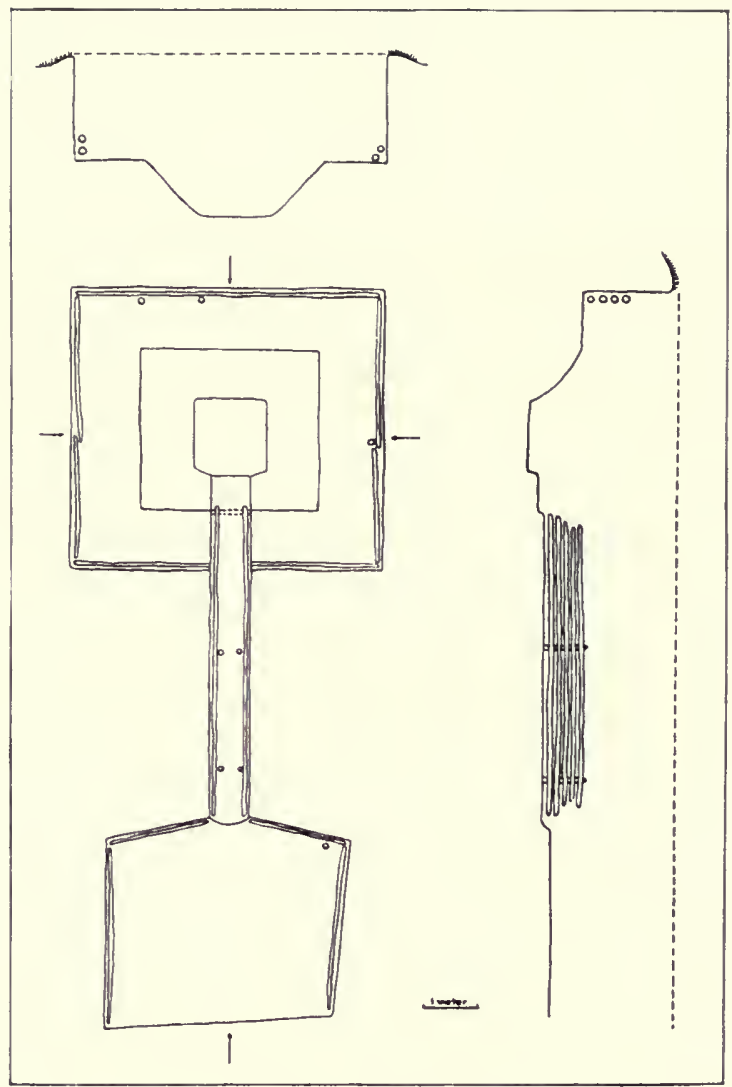

FIG. 18. Kashgee 2.

observer and continues to impress him. Located in the extreme southeastern corner of the site, it stood apart from the other structures and rose above them at the same time. The large amount of earth that had been piled around the tunnel and the front wall is also impressive. In fact, it is worth noting that the kashgee was not dug into relatively level ground as were the dwellings, but was actually cut into the side of the hill. Thus it was possible to make it deep with a minimum of digging.

Although large and impressive looking, this kashgee was not as difficult or as time consuming to excavate as the one previously described. Roof beams had apparently been removed prior to their collapse so that their presence did not impede the excavation. The main room was not extensively filled with debris and although the 
removal of sod and overlying fill required some exertion on the part of the excavators because of the depth of the room, the excavation was completed in a reasonable amount of time. Only the tunnel, being long and nearly completely filled, was difficult to excavate.

The main chamber of kashgee 2 was virtually square. Horizontal wall logs were found around all four sides and they were held in place with vertical supports. There were at least four logs along each wall and possibly five. Single timbers stretched the entire length of the back wall but on the sides two sets of shorter logs were used. Benches were located on all four sides and were easy to define because of being partly made of beach gravel that had apparently been brought up from the river bank. The hauling of gravel fill in this manner must have been a major undertaking. An effort was made to determine how deep the gravel was and it turned out to be at least $70 \mathrm{~cm}$. in the three places tested. The surfaces of the benches consisted of a dark compact layer beneath which it was virtually impossible to dig because of the gravel. There was some indication that thin planks may have covered at least one bench, but this was uncertain. The benches sloped away toward the center of the chamber in much the same manner as in kashgee 1 and the center floor, or hearth pit, $117 \mathrm{~cm}$. below the bench surfaces, was approximately $11 / 2 \mathrm{~m}$. square. This entire area was covered with bits of charcoal and darkened earth and gravel. The tunnel extended through the front bench and entered the hearth pit at the floor level, an arrangement described by Zagoskin (1967, p. 115) for kashgees which he saw in southwestern Alaska in 1842-1844. There was a slight step-up about $75 \mathrm{~cm}$. in front of the hearth pit and another one at the point where the tunnel entered. It will be noted that the tunnel did not form a cold trap in the usual sense, but doubtless served as one in terms of those seated on the high benches. It is probable that some form of trap door connected the two sections of bench on either side of the tunnel and, in fact, the remains of a short horizontal plank at this point suggests such a disposition. This trap door would doubtless be down most of the time but could be raised to allow people to enter the hearth pit area easily. A trap door may also have covered the center of the kashgee at a point level with the bench surfaces. This arrangement has been described for the kashgee at Nushagak (Swineford, 1898, pp. 164-166) and would not only give more room for activities in the kashgee, but would allow performers in the ceremonies to appear mysteriously before those seated on the benches. 
Tunnel construction featured extremely long horizontal logs, five in number on each side, held in place by widely-spaced vertical supports. At the point where the tunnel entered the entryroom there was a slight step-up. Wood preservation in the entryroom was unusually good but, as usual, the floor level was uneven and poorly defined. It seems likely that the front of the entryroom was completely open.

As with kashgee 1 , the roofing of this structure cannot be determined with certainty. Again it is at least possible that the main chamber had a cribbed roof. Certainly no posts were encountered anywhere within it. There were indications along the tunnel walls that the tunnel had been roofed with short, horizontal planks. The single post hole located in the entryroom was probably a vertical support and there is no indication of how the structure was roofed. It is wide, but it could have been roofed with logs or hewn planks laid horizontally across the uppermost wall timbers.

\section{Middens and Test Trenches}

A cursory examination of the Tikchik site at the beginning of the field season revealed only one obvious midden deposit; that located in front of kashgee 2. This was excavated fully and a number of test trenches were opened, mainly in front of house tunnels, both in the hope of locating deposits of trash thrown out by the residents and for the purpose of determining the depth of the cultural deposit at various points on the site (see Fig. 3). The excavation of the kashgee 2 midden, designated test 1 ( $\mathrm{T}-1)$, and the other test trenches ( $\mathrm{T}-2-6)$ will now be described.

$T-1$

The obvious midden in front of kashgee 2 appeared, prior to excavation, as a long, narrow, grass-covered hump extending almost at right angles to the kashgee entryroom. It appeared to be about $71 / 2 \mathrm{~m}$. long, perhaps $31 / 2 \mathrm{~m}$. wide, and 92 to $107 \mathrm{~cm}$. above the surface of the ground. Sod was stripped from an area $71 / 2$ by $41 / 2 \mathrm{~m}$. and frozen ground was immedately encountered. This thawed rapidly, however, suggesting that the frost was only seasonal and its retention in the midden due to the very compact nature of the deposit. The midden was excavated in $15 \mathrm{~cm}$. levels in the hope that it might be possible to distinguish significant differences in the artifacts at various levels. However, this proved not to be possible and 
the midden collection, which was not extensive, has been considered as a single unit.

As was expected, the midden consisted almost exclusively of workshop debris; broken tools, weapons, and other artifacts that would have been made, used or repaired by men in the kashgee. In addition, there were large amounts of charcoal, wood chips, by-products of the manufacture of stone implements, animal and fish bones, and cut pieces of birch bark. At no point was the cultural debris more than $95 \mathrm{~cm}$. in depth and it did not extend more than $30 \mathrm{~cm}$. below the present surface.

\section{$T-2$}

This test trench, which measured 6 by $3 \mathrm{~m}$., was opened to uncover any midden material that might have been deposited in front of kashgee 1. Before excavation, this area was characterized by very tall, lush grass but there was no obvious mound. The cultural layer proved not to be thick; no more than $46 \mathrm{~cm}$. at any point and less in some places. Very few artifacts were recovered although there was a great deal of cut birch bark and at several points in the excavated area there were small deposits of charcoal. These doubtless represented hearth debris.

\section{$T-3$}

This small test trench, measuring $3 \mathrm{~m}$. by $11 / 2 \mathrm{~m}$. and located in back of and between houses 7 and 8 , was opened to investigate the significance of a pit similar to many on the site. Cultural debris was noted to a depth of $46 \mathrm{~cm}$. where sterile sand was encountered. Only a few bones, flint chips, and can fragments were recovered.

\section{$T-4$}

A test trench, 7 by $3 \mathrm{~m}$., was opened in front of house 7 and then extended toward the river bank to determine the depth of cultural deposit. Again, it was determined that at no point did this exceed $46 \mathrm{~cm}$. in depth and in most places it was less than $30 \mathrm{~cm}$. At two places in this test trench small, filled pits were discovered cut into the brownish-red, sterile subsoil. These were about $60 \mathrm{~cm}$. wide and $90 \mathrm{~cm}$. deep. They had been carefully lined with sections of birch bark and contained a few caribou bones. It seems certain that they were the remains of meat caches. 
$T-5$

This small test trench, $31 / 2$ by $11 / 2 \mathrm{~m}$. in size, was opened in front of house 5 but revealed no midden deposit exceeding a depth of $46 \mathrm{~cm}$.

\section{$T-6$}

A similar small trench, $3 \mathrm{~m}$. square, in front of house 8 . Here the the cultural layer, in most places, ended $30 \mathrm{~cm}$. below the sod level. Toward the front of the trench and at no more than $3 \mathrm{~m}$. from the entryroom of house 8 , the sod rested directly on sterile subsoil.

In addition to the midden and test trenches just described, it is also necessary to mention an even row of eight pits which were located at the extreme northwest end of the site in back of house 9, beyond house 1 and almost in the willows which border the site at this point. These pits, which were approximately $90 \mathrm{~cm}$. deep and about the same distance across, were not excavated. Informants reported that they were for the storage of freshly-caught fish. In the late summer salmon that were taken just prior to the end of the runs were buried immediately and allowed to rot; then taken out later in the year and eaten. Similar fish caches have been reported for the now abandoned village of Kanulik on Nushagak Bay (Moravian Church, SPG Proceedings, 1888, p. 29).

In conclusion it can be noted that there were no residential middens at Tikchik and it is unlikely that the cultural debris exceeded $60 \mathrm{~cm}$. in depth anywhere on the site except in front of kashgee 2. This raises the question of where the residents of the various houses deposited their trash. It is likely that those in houses $1,7,8$, and 9 may have thrown theirs over the river bank. It is surprising, however, not to find some debris concentration in front of the dwellings farther back on the site. Perhaps the length of occupation was not sufficient for the accumulation of any significant amount of midden debris around the houses. What did accumulate would be dispersed by dogs and perhaps by the people themselves. Kashgee 2 would be an exception since, as a workshop used by all or most of the men in the village, there would be a greater amount of trash of which to dispose. Kashgee 1, which is known to be later, may lack a similar midden for that reason.

\section{BURIALS}

When I first discussed the Tikchik site with informants along the Nushagak River during the summer of 1964 , I was told to be sure to 
look for the cemetery which would be easy to find because of the memorial images and figures still standing above the box graves which were themselves still lying on the surface of the ground. It turned out that those informants who had mentioned the standing memorial images had not visited the site for more than 20 years. In 1965 there were no surface indications of a cemetery anywhere on the site. Ivan Ishnook told me that it was located north and slightly west of kashgee 2 extending down into the draw and almost reaching the back wall of house 5 (see Fig. 3). No excavations were made in this area. The three burials that were uncovered during the course of the excavations were found on the benches in houses and they will now be described.

\section{Burial 1}

Soon after the sod was stripped from house 3 and excavation begun in the southwest corner, a human skull was uncovered. Somewhat later the rest of the skeleton was exposed. It proved to be that of a female between the ages of 30 and 35 . The skeleton lay on its back in an east-west direction and in an extended position. The left arm lay across the pelvic region and the right was partially outstretched. The skull was turned on its right side with the lower jaw lying on a complete clay lamp which had been "killed" by having a small, irregular hole made almost exactly in the center (Pl. 11,c). The skeleton was complete down to and including the right and left femurs, but was badly disarticulated below that. Nearly all the bones of the lower extremities were found in the vicinity. Spongy roof logs were found above the skeleton and it seems likely that the deceased was laid out on the bench in an extended position and the subsequent disturbance was caused by falling roof beams and sod when the house eventually collapsed.

\section{Burial 2}

Midway along the north bench of house 5 the tightly-flexed burial of a female more than 40 years of age was encountered. The skeleton lay at right angles to the wall and was complete, although badly crushed by falling roof timbers. There were no grave goods in association, but the body had been covered completely with long strips of spruce bark.

\section{Burial 3}

Parts of a badly disturbed human skeleton were recovered from house 6 under circumstances which at least suggest a burial. The 
skull of a male was found midway along the south bench against the wall. Along the north wall in approximately the same place the disarticulated lower half of a skeleton was uncovered. In association with it were two iron adze blades and two large ulus made from can metal. The bones were so disturbed that it was impossible to determine the orientation of the skeleton. The general disturbance seems greater than would have been caused by the collapse of the roof alone. It may have been that animals got to the body while the house was still relatively intact. The skull was that of an individual more than 40 years of age.

The burials just described raise a number of interesting points with regard to the history and occupation of the site. First of all it is clear that these are not Christian burials. We have noted that the residents of Tikchik were exposed to Christianity at least as early as 1847 , and there are indications in the historical records that a priest may have been paying visits to the village by 1850 . On the other hand, Ivan Ishnook maintained that no priest visited the village in his youth and that the members of his family were not baptized until they moved to Old Koliganek. At any rate, it seems clear that the villagers' contacts with the Orthodox Church were always tenuous and sporadic and it is certain that many, if not most, of the residents remained pagans right up until the settlement was abandoned.

It is almost certain that a burial on the bench of a house would not take place unless the dwelling was about to be or already had been abandoned. The whole arrangement seems to suggest the hasty departure of at least some of the inhabitants. It may be that the individuals buried were victims of one of the many epidemics that swept the Nushagak region regularly beginning with the small pox epidemic of 1837. In this case the inhabitants may have left the village suddenly after laying out the recent dead in their about-to-beabandoned houses. It is also possible, of course, that the burials are not contemporary with the dwellings in which they were found. Residents may have considered an abandoned but still standing structure as a satisfactory place for a burial, particularly if the dead were epidemic victims and the living were few in number and already planning to leave the village. At any rate, the whole problem of the burials raises the question of whether all the houses at Tikchik were occupied at the same time and this will be discussed in a later chapter. 


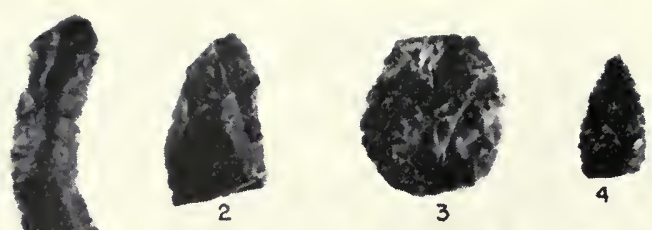

3
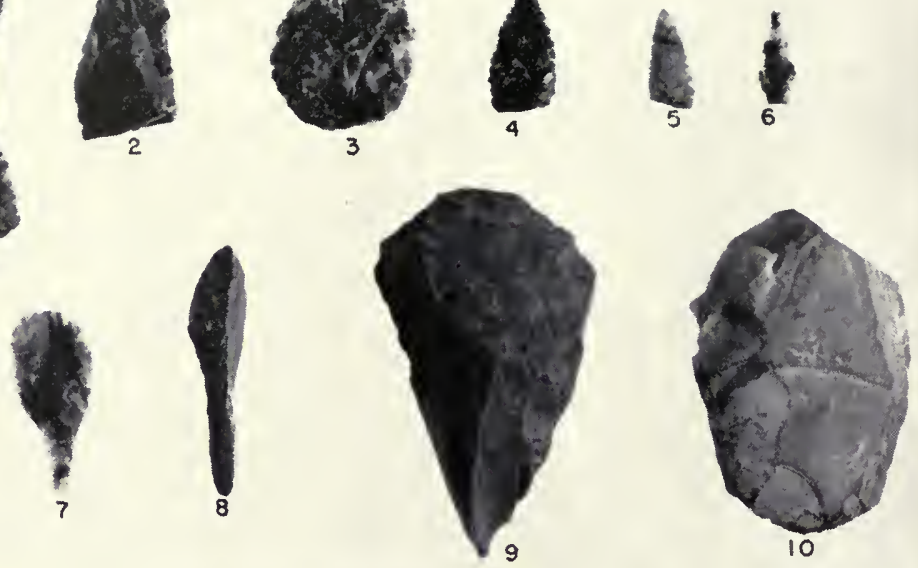

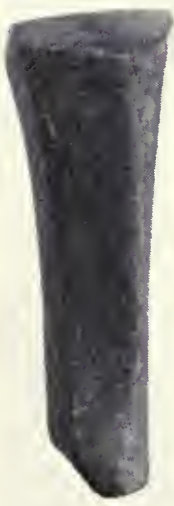

11

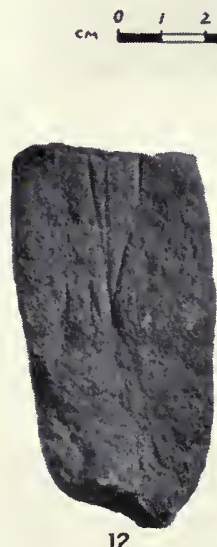

12

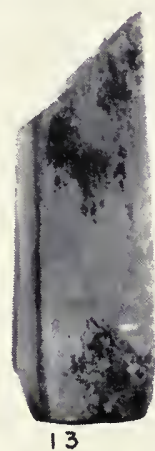

13
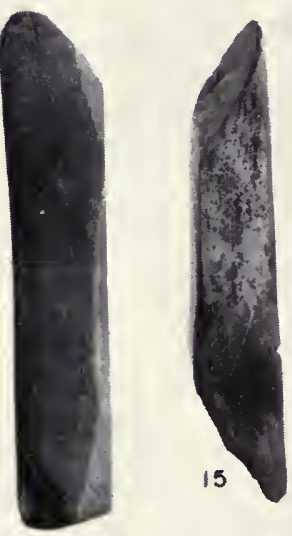

14

Plate 1. Chipped and Ground Stone Artifacts. 1. Plano-convex scraper, p. 265 ; 2. Plano-convex scraper, p. 265 ; 3. Discoidal scraper blank, p. 266; 4. End blade, p. 266; 5. End blade, p. 266; 6. End blade, p. 266; 7. Hand drill, p. 266; 8. Hand drill, p. 266; 9. Hand drill, p. 266; 9. Awl or gouge, p. $266 ; 10$. End scraper (?), p. 266; 11. Whetstone, p. 267; 12. Whetstone, p. 267 ; 13. Whetstone, p. 267; 14. Whetstone, p. 267; 15. Whetstone. p. 267. 


\section{Collections}

In this chapter the artifacts from the Tikchik Village site will be described under the major headings of locally manufactured goods and imported manufactured goods. Further subdivisions under each of these headings will be according to the material used in the manufacture of the artifacts. The approach will be largely descriptive with some comparative material and an analysis of the trade goods being reserved for the following chapter on continuity and innovation.

\section{Locally Manufactured Goods}

Under this heading are included all artifacts manufactured locally by Eskimos irrespective of whether or not they are traditional Eskimo forms. Thus this section will include descriptions of artifacts made from materials unknown to precontact Eskimos as well as forms that were the direct product of the contact situation.

\section{Chipped Stone}

The only artifacts considered here are those which show chipping as the final technique in their manufacture. Thus many implement blanks as well as finished implements which have chipped surfaces but which either would have been ground or polished or have had ground and polished working edges are not described. This rather narrow definition of a chipped stone implement is applied here in order to emphasize the importance of flint working to the nineteenth century Eskimos at Tikchik.

Plano-convex scrapers of chert include one relatively large specimen $9 \mathrm{~cm}$. in length with a steep, carefully prepared, working edge; this scraper probably was used unhafted. Three roughly rectangular flakes have two parallel working edges and were probably also used unhafted; two of these show careful chipping over their entire surfaces (Pl. 1,1). Another type of double-edged scraper, represented by two specimens, is slightly curved, flat across one end and carefully worked on all surfaces (Pl. 1,2). The remaining eight chert examples are crude flakes retouched on one or more edges, and there are also two scrapers of this type made from flakes of fine-grained schist. A single end scraper of fine-grained schist is large and roughly flaked 
over most of its surface and has a more finely retouched working edge. This implement, the identification of which should be considered tentative, would presumably have been used unhafted (Pl. 1, 10). Scraper blanks of blue and black chert number nine specimens, all of which show rough chipping; one appears to have been intended as a discoidal scraper (Pl. 1,3).

Nine fragmentary chert end blades vary in width from $9 \mathrm{~mm}$. to $1.7 \mathrm{~cm}$. and show uniformly even flaking on all surfaces. Eight are tip fragments and the two most carefully made specimens have serrated edges (Pl. 1,4,5). Of the two blades showing the form of the base, both have slight stems and one is very small and virtually complete $(\mathrm{Pl} .1,6)$. The larger specimens might have been end-bladed knife blades, while the smaller ones were probably projectile points. There are 14 blanks for end blades, all of chert, and ranging in length from 3 to $8 \mathrm{~cm}$.

Two hand drills are similarly constructed but made from different materials. A chert specimen has been carefully flaked to a slender point at the distal end and has been thinned at the proximal end by the removal of a single large flake on each surface (Pl. 1,7). The other drill is made of fine-grained schist, has a thinner point, and is longer (Pl. 1,8).

A single implement of fine-grained schist is tentatively identified as an awl or gouge. It is a pebble that appears to have been roughly flaked at the proximal end to facilitate holding in the hand. The distal end has been sharpened by the removal of a long flake along one side and a certain amount of rough chipping on the other (Pl. 1,9).

In addition to the chipped stone artifacts described above, a total of 322 flint chips were carefully examined, counted and discarded either in the field or the laboratory.

\section{Ground Stone}

Objects of ground stone form the largest category of locally manufactured artifacts in the collection and the relatively large number of types represented gives a clear idea of the importance of this toolmaking technique to the people of Tikchik. The most abundant artifacts in this category are whetstones, of which there are 61 specimens. These have been divided into two types based on the nature of the stone from which they were made. The 45 specimens belonging to type 1 are made of a relatively soft material ranging from a very fine-grained sandstone or siltstone to a relatively coarse-grained schist. A wide range in size is represented. Three whetstones of this 
type in excess of $17 \mathrm{~cm}$. in length and $8.5 \mathrm{~cm}$. in width were discarded in the field, while a number in the collection are more than $13 \mathrm{~cm}$. long. The smallest fragments are 2 to $4 \mathrm{~cm}$. in length. All of the type 1 specimens have at least two flat surfaces showing varying degrees of use. In many cases the unbroken edges of the whetstones have been roughly worked, and ten can be said to be well shaped (Pl. 1,11-13). The illustrated specimens indicate the better made examples.

Whetstones of type 2 number 16, half of them being complete or nearly so. They have been shaped from a relatively hard material, in most cases a very fine-grained schist. They tend to be somewhat smaller than the whetstones of type 1 , the largest, a complete implement, being $16 \mathrm{~cm}$. in length. All the specimens show wear on at least two surfaces and the best examples, like those of type 1, are worked to a rectangular form and show wear on four surfaces (Pl. 1, 14-15).

Five of the type 1 whetstones have deep, narrow striations on their worn surfaces which would appear to be the result of their use as sharpeners for steel needles (Pl. 1,12). On all of these implements the striations are as much as $2 \mathrm{~mm}$. in width, which would seem to suggest a heavy sail-makers' needle. This type of secondary usage is of particular significance because there are no needles in the collection. Strictly speaking, of course, it is difficult to be sure whether such a use for a whetstone was a secondary one. All the striations, however, occur on worn surfaces of specimens and in all cases are relatively sharp and clear. It is also noteworthy that only whetstones of the softer material were used for this purpose.

There are eight hammerstones in the Tikchik collection, seven of which are pebbles of coarse to fine-grained sandstone blunted at one or both ends by use. The largest of these is approximately $16 \mathrm{~cm}$. long and $10 \mathrm{~cm}$. wide, while the smallest is 8.5 by $4 \mathrm{~cm}$. (Pl. 2,1). The ninth implement is similar to the others except that it is broken at one end and this flat surface has also been used for hammering (Pl. 2,2).

Eight slate end blades and 16 fragments all exhibit finely-ground surfaces and bilateral cutting edges. Three of the complete specimens are characterized by a hollow-ground groove running parallel to the entire length of the blade (Pl. 2,4), while the others are flat on both surfaces and have beveled edges (Pl.2,5,6). Seven are flat across the proximal end ( $\mathrm{Pl} .2,4-6)$, while one has a pronounced concave base $(\mathrm{Pl} .2,3)$. Of the fragments, six are blade tips and 


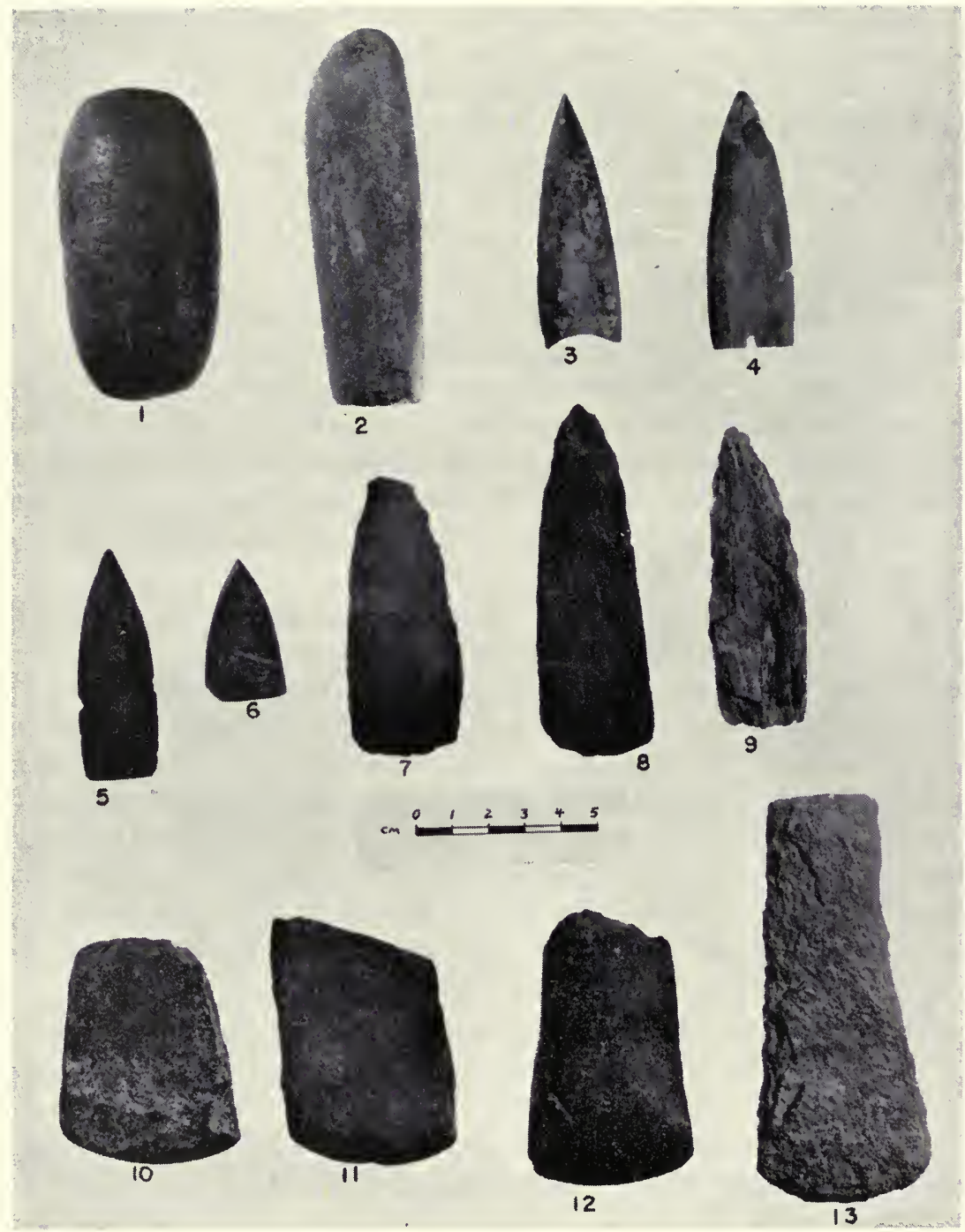

Plate 2. Ground Stone Artifacts. 1. Hammerstone, p. 267; 2. Hammerstone, p. 267; 3. End blade, p. 267; 4. End blade, p. 267; 5. End blade, p. 267; 6. End blade, p. 267; 7. End blade blank, p. 270; 8. End blade blank p. 270; 9. End blade blank, p. 270; 10. End hafted skin-scraper blade, p. 270; 11. End hafted skin-scraper blade, p. 270; 12. End hafted skin-scraper blade, p. 270; 13. Skin-scraper blade blank, p. 270. 


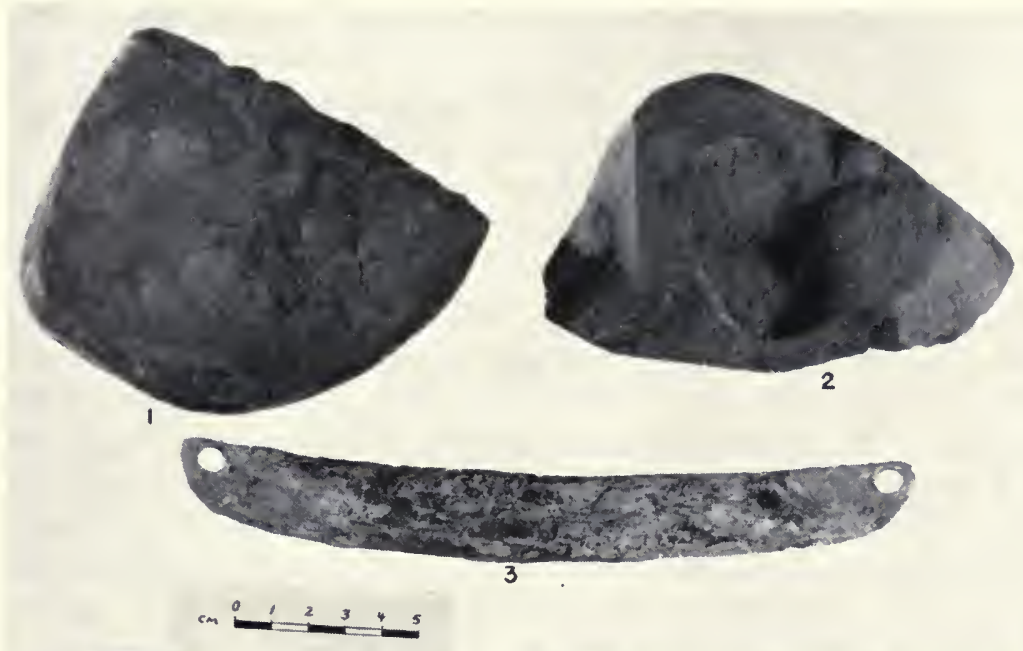

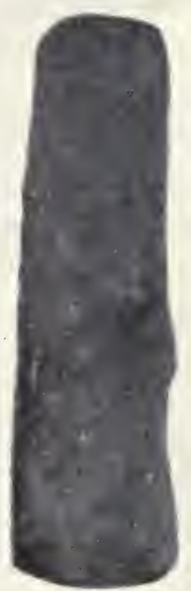

5

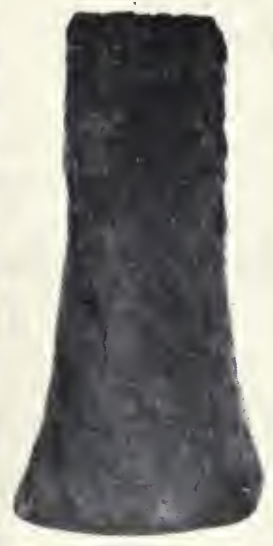

6

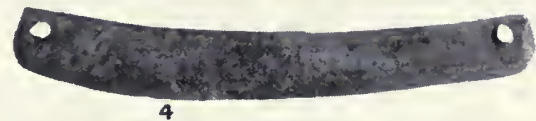

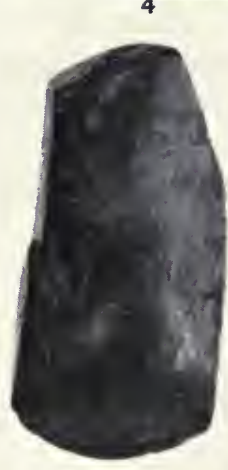

7

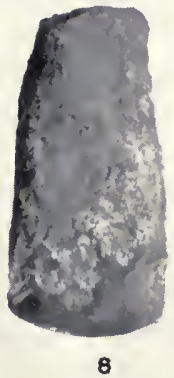

8

Plate 3. Ground Stone and Antler Artifacts. 1. Stone lamp, p. 272; 2. Paint mortar, pigment grinder or fungus grinder, p. 271; 3. Net sinker, p. 272; 4. Net sinker, p. 272; 5. Axe blade, p. 271; 6. Planing adze blade, p. 271; 7. Planing adze blade, p. 271; 8. Planing adze blade, p. 271. 
five of these show the hollow-ground groove as do all five of the basal fragments. Four of these have flat bases and one is concave. There are five sections from the centers of blades and all but one are characterized by the hollow-ground groove. All the complete specimens and fragments are of a size to suggest their use as arrow or lance heads, although the larger implements may have been knife blades.

The larger number of slate end blade blanks attests to the importance of the finished implement. There are 53 of these blanks and they range from a very small blank, $3.1 \mathrm{~cm}$. in length, presumably intended as an arrowhead, to specimens in excess of $10 \mathrm{~cm}$. long which would undoubtedly have been finished as knife blades or lance heads. The nature of the workmanship exhibited by these blanks seems to suggest that a piece of slate was first chipped to roughly the correct size and shape, and then finished by grinding first the flat surfaces and then the working edges. Three of the larger, more carefully worked blanks are illustrated (Pl. 2,7-9).

There are no ground slate ulu blades in the collection, but six ulu blade blanks are of this material. All are roughly flaked and do not clearly suggest the final shape of the blade. All specimens, however, would probably have been finished with a convex cutting edge, there being some degree of variability in this convexity. It also appears that none of these ulu blades would have been tanged but would rather have had flat or convex proximal surfaces for insertion into the handle.

Ten artifacts served as blades for end-hafted skin scrapers. Each is made of a soft, fine-grained schist and all are crudely fashioned except for the working edge which is V-shaped in cross-section. Five complete or nearly complete specimens taper toward the proximal end for insertion into an antler handle (Pl. 2,10,12). Three scrapers appear to have had straight sides ( $\mathrm{Pl} .2,11)$, while two fragments are not complete enough to indicate their shape. Skin scraper blades are always made of a soft material but otherwise they are difficult to distinguish from small adze blades. Were it not for this distinction, at least two of these specimens would have been referred to as planing adze blades. Eight skin scraper blade blanks of soft schist are roughly chipped on all surfaces preparatory to the final polishing and grinding of the working edges. All would have had tapered sides when finished (Pl. 2,13).

A single axe blade of very fine-grained schist is so identified because of a pronounced lashing knob about $6 \mathrm{~cm}$. above the working 
edge. The blade also appears to have been thinned slightly toward the proximal end as an aid to hafting. Were it not for the knob, however, this implement would probably have been identified as a planing adze blade (Pl. 3,5).

Although artifacts of wood are almost completely lacking in the Tikchik collection, the importance of wood working is suggested by the large number of planing adze blades. The 14 complete or virtually complete specimens vary in size but conform to a single type. All are roughly worked except for finely-ground, V-shaped working edges, and all show varying degrees of taper toward the proximal end (Pl. 3,6-8). Some may have been hafted directly to a shouldered handle but most, particularly the smaller specimens with pronounced tapering sides, were fashioned for hafting in a socketed or bedded adze head. It should be emphasized that several of the smaller adze blades closely resemble the previously described skin scraper blades and probably would have been so described had it not been for the hardness of the material from which they are manufactured. Actually, both the skin scraper blades and the planing adze blades are made from a fine-grained schist. The latter, however, are made from a much finer-grained, and therefore harder, type of schist. The relatively large number of these adze blades contrasts markedly with the complete absence of adze heads of any form. Ten planing adze blade blanks of fine grained schist are roughly chipped to their approximate final shape. Two specimens show some traces of polishing at the working ends.

A single net sinker is simply a pebble of fine conglomerate crudely notched on opposite sides for lashing. Carefully finished bone and antler net sinkers are common in the Tikchik collection, but the single stone specimen suggests that this form was rarely used.

Two large, irregularly shaped boulders of fine-grained schist have carefully rounded, ground depressions on one side. These have been identified as paint mortars, pigment grinders or fungus grinders even though there are few indications of use. The larger specimen, not illustrated, is approximately 17 by 14 by $12 \mathrm{~cm}$. and has a "bowl" that is $8 \mathrm{~cm}$. in diameter and $5 \mathrm{~cm}$. deep. The smaller specimen has a much shallower depression (Pl. 3,2). Two other fragmentary sections of schist with ground flat surfaces also suggest grinders of some kind. One is approximately 14 by $9 \mathrm{~cm}$. and has one ground surface which slopes up slightly toward the edge. The other is similar but about half the size. Neither shows indications of use. 
One complete and two fragmentary stone lamps were recovered. The complete lamp was discarded in the field since it weighed an estimated twenty pounds. It was made from a large, coarse-grained boulder that had not been worked on the exterior surface but which had a deep, irregularly-shaped concavity ground into it to a depth of approximately $6 \mathrm{~cm}$. at the deepest point. The dimensions of the boulder as a whole were approximately $32 \mathrm{~cm}$. in length and $18.5 \mathrm{~cm}$. in width. The bowl of the lamp, which was much blackened and encrusted from use, was 22 by $17.5 \mathrm{~cm}$. The largest fragmentary specimen, made of a fine-grained material, probably a schist, appears also to have been a hollowed-out natural boulder. The fragment is $25 \mathrm{~cm}$. long and $14 \mathrm{~cm}$. wide at its widest point. The sides are broken except in one place but it would seem that the bowl was approximately $5 \mathrm{~cm}$. deep. The entire fragment is blackened and encrusted from use. The smaller lamp fragment, apparently manufactured from a fine-grained siltstone, is more carefully made. All surfaces show grinding and the complete specimen would appear to have been round or nearly so with an inverted U-shaped rim. The blackened bowl is approximately $3.5 \mathrm{~cm}$. deep (Pl. 3,1$)$. Since pottery lamps were well established throughout all of southwestern Alaska during the nineteenth century, these stone specimens would appear to be the result of influence from stone lamp using areas to the south and east. The large crude lamp and fragments are not unlike those from Kachemak Bay and Prince William Sound (deLaguna, 1934, Pl. 23,1; 1956, Pl. 25,1).

\section{Bone and Antler}

Artifacts of bone and antler are common in the Tikchik collection, with 153 identifiable objects made from these materials.

Antler net sinkers, of which there are 13 complete and six fragmentary specimens, are roughly rectangular in outline with laterally drilled holes at each end for attachment to the net (Pl. 3,3-4). In cross-section these implements have a rounded triangular form, narrow at the top and thick at the bottom. The complete specimens range in length from $14.5 \mathrm{~cm}$. to $20.5 \mathrm{~cm}$., and all are well made. Two of these sinkers have regularly spaced notches along the upper edge; that is, the edge closest to the net. On one, the notches are $3.6 \mathrm{~cm}$. apart and on the other, $2.5 \mathrm{~cm}$. It may be that these notches indicate the size of the mesh of the net to which the sinkers were fastened. If that is the case, the fisherman, having notched his sinkers, would then be able to tell how much length of net each sinker 


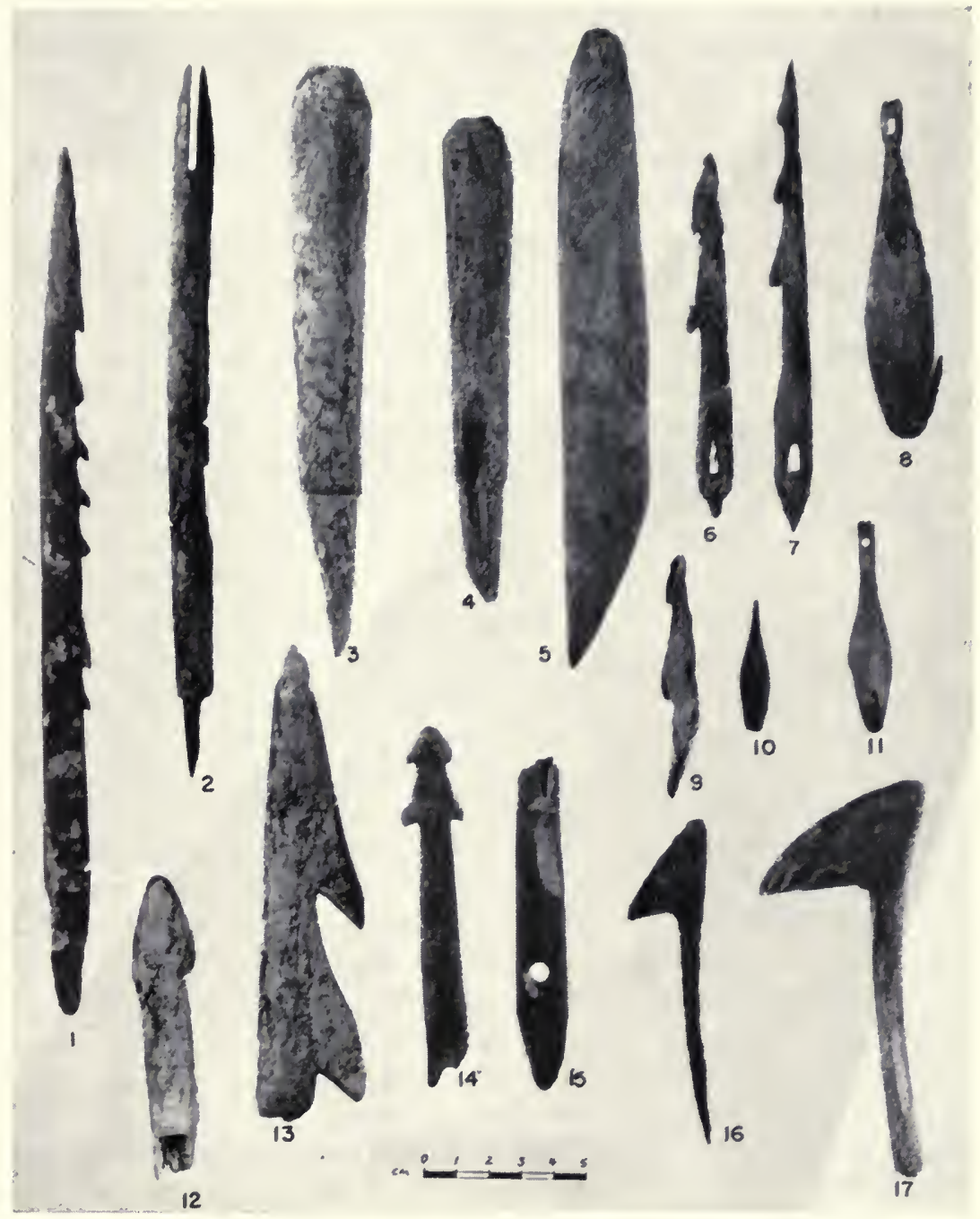

Plate 4. Bone and Antler Artifacts. 1. Arrowhead, p. 275: 2. Arrowhead, p. 275; 3. Salmon harpoon socket piece, p. 274; 4. Salmon harpoon socket piece, p. 274; 5. Fishing ice pick, p. 274; 6. Salmon harpoon dart head, p. 274; 7. Salmon harpoon dart head, p. 274; 8. Lure-hook, p. 274; 9. Side prong for fish spear, p. 274; 10. Lure-hook, p. 274; 11. Lure-hook, p. 274; 12. Center prong for fish spear (?), p. 275; 13. Center prong for fish spear, p. 275; 14. Center prong for fish spear, p. 275; 15. Salmon harpoon dart head, p. 274; 16. Side prong for fish spear, p. 274; 17. Side prong for fish spear, p. 274. 
would cover and thus how many sinkers he would need for the entire net. The two notched specimens are $17.5 \mathrm{~cm}$. and $14.5 \mathrm{~cm}$. in length respectively and are both less than $1.5 \mathrm{~cm}$. in width. This, together with the length of the interval between the notches, suggests their use with light nets of small mesh, perhaps nets that would have been set for whitefish in small creeks and lakes near the village.

The seven lure-hooks, only two of which are complete, have antler shanks in a stylized fish shape with drilled holes at the distal end to receive a metal hook. On three specimens the barb, a bent nail, is in place ( $\mathrm{Pl} .4,8,11)$. The proximal ends of five specimens are complete, the three longest of these having a small drilled hole for suspension that runs parallel to the hole for the barb. The two smallest specimens, on the other hand, have their suspension holes at right angles to the barb hole ( $\mathrm{Pl} .4,10)$. It is probable that the larger lure-hooks were used for winter fishing through the river ice for pike while the smaller ones would have been similarly used for grayling.

Three of the four salmon harpoon socket pieces, all of bone, have pronounced shoulders and conical tangs of varying degrees of irregularity (Pl. 4,3-4). The largest specimen has a small rivet hole at the tip of the tang. All three are drilled at the distal end to receive the dart head. The fourth socket piece, made of antler, is too fragmentary to determine its shape but a wedge-shaped tang is suggested. The four fishing ice picks are all of antler and range in length from 10.5 to $20 \mathrm{~cm}$. They are made from the split half of an antler tip and are carefully flattened on one side to form a smooth contact with a wooden shaft (Pl. 4,5). Such picks would have been used to open holes in the ice for hook fishing or for the setting of nets and traps.

There are six salmon harpoon dart heads of antler in the collection, four of which are complete but poorly preserved. All are asymetrically barbed and three have sloping shoulders and conical tangs (Pl. 4,7), while the fourth has a sharp shoulder with a conical tang (Pl. 4,6). All line holes are in the center, three being gouged and the fourth drilled and round. The two basal fragments are from much larger heads. They have centrally placed, round, drilled line holes and sloping shoulders with wedge-shaped tangs (Pl. 4,15).

Side prongs for fish spears are of two types. Simple leister prongs, of which there are two antler examples, are asymmetrically barbed and have pointed tangs (Pl. 4,9). Both are very poorly preserved and small enough to have been used with fish arrows. The second type consists of a strip of antler with a large barb at the end (Pl. 4, $16-17)$. There are four of these and although none is complete, it 
is obvious that they would have been hafted, one on either side of the shaft, with the large barbs facing each other (Nelson, 1899, Pl. LXVII, 3). When a fish was struck these barbs would be forced apart to help hold the fish transfixed on a barbed or plain center prong. Five barbless prongs of antler appear to have been scored for hafting as center prongs for the two or three-pronged fish spear, while a sixth specimen of the same material is thicker than the others and has a pair of symmetrically-placed barbs on each side near the point (Pl. 4,14). A large fish spear point of antler is broken at the proximal end and has two large barbs along one side near the tip (Pl. 4,13). A point such as this would presumably be hafted to a long shaft; a spear of this type is illustrated by Nelson (1899, Pl. LXVII, 4). The identification of another antler specimen is doubtful. It is socketed at the proximal end to receive a thin shaft, but the tip is unfinished (Pl. 4,12). This implement may have been intended as an arrowhead.

There are two antler artifacts which are definitely arrowheads. One specimen has a sharp shoulder and plain conical tang, two broken barbs along one side, a blade slit and a single engraved line running along one side from the proximal end of the blade slit to the shoulder of the tang (Pl. 4,2). The other has a sloping shoulder and thin spatulate tang; there are seven small barbs along one side and a small notch just above the shoulder of the tang (Pl. 4,1). There is also a small, antler blunt arrowhead, probably unfinished. It has a sharp shoulder, rectangular tang and comes to a point at the top (Pl. 5,9).

The 18 antler splitting wedges vary in length from 8 to $18 \mathrm{~cm}$. and average $12 \mathrm{~cm}$. All are of the same type, being blunt at one end and tapering to a wedge-shaped tip at the other ( $\mathrm{Pl} .5,6-7)$. None, however, shows signs of extensive use. There is also a single bone specimen $21 \mathrm{~cm}$. in length made from the proximal end of a caribou femur.

Two skin scrapers made from caribou scapulae have been cut longitudinally to form a sharp scraping edge (Pl. 5,13). Two complete chisels have thick metal blades inserted into antler sleeves. The handle of one specimen has a series of parallel incised lines running longitudinally from the proximal end to a series of three barely visible parallel incisions running around the implement near the point where the blade is inserted (Pl. 5,8).

$A w l s$ are divided into two types. The first is represented by 12 specimens made from split pieces of bone and worked to a fine point 


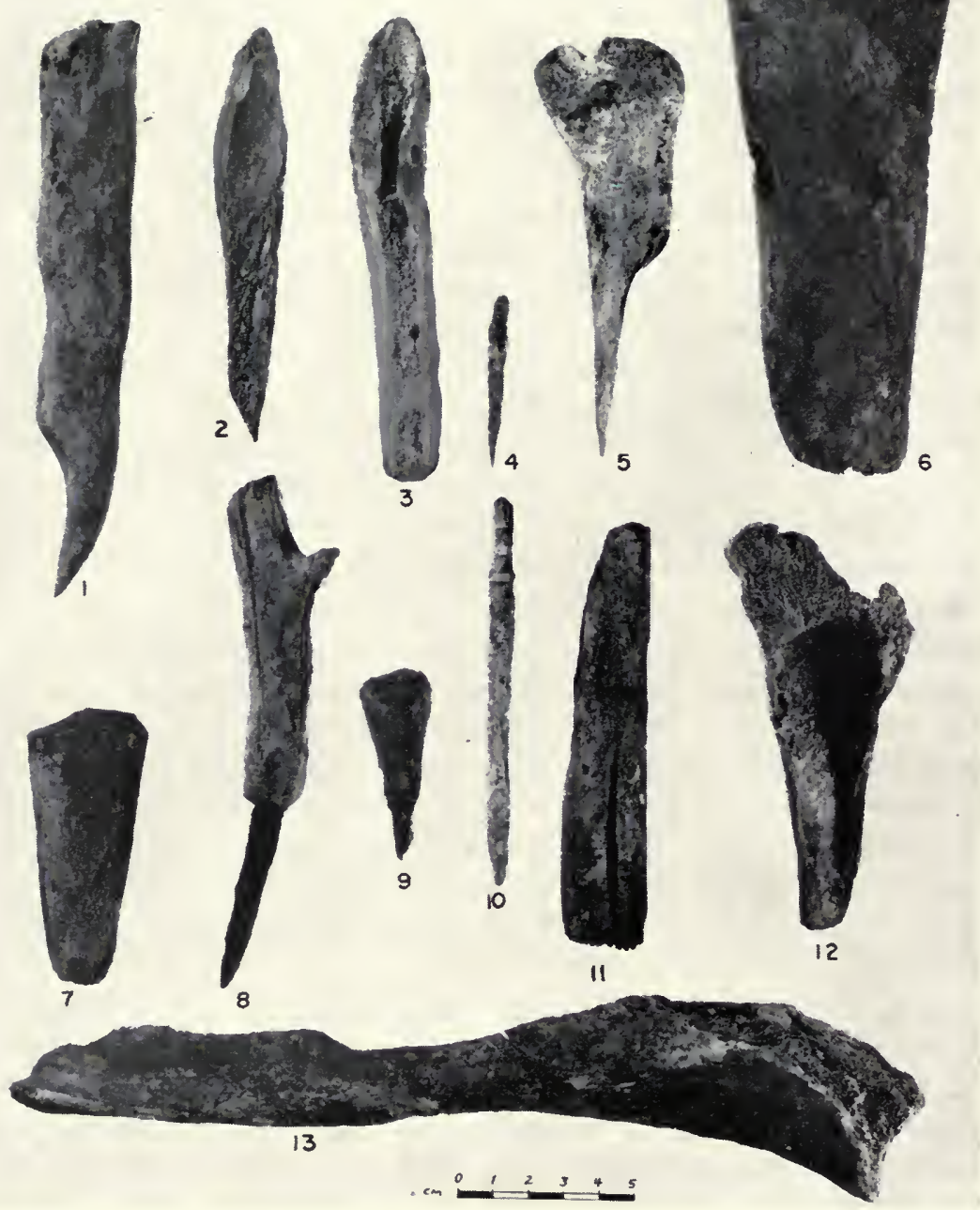

Plate 5. Bone and Antler Artifacts. 1. Awl, p. 278; 2. Awl, p. 278; 3. Awl (?), p. 278; 4. Needle (?), p. 278; 5. Awl, p. 278; 6. Wedge, p. 275; 7. Wedge, p. 275; 8. Chisel, p. 275; 9. Blunt arrowhead, p. 275; 10. Engraving tool handle (?), p. 278; 11. Crooked knife handle, p. 278; 12. Bark peeling tool (?), p. 278; 13. Skin scraper, p. 275. 


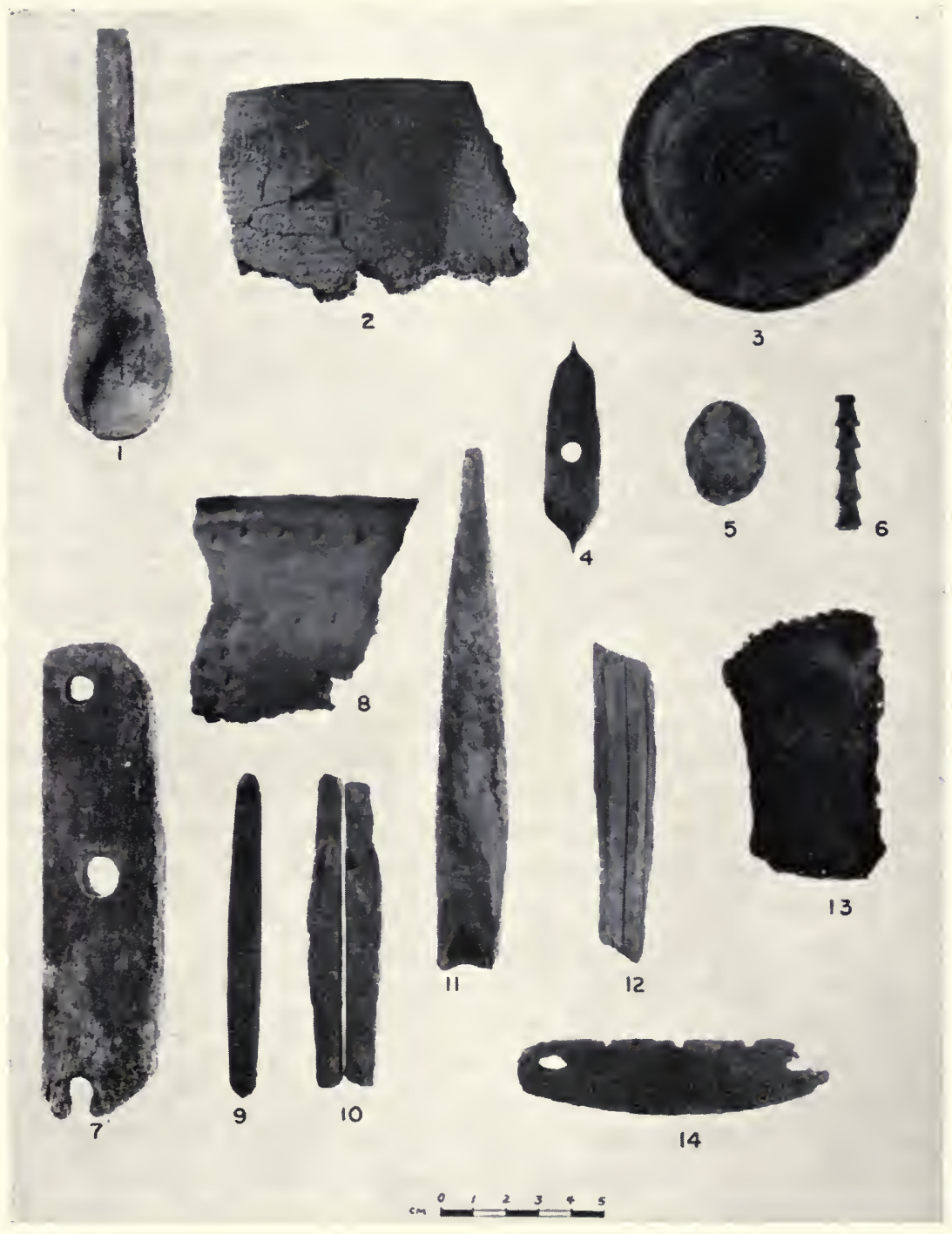

Plate 6. Bone, Antler, Bark and Leather Artifacts, and Locally made Pottery. 1. Spoon, p. 278; 2. Potsherd, p. 282; 3. Lamp, p. 283; 4. Unidentified object, p. 279 ; 5. Unidentified object, p. 279 ; 6. Unidentified object, p. 279; 7. Sled shoe section, p. 279; 8. Potsherd, p. 281; 9. Unidentified object, p. 279; 10. Composite knife handle, p. $278 ; 11$. Scraper handle (?), p. 278; 12. Unidentified object, p. $279 ; 13$. Leather patch or reinforcing piece, p. $284 ; 14$. Net float, p. 284. 
at one end (Pl. 5,2,5). Type 2 awls, of which there are ten, are made from sections of antler tine, blunt at one end and sharpened to a point at the other ( $\mathrm{Pl} .5,1)$. A thirteenth specimen, tentatively identified as an awl, is made of bone. It is spatulate shaped at the distal end and could conceivably have been used as a bark peeler (Pl. 5,3).

A small sliver of antler with a very sharp point but without a hole for the thread at the proximal end may be an unfinished needle (Pl. 5,4).

Three crooked knife handles are made from slightly curved pieces of antler. The curved blade slits are $3.5 \mathrm{~cm} ., 7.3 \mathrm{~cm}$., and $8.5 \mathrm{~cm}$. in length, respectively. One of the handles has three drill bearing holes on one side and a suspension hole at the proximal end. Another specimen (Pl. 5,11) has a deeply cut groove toward the proximal end on one side and also has a series of small tooth-like projections at the proximal end which suggest its secondary use as a defleshing tool (see Steinbring, 1966).

A single composite knife handle consists of two rectangular pieces of antler flat on the inner side and rounded on the outside. Holes have been drilled laterally through both pieces in two places and the remains of wooden pegs are still inserted. The blade slit is broken, but it was rather wide and was probably meant to receive a tanged slate blade; there is a raised lashing lip at the distal end of the blade slit (Pl. 6,10).

A tentative identification is necessary with regard to a single antler implement that may have been a scraper handle. The specimen is pointed at one end, and at the other is a small, triangular socket, possibly for a flint or metal scraper (Pl. 6,11). Another tentatively identified artifact is an antler engraving tool handle. The specimen does not appear to be complete and no slot is visible for an animal tooth or metal blade. There are, however, a series of three raised bands running around the implement near one end, a type of decoration that is characteristic of Alaskan Eskimo engraving tools (Pl. 5,10).

Three crudely made bone objects may have been used as barik peeling tools. They are spatulate shaped at one end and measure $12,13.5$, and $24 \mathrm{~cm}$. in length, respectively ( $\mathrm{Pl} .5,12$ ).

A single antler spoon has a deep, oblong bowl and a straight handle (PI. 6,1). 
One of the more abundant artifact types in the entire Tikchik collection is sled shoe sections of which there are $37 ; 30$ are of whale bone and seven of antler (Pl. 6,7). Holes for pegging to a runner are drilled $8 \mathrm{~mm}$. to $1.3 \mathrm{~cm}$. in diameter and are irregularly spaced. The width of the unbroken shoes ranges from 2 to $5 \mathrm{~cm}$. and many of the sections are thin, showing considerable wear. As might be expected, the antler shoes are shorter, narrower, and thinner than those made of bone.

Three story knives are made of curved, flat antler sections which widen at the distal end to form a knife-like blade. The specimens range in length from 14.3 to $27 \mathrm{~cm}$., the longest being extremely thin with two parallel engraved lines running along one side. Inside these lines, pairs of short, chevron-shaped lines occur at $5 \mathrm{~cm}$. intervals. This decorative motif extends the entire length of one edge of the specimen.

There are five artifacts, all of antler and complete or nearly complete, that cannot be identified. One is a thin, oblong piece of antler, rounded and with a raised lip at each end on one side (Pl. 6,9). Obviously this specimen was intended for lashing to something. A short, thick section of antler comes to a point at each end and has a round hole drilled through the center (Pl. 6,4). A thin, flat fragment of antler has been cut almost to a round shape and may have been a gaming piece (Pl. 6,5). A narrow fragment of antler is decorated along one surface with parallel incised lines (Pl. 6,12). The final unidentified object is a section of antler carved into a series of bellshaped sections and flat across what appears to be the top (Pl. 6,6). The lower end of this object is broken. It resembles the distal end of a ramrod for cleaning guns but it seems rather light and thin to have been used for that purpose.

In addition to the identified and unidentified artifacts described above, a total of 139 sections of cut antler and 12 pieces of cut bone were counted and discarded in the field.

\section{Clay}

A total of 310 clay cooking pot fragments was recovered from the Tikchik site. This count was made in the laboratory and it is possible that the number of excavated sherds was slightly increased by breakage during shipment. An attempt was made to join together all sherds which could be joined and, as a result, seven vessels were partially reconstructed and the total collection was reduced to 213 sherds. 
The reconstructed size and shape of the cooking pots is based on the seven fragmentary vessels, one of which is virtually complete. Of the remaining six, one is also nearly complete but lacks a rim which was probably broken off before the vessel ceased to be used. Two show nearly complete rims but lack bases, while three represent the lower half of vessels. It would appear on the basis of this material that only one type of vessel shape is represented; a pot with a disc-shaped, slightly concave bottom and sides that flare evenly, constrict at the neck and flare again at the mouth. This is the situla shape and vessels of this type are widely spread in Alaska from Hotham Inlet south to Kodiak Island. It should be kept in mind that other shapes are represented in the collection as will be noted when rim sherds are described. But the situla shape is the only one that can be fully reconstructed on the basis of complete or nearly complete vessels.

The two most complete reconstructed pots represent extremes in vessel size. One is very small, standing $12 \mathrm{~cm}$. in height. It has a diameter at the mouth of $11.5 \mathrm{~cm}$., a basal diameter of $8.5 \mathrm{~cm}$., and an average thickness of $6 \mathrm{~mm}$. (PI. 11,a). The other is the largest vessel I have ever seen in a collection of Eskimo pottery. It stands $30 \mathrm{~cm}$. in height but the rim is broken off all the way around at the point where the neck constriction would have begun, so the complete specimen was doubtless another 8 to $10 \mathrm{~cm}$. in height. This vessel has a diameter at the neck constriction point of $26 \mathrm{~cm}$., a basal diameter of $18 \mathrm{~cm}$., and an average thickness of $8 \mathrm{~mm}$. (Pl. 11,b). The two vessels lacking bases but showing nearly complete rims are 12.5 and $12 \mathrm{~cm}$. in diameter, respectively, at the mouth, while the three lower halves of vessels have bases which measure 9,10 , and $11.5 \mathrm{~cm}$. across. It would seem that the average-sized, situla-shaped vessel used at Tikchik was somewhat larger than the small virtually complete specimen, but a good deal smaller than the large one. In addition to the reconstructed vessels just described, there are 17 basal sherds in the collection, all of them from flat-bottomed vessels. It would thus appear that whatever may have been the shapes represented in addition to the situla shape, all pots had flat bottoms.

Lip sherds too small to allow a definite reconstruction of the vessel shape total 22. In cross-section these sherds are rounded (9 sherds), flat and sloping out (4), flat (4), flat and sloping in (1), flat with incised line on the top (1), flat and sloping out with an incised line on the top (3). Of the three partially reconstructed vessels with rims, two are flat and sloping out in cross-section, while the third 
is flat and sloping out with an incised line. A single sherd from a pot of undetermined form has a hole running through it. Since this sherd does not appear to be from near the rim of the vessel, it is probably a mending hole.

Of the 213 sherds examined, 26 are decorated as are the rims of four partially reconstructed vessels; thus a total of 30 decorated sherds will be considered here. The three types of decoration in order of frequency are Yukon Line Dot (18 sherds), Nunivak Check Stamp (8), Norton Check Stamp (4). Of the Yukon Line Dot sherds (Oswalt, 1955, p. 37), 14 are from the rims of vessels, including four from partially reconstructed pots. The forms of decoration on these latter four are all different. They include a single line with a row of dots beneath it which run around the vessel at the point where the neck constricts; a single encircling line just below the lip with a row of dots immediately below and the motif repeated at the point where the neck constricts; a similar pattern but with two encircling lines instead of one at the neck constriction point and two rows of vertical dots running from just below the constriction to the lip repeated at intervals around the vessel; and a single row of dots encircling the vessel below the rim and again at the neck constriction point. One of these reconstructed pots has a series of three encircling lines around the inside of the vessel just below the lip. The remaining ten rim sherds of the Yukon Line Dot type are characterized by a single row of dots below the lip with a series of ridges on the inside (4); a single row of dots below the lip (1); a row of dots under the lip, at the neck constriction point, and a short double row of vertical dots (1) (Pl. 6,8); a single encircling line and row of dots below the lip with interior ridges (3); and a unique sherd with two parallel lines just below the lip and a large circle dot design below the lines. In addition, there are four body sherds all showing a row of dots and a line in combination. Only three of the Yukon Line Dot decorated rim sherds are large enough to show the full shape of the rim and these all come from vessels with constricted necks and flaring rims similar to those described above.

The Nunivak Check Stamped sherds (Oswalt, 1955, p. 35) include four rim fragments, two basal sherds, and two body sherds. All are characterized by relatively large rectangular checks, 4 to $6 \mathrm{~mm}$. wide, separated by comparatively wide bands. The decoration is badly weathered on all but two sherds. The four rim sherds are all from vessels with straight sides that curve in slightly at the rim; the lips are all round in cross-section. Sherds with Norton Check Stamped 
TABLE 2.-Distribution of tempering material in Tikchik potsherds and reconstructed pots by house, kashgee, and test trench.

$\begin{array}{lcccccccccccccc}\quad \text { Temper } & \mathrm{H} 1 & \mathrm{H} 2 & \mathrm{H} 3 & \mathrm{H} 4 & \mathrm{H} 5 & \mathrm{H} 6 & \mathrm{H} 7 & \mathrm{H} 8 & \mathrm{H} 9 & \mathrm{H} 10 & \mathrm{~K} 1 & \mathrm{~K} 2 & \mathrm{~T} 1 & \text { T2 } \\ \text { Gravel } & 3 & 4 & 2 & 2 & 12 & 39 & 6 & 1 & \ldots & 45 & 5 & \ldots & 4 & 2 \\ \text { Sand } & \ldots & 1 & 2 & \ldots & 1 & \ldots & 1 & \ldots & \ldots & \ldots & 16 & \ldots & \ldots & \ldots \\ \text { Hair } & \ldots & \ldots & 4 & \ldots & \ldots & \ldots & \ldots & \ldots & \ldots & 6 & \ldots & \ldots & \ldots & \ldots \\ \begin{array}{l}\text { Vegetal fiber } \\ \text { Hair and }\end{array} & \ldots & 1 & 6 & \ldots & 2 & \ldots & \ldots & \ldots & \ldots & 17 & 20 & \ldots & \ldots & \ldots \\ \quad \text { vegetal fiber } & \ldots & 1 & \ldots & \ldots & \ldots & \ldots & \ldots & \ldots & \ldots & 2 & 1 & \ldots & \ldots & \ldots \\ \begin{array}{l}\text { Gravel and } \\ \quad \text { vegetal fiber }\end{array} & \ldots & \ldots & 3 & \ldots & \ldots & \ldots & 1 & \ldots & \ldots & 5 & 1 & \ldots & \ldots & \ldots \\ \text { Gravel and hair } & \ldots & \ldots & 1 & \ldots & \ldots & \ldots & \ldots & \ldots & \ldots & 2 & 1 & \ldots & \ldots & \ldots\end{array}$

decoration (Oswalt, 1955, p. 34) include two rim fragments (Pl. 6,2), a body sherd, and a basal fragment. All have small checks, 2 to $4 \mathrm{~mm}$. in width, that are more nearly square than those of the Nunivak Check Stamped variety. The rim sherds indicate a similar vessel shape, however. The Norton Check Stamped sherds average $9 \mathrm{~mm}$. in thickness with the thickest being $11 \mathrm{~mm}$. and the thinnest $6 \mathrm{~mm}$. Those with Nunivak Check Stamped decoration average $8 \mathrm{~mm}$. with the thickest sherd measuring $11 \mathrm{~mm}$. and the thinnest $7 \mathrm{~mm}$.

All the 213 sherds and seven partially reconstructed vessels were examined to determine the type of temper used in their manufacture. The temper proved to be predominantly inorganic, but sherds containing organic and a combination of organic and inorganic tempering agents are also present. The inorganic temper consists of sand and gravel with the coarser material being by far the most common; hair and vegetal fibers are the only organic tempering materials. The texture of Tikchik pottery is not particularly fine, although generally speaking the tempering materials are distributed uniformly throughout the ware. Some of the gravel temper is large enough to be considered pebbles, the largest measuring in excess of $5 \mathrm{~mm}$. in length. Large pieces of tempering material like this frequently protrude through the surface of the sherds. Table 2 shows the distribution of tempering material by house, kashgee, and test trench, while Table 3 compares surface treatment with the tempering agents. It will

TABLE 3.- Surface treatment and temper comparison.

\begin{tabular}{|c|c|c|c|c|c|c|c|}
\hline & & & & & $\begin{array}{l}\text { Hair } \\
\text { and }\end{array}$ & $\begin{array}{l}\text { Gravel } \\
\text { and }\end{array}$ & Gravel \\
\hline Surface Treatment & Gravel & Sand & Hair & $\begin{array}{c}\text { Vegetal } \\
\text { fiber }\end{array}$ & $\begin{array}{l}\text { vegetal } \\
\text { fiber }\end{array}$ & $\begin{array}{l}\text { vegetal } \\
\text { fiber }\end{array}$ & $\begin{array}{l}\text { and } \\
\text { hair }\end{array}$ \\
\hline Yukon line dot & 18 & & & & & & \\
\hline Nunivak check stamp & 3 & 2 & 1 & & & 2 & \\
\hline Norton check stamp & & & & 4 & & & \\
\hline Plain & 105 & 19 & 9 & 41 & 4 & 8 & 4 \\
\hline
\end{tabular}


be noted that the check-stamped pottery of both types is predominantly fiber tempered, while coarse, inorganic temper is generally characteristic of the Yukon Line Dot and plain pottery.

To determine the thickness of the ware, all the unexfoliated sherds were measured. The thickest was $1.5 \mathrm{~cm}$., the thinnest $5 \mathrm{~mm}$., and the average $8 \mathrm{~mm}$. Nearly all the sherds are black or grey-black in color but the range is from black to buff with a few sherds that are reddish brown. The fiber-tempered sherds are uniformly lighter in color, most of ten a brown or buff, than those with inorganic temper.

Lamps in the Tikchik collection of clay artifacts are represented by one complete specimen, another that is virtually complete, a half of a lamp, and five sherds. The complete lamp is small, probably for use by a hunter, and has three circular lines near the center of the bowl with a central knob surrounded by a series of dots. Barely visible is a row of dots around the outside ring ( $\mathrm{Pl}$. 6,3). The virtually complete lamp has one encircling line outside the rim, five lines just inside the bowl, and a spoke-like design of three lines each of which divides the center of the bowl into quarters (Pl. 11,c). This central cross motif seems to have made its appearance in southwestern Alaska after 1830 (Oswalt, 1953, p. 22). The lamp half has two encircling lines outside the rim and five lines just inside the bowl. The five sherds all have either one or two encircling lines outside the rim and a number of lines just inside the bowl. All the lamps and fragments are tempered with gravel.

\section{Bark and Root}

It might be expected that at an interior site like Tikchik Village, birch bark would have been a basic and important material in the manufacture of artifacts, particularly baskets. The fact that so little preserved birch bark was collected can doubtless be explained by the generally poor preservation at the site, a situation that resulted in the complete absence of artifacts made of wood, and the recovery of only a single fragment of worked birch bark. The importance of this material in house construction has already been mentioned, and it has also been noted that the bench burial in house 5 was covered with spruce bark. The only object that can be described as a birch bark artifact, however, is a large fragment, possibly part of a basket, with widely spaced and fairly sizeable holes, probably for sewing with spruce root.

The only other bark artifacts in the collection are net floats made of cottonwood bark. Two specimens, neither complete, are roughly 
rectangular in outline with laterally gouged rectangular holes at each end for attachment to the net. In cross-section these implements have a rounded triangular form, narrow at the top and thick at the bottom. One of the floats has a series of notches across the upper surface similar to those on two of the previously described net sinkers $(\mathrm{Pl} .6,14)$. It may be that their purpose was the same as that described for the sinkers.

Glass

Two pieces of light green bottle glass have been extensively retouched for use as scrapers. One fragment is $3 \mathrm{~mm}$. and the other $2 \mathrm{~mm}$. in thickness.

\section{Non-Eskimo Pottery}

A single sherd of undecorated ironstone china has been worked into a round shape for an unknown purpose. The specimen is $2.1 \mathrm{~cm}$. in diameter.

\section{Leather}

All three fragments of leather in the collection have been derived from commercially prepared cowhide. The largest is $8.5 \mathrm{~cm}$. in length, while the other two are about two-thirds that size. They are described here because all three have been prepared as patches or reinforcing pieces. They are carefully cut and rows of closelyspaced stitching holes surround the outer edges on at least two sides. The illustrated specimen would appear to have been the patch on the sole of a shoe or other type of footgear as it is noticeably roughened on one side $(\mathrm{Pl} .6,13)$.

\section{Metal}

The artifacts described thus far in this chapter are of indigenous manufacture. Identifying such artifacts has given little difficulty because most of them have been associated with the traditional Eskimo material culture. When it comes to a description of metal artifacts, however, the identification of indigenous objects is not so simple. Some items made of metal are easy to recognize as complete artifacts acquired by the Eskimos from outside. Others are just as readily identifiable as attempts by Eskimos to work in a new medium. Between these two clear-cut categories, however, are a number of artifacts that could belong to either one. Some are so crudely made as to suggest local manufacture, while others are poorly preserved making it difficult to determine their provenience with any 
degree of certainty. Thus the listing of some artifacts as being of local manufacture should be considered tentative (see Oswalt and VanStone, 1967, pp. 48-49).

The largest number of indigenously manufactured metal artifacts are made from tinned steel plate of the type normally used in the manufacture of tin cans. Wrought and cast iron, together with other heavy metals and brass were available in small quantities, but can metal could be cut and worked more easily and rapidly than any of these metals and even easier than stone and other indigenous materials. Therefore, it is not surprising that, once it was readily available in sufficient quantities, can metal was favored for a variety of implements.

A single fish spear point has been crudely fashioned from the rim of a large bucket. It is $21.5 \mathrm{~cm}$. in length and a large single barb has been cut along one side approximately $8 \mathrm{~cm}$. from the distal end.

Three blunt arrowheads have been constructed by fitting a spent rifle cartridge over the end of a thin wooden shaft. A small section of the shaft protrudes from the open end of each cartridge. On one of these arrowheads the cartridge is held in place by a crude metal rivet which has been driven through one side of the case and into the shaft. The other two cases simply fit tightly over their shafts (Pl. 7,4). All three cartridges are of the centerfire type; one is .44 caliber but the caliber of the other two is unknown.

The three lead musket balls are all of different sizes. All have a burr running medially around them, indicating the division of the two halves of the mold in which they were made. These balls would have been used in weapons with barrel diameters of approximately $1.2,1.5$, and $1.8 \mathrm{~cm}$., respectively (Pl. 7,5-6).

End bladed knife blades of light can metal are considered to be of local manufacture largely because the material could easily be worked by the Eskimos with available tools. There are 13 specimens which range in length from $8.5 \mathrm{~cm}$. to $20.5 \mathrm{~cm}$. Two of the blades are made of metal that has been folded for added strength. All specimens, with one exception, are roughly rectangular in shape and pointed at the distal end ( $\mathrm{Pl} .7,8)$; the exception has a broad tang for insertion into a handle (Pl. 7,18).

There are five $u l u$ blades, all of which have been cut from the sides or tops of cans. They vary in length from 7.5 to $16 \mathrm{~cm}$., and all are flat across the top with a semilunar edge (Pl. 7,12,14).

Eight crooked knife blades are all similar although they vary in length from 4.5 to $11.5 \mathrm{~cm}$. They curve up at the distal end, nar- 


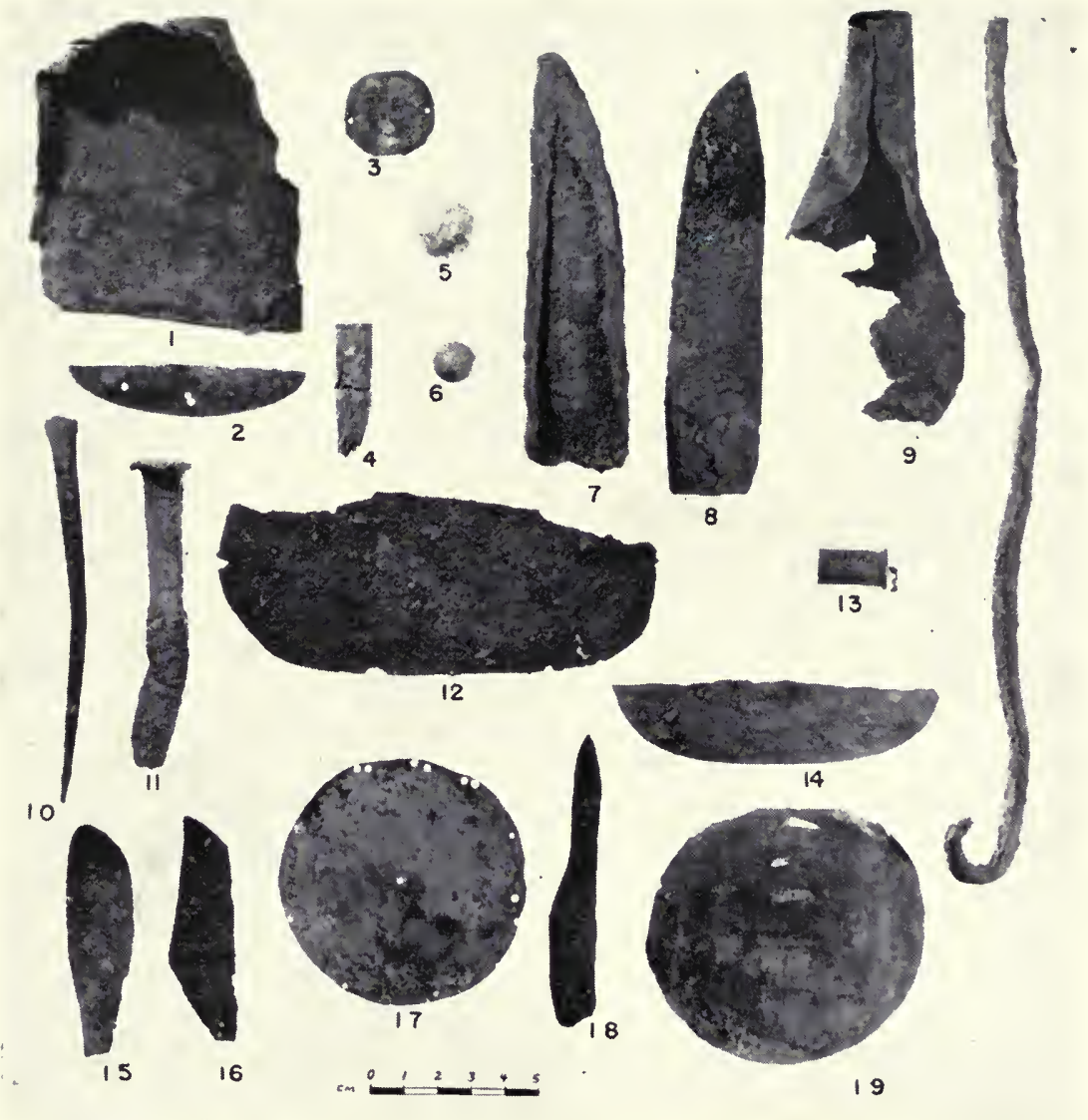

Plate 7. Metal Artifacts. 1. Dish, p. 287; 2. Pendant (?), p. 287; 3. Necklace section, p. 287; 4. Blunt arrowhead, p. 285; 5. Musket ball, p. 285; 6. Musket ball, p. 285; 7. Chisel or gouge, p. 287 ; 8. End bladed knife blade, p. $285 ; 9$. Scoop, p. $287 ; 10$. Nail with flattened head, p. $288 ; 11$. Spike with flattened end, p. 288; 12 . Ulu blade, p. 285; 13. Necklace section, p. 287: 14. Ulu blade, p. 285; 15. Crooked knife blade, p. 287; 16. Crooked knife blade, p. 287 ; 17. Pendant, p. 287; 18. End bladed knife blade, p. 285; 19. Pendant, p. $287 ; 20$. Pot hook, p. 287. 
row slightly at the proximal end, and are made from somewhat heavier metal than the previously described end bladed knife blades (Pl. 7,15-16).

A single skin scraper blade is badly corroded but it has obviously been cut from the side of a can. It is $6.7 \mathrm{~cm}$. in length, has a slightly convex working edge, and tapers toward the proximal end.

A heavy piece of cast iron has been crudely shaped in the form of a chisel or gouge $(\mathrm{Pl} .7,7)$ and a very small fragment seems to have been similarly worked.

Among the most interesting of the indigenously constructed metal artifacts are six complete or nearly complete dishes or small containers, all in a very bad state of preservation. They are made from pieces of can siding which have been folded at the corners to form shallow, roughly rectangular containers. The best preserved example is folded at one end only and may have been a scoop $(\mathrm{Pl} .7,1)$. Much more clearly identifiable as scoops are two pieces of can metal which have been bent in such a way as to form a round hole at the proximal end into which a short wooden handle would have been fitted. Such scoops might have been used for flour or sugar (Pl. 7,9).

Two light pieces of metal, probably fragments of the rims of large cans or buckets, have been folded for added strength and then turned up at one end to form a hook. Such implements might have been used as pothooks (Pl. 7,20).

A series of five round pieces of cut can metal found together in test trench 1 have small holes on opposite sides near the edges; they were presumably strung together as a necklace (Pl. 7,3). Another type of necklace, part of which is represented in the collection, was made from beads and spent rifle cartridges strung together at intervals. A single rimfire cartridge case of undetermined caliber is drilled at the proximal end and has stringing material knotted on the inside and a single white bead still attached to the outside (Pl. 7,13).

The lid of a tin can has been slit on one side and folded in the vicinity of the slit, presumably to be worn as a pendant (Pl. 719,). Two other objects may also possibly be pendants. One is a round piece of metal, almost exactly the same size as the preceding artifact but made of heavier material, with a single drilled hole in the center and a series of 12 holes drilled at intervals around the edges (Pl. 7,17). The other, somewhat lighter, is of semilunar shape and has three irregularly-spaced drilled holes (Pl. 7,2). 
A narrow strip of brass has been curved to form a small, adjustable ring, probably for a child.

A single cut can fragment and a rectangular piece of light metal $28 \mathrm{~cm}$. long and $2.8 \mathrm{~cm}$. wide, possibly a section of barrel coopering, appear to have been used as reinforcement pieces. The can fragment has a number of holes around the sides through one of which a piece of wire protrudes. The long rectangular fragment has a series of punched holes running down the center at irregular intervals. Such reinforcement pieces might be used to strengthen the cracked shaft of a lance or to repair wooden artifacts in a variety of ways.

Two long nails and a small spike show signs of having been partially prepared for a secondary use. The nails, one of them square cut, have had their heads flattened $(\mathrm{Pl} .7,10)$, while the spike has been flattened at the distal end, perhaps in preparation for its use as a knife blade (Pl. 7,11).

In addition to the metal artifacts described above, six pieces of heavy metal were recovered which show signs of having been cut, but have not been worked into any identifiable artifact. Probably they are the by-products of artifact manufacture. Also recovered were 170 cut can fragments, all but ten of which were counted and discarded in the field. These show a variety of lengths and shapes and indicate by their abundance the extent to which can metal was used as a raw material for implement manufacture. Two sections of bucket handles have been cut for future use and ten fragments of cut brass were also recovered.

\section{IMPORTED ManUfactured GOOdS}

The artifacts described under this heading are what normally are referred to as trade goods. They were made elsewhere by nonEskimos and traded to the residents of Tikchik, probably in exchange for furs or labor. For a more detailed statement concerning the occurrence of various types of trade goods in a nineteenth century site in southwestern Alaska, see Oswalt and VanStone (1967).

\section{Non-Eskimo Pottery}

The excavations at the Tikchik site resulted in the recovery of 223 sherds of non-Eskimo pottery including five identifiable saucer fragments and 11 cup fragments. All the collected sherds are fragments of ironstone china, a stoneware variant that was extremely popular during the nineteenth century. In spite of the uniformity 
of the ware, there is considerable variation in the structure of the sherds themselves. In addition to variable thickness, it has been noted that some sherds are from vessels that were better fired than others, that some have a smoother glaze, and that exposure to the elements has resulted in differential surface deterioration.

The collection of non-Eskimo pottery can be classified most satisfactorily according to the three types of surface treatment: undecorated white ware, transfer-printed ware, and hand-decorated ware. The most common ware represented is undecorated and white. There are 84 sherds of this utilitarian pottery in the collection, including two identifiable cup fragments. This ware is remarkably uniform although there is some variation in thickness, firing, and smoothness of the glaze.

Transfer-printed ware is represented by 57 sherds including five identifiable saucer fragments and four cup fragments. Transfer printing is an English development which spread widely and rapidly during the nineteenth century. The most common transfer print of all is the "willow" pattern, 18 sherds of which occur in the Tikchik collection (Pl. 8,1-2). In general, the transfer-printed ware tends to be somewhat thinner than the undecorated ware and has a smoother glaze. In addition to the "willow" pattern, other designs, mostly floral, are represented in brown, black, light blue, yellow, and gray colors. Some of the floral representations are combined with geometric designs, and many have a distinctive oriental appearance $(\mathrm{Pl} .8,6)$. A large saucer fragment has a triangular design around the rim and a jungle scene with the head of a tiger in the center (Pl. 8,3). Several cup fragments are obviously from the same set.

The hand-painted ware, of which there are 81 sherds including five saucer and four cup fragments, is approximately the same thickness as the plain ware and definitely thicker than the transfer-printed sherds. All designs appear to be floral and are crudely applied (Pl. 8,7-8). Various shades of blue, green, red, and purple predominate. Painted lines around the inner and outer surfaces of the vessels, usually around the rim or base, are common.

In addition to the wares described above, there is a single fragment of heavy ironstone with a thick, brown glaze, possibly a fragment of a teapot or kitchen bowl.

As far as identifiable forms are concerned, fragments of all types of ware appear to be from cups or saucers and there are no identifiable plate fragments. A number of flat-bottomed sherds suggest large, heavy mugs with straight sides and indented bottoms. Saucer frag- 
ments tend to be from deep vessels with smooth rims. Generally speaking, all the wares, with the possible exception of a few transferprinted saucer fragments, give the impression of being heavy, crudely decorated, and highly utilitarian.

Unfortunately, the non-Eskimo pottery from Tikchik, like that from other historic sites in Alaska, is not useful for dating within narrow limits. Ironstone ware is still being made and design elements, both in the United States and England, were so widely borrowed that they appear to have no chronological significance. Specimens of transfer-printed ware and hand-painted ware in the Tikchik collection closely resemble examples from the Taral site on the Copper River (VanStone, 1955) and the Crow Village site (Oswalt and VanStone, 1967). At these latter sites the wares exhibited definite late nineteenth or early twentieth century characteristics such as shade of color, sharply-cut design, rounded saucer foot rims, extreme hard whiteness, crude application of color and design, etc. The Tikchik transfer-printed and hand-painted wares thus can date no earlier than the latter part of the nineteenth century.

A single bottom sherd of hand-painted ware and a plain white mug fragment have clearly visible potter's marks. The former mark consists of a lion and unicorn coat of arms with the words "Royal Ironstone China" above and "Johnson Bros., England" below (Pl. 8,4). This is one of the marks of Johnson Brothers (Hanley) Ltd., an old English firm dating back to 1758 which, in 1883, was acquired by the Johnson brothers and began to produce white ware for the American market (Rhead, 1910, pp. 152-153; Thorn, 1947, p. 80; Godden, 1964, p. 355). The second mark also had the words "Royal Ironstone China," this time located above and below a crown design. Below this are the words "Maddock \& Co.," "Burslem, England," "trade mark." The firm of John Maddock and Sons, Ltd. in Burslem was founded in 1830 and specialized in the manufacture of "useful merchantile wares," chiefly for export to the American market. The company is still in existence but this particular mark began to be used around the turn of the century (Rhead, 1910, p. 171; Godden, 1964, p. 406).

On the basis of these two marks it would seem that at least part of the ironstone ware from the Tikchik site is of British manufacture. However, it is also possible that some of the ware is American. In 1891 the United States began to require that all imports, including pottery, be labeled with the name of the country of origin. Therefore, after 1891 all English pottery exported to the United States was 

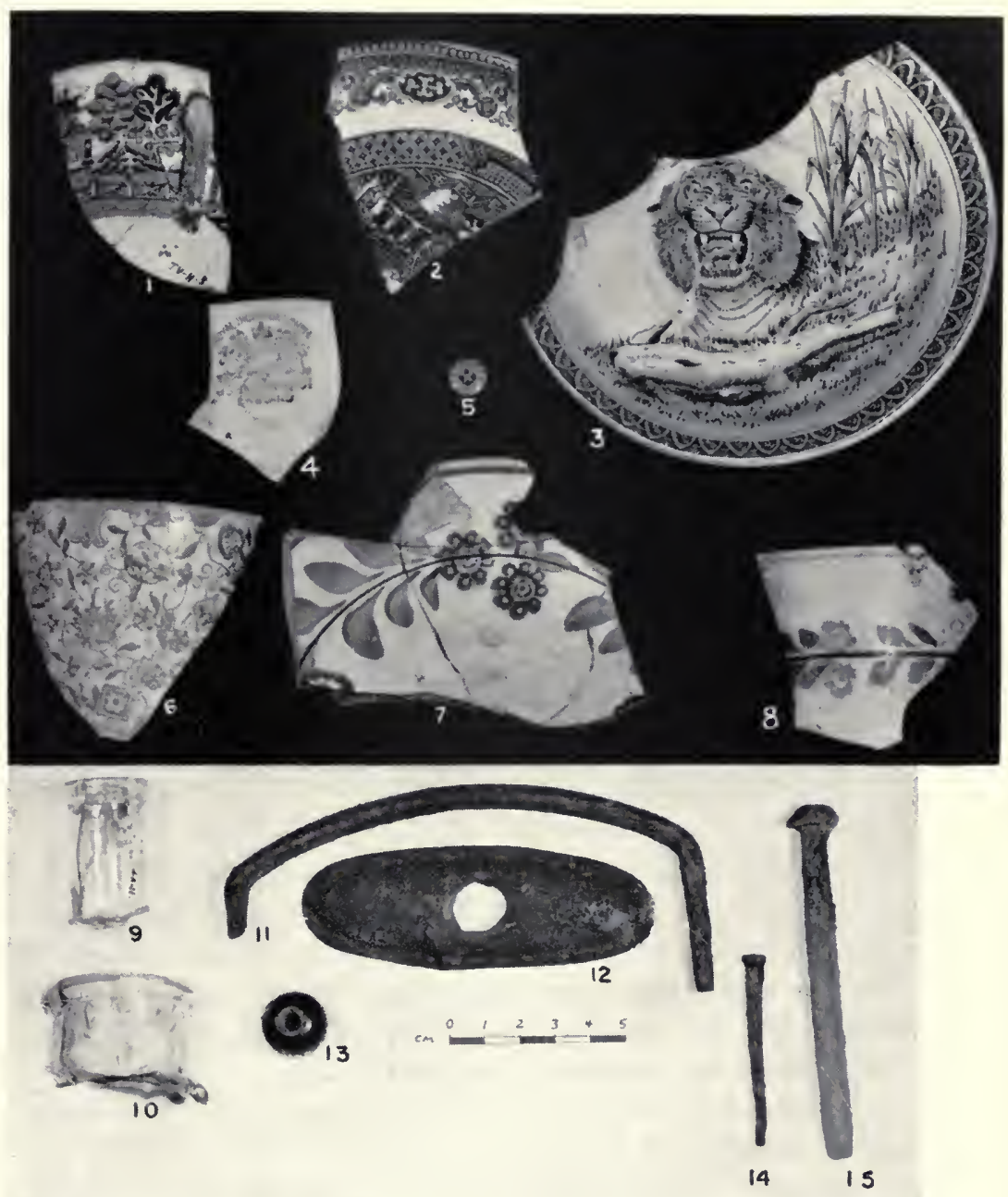

Plate 8. Metal, Glass and Imported Pottery Artifacts. 1. Transfer-printed pottery fragment, p. 289; 2. Transfer-printed pottery fragment, p. 289; 3 . Transfer-printed pottery fragment, p. 289: 4. Sherd showing potter's mark, p. 290; 5. Button, p. 292; 6. Transfer-printed pottery fragment, p. 289; 7. Hand-painted pottery fragment, p. 289; 8. Hand-painted pottery fragment, p. 289; 9. Bottle neck fragment, p. 293; 10. Bottle neck fragment, p. 293; 11. Iron handle, p. 298; 12. Can top or bottom, p. 298; 13. Wire-wound, translucent blue bead, p. 294; 14. Nail, p. 296; 15. Spike, p. 296. 
marked "England" just as it is at the present time. In the Tikchik collection there are, in addition to the two fragments with potter's marks already described, eight basal sherds large enough so that parts of the marks would be visible if they were present. Thus it appears likely that much of the pottery used at Tikchik was unmarked. Unmarked pottery must have been made in America, imported before 1891 , or brought into the country through other than the usual import channels (Ormsbee, 1959, pp. 16-17; Fontana and Greenleaf, 1962 , p. 93; Godden, 1964, p. 11). Although it is impossible to say with any degree of certainty, there seems little reason to doubt that the Tikchik non-Eskimo pottery is both American and British and dates no earlier than the last two decades of the nineteenth and beginning of the twentieth century.

In addition to the non-Eskimo pottery described above, the collection contains a single large, round, white bead of ironstone china.

\section{Glass}

With the exception of beads, objects of glass and even glass fragments are not common in the Tikchik collection. It seems certain, therefore, that glass, at least as a container material, was an unimportant aspect of the material culture.

Three complete and four fragmentary milk glass buttons, all of the four-hole shirt button variety, occur in the collection. They are molded in a bi-convex shape with a slight depression in one face. All are size 30 and have large holes. A single complete specimen is of the "calico" type and decorated with a series of tiny green rosettes $(\mathrm{Pl} .8,5)$, while the others are plain. Such buttons were first made in France and introduced to the United States about 1860 (Fontana and Greenleaf, 1962, p. 98). In addition to the four-hole shirt buttons just described, there are two circular pieces of glass, one milk white and the other black, which are approximately $5 \mathrm{~mm}$. in thickness and flat on one surface. These were presumably molds for fabric buttons, to the flat side of which would have been fastened an eye or small clasp. Such button molds, covered with the same material as that used in making the garment, were very popular in the United States after 1860 (Albert and Kent, 1949, p. 48).

Ten fragments of window glass also are included in the collection. All are approximately $2 \mathrm{~mm}$. in thickness and two fragments have edges that are straight and smooth, suggesting the use of a glass-cutter. The most likely use for window glass at the site would 
have been as covering for the skylights in the houses replacing the traditionally used gut or fishskin covering.

The number of bottle glass fragments recovered from the Tikchik site is extremely small and no complete specimens were found. There are 11 fragments, two of which have been retouched as scrapers and previously described. Of the nine remaining, four are neck segments, two from narrow, long-necked containers and the others from short-necked, wide-mouthed bottles. One of the narrownecked specimens is virtually complete and is a light green color (Pl. 8,9), while the other, more fragmentary, is light brown. Of the wide-mouthed fragments, one is pale purple in color (Pl. 8,10) and the other clear. Four of the remaining five fragments are so small that it is impossible to say anything about the shape of the original bottle; three of these are thin and clear while the fourth is thick and dark brown. The fifth, however, is more interesting. It is recognizable as being associated with a bottle of the patent medicine type, tall with a rectangular body and "panels" on which the trade name would frequently appear. The panels of this particular specimen were apparently clear, but on one of the narrow sides the letters "- IN KILLER" can be seen. This, of course, suggests that the contents were a pain killer of some type.

The four neck fragments are from bottles with hand-finished necks, a fact that can be determined because seams from the molds in which they were made do not extend across the lip of the neck. Thus they can be said definitely to date prior to World War I. It can further be noted that the bottles from which these neck fragments came were made to receive cork stoppers, a characteristic of nearly all bottles made before about 1900 when metal caps were introduced (Hunt, 1959, pp. 9-10; P. and B. Ferraro, 1964, p. 79). These facts alone would tend to place the bottle fragments chronologically where we would expect to find them-at the end of the nineteenth century.

In addition to buttons, window glass and bottles, there is a single fragment of what appears to have been a barrel-shaped, flat-bottomed drinking glass.

Various types of glass trade beads were found in six of the houses, one kashgee, and two test trenches. They form an important group of artifacts whose structure, color, form, and size lend themselves to typological analysis. Their value as dating aids, however, is lim- 
ited, and it will be possible to make only the most general statements about the chronological position of the Tikchik beads.

Four hundred and seven beads of the various types make up the collection. For study purposes these were first separated into groups based on color alone. The colors are given as they appear to me

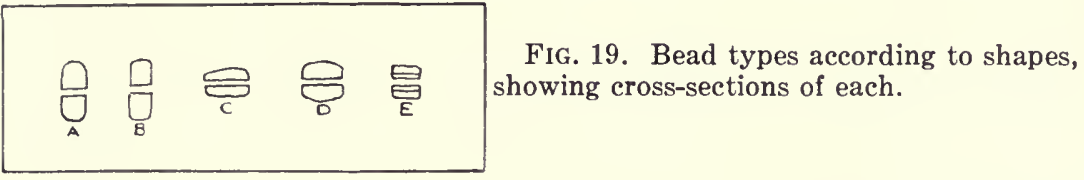

and not through comparison with a standard color chart. Gradations in color are often imperceptible, and some of the beads described also appear to be discolored because of changes caused by chemical actions of the soil. It was found that there were 267 white, 72 blue, 18 brown-lined red, 2 white-lined red, 7 dark red, 36 pink, 1 yellow, 1 yellow hexagonal, 2 clear, and 1 white with a pink painted design. Next the beads were separated according to shape within each color group, and it was found that five different types are represented (Fig. 19). Sizing came next and out of the total there are 69 of the "seed" form, those that do not exceed $2 \mathrm{~mm}$. in diameter. However, there are a large number that average 3 to $5 \mathrm{~mm}$. in diameter. White, blue, dark red, clear, and pink are the colors represented, and these beads are generally similar to those sold in tubes in stores in the general area today for sewing into beadwork designs.

Of the 267 white beads, 159 belong to type a, 107 to type b, and 1 to type $\mathrm{c}$. The color varies from an extremely bright, hard whiteness that characterizes the 18 seed beads to a grayish white that is typical of this color category as a whole. The largest white beads belong to type a and one of these, approximately $1 \mathrm{~cm}$. in diameter, exhibits the "wire wound" process of manufacture. The others have been cut from canes.

The blue beads are confined to two shapes, there being 43 of type a and 49 of type $b$. There are five seed beads of a very bright blue color, and the range of color in the others is from a light greenish blue to a deep marine blue and there is one bead that is almost purple. In fact, it can be said that the color range is greater in the blue beads than in those of any other color category. As with the white beads, the largest blue specimens belong to type a and there are four in the "wire wound" category. The largest of these, a translucent bead of deep marine blue color, is illustrated (Pl. 8,13). 
Of the two white-lined red beads, one belongs to type a and the other to type c. They both have dark, translucent, orange-red exteriors and opaque, white interiors. This is a variety of the "Cornaline d'Aleppo" bead, the significance of which will be discussed presently.

There are 18 brown-lined red beads, 5 belonging to type a, 11 to type $\mathrm{b}$, and 2 to type $\mathrm{c}$. All have an opaque, dull, reddish-brown exterior and a translucent, dark brown interior which, on casual inspection, sometimes appears black. This is another type of "Cornaline d'Aleppo" bead.

The 36 pink, seven dark red, and two clear beads are all in the seed category and thus belong to type a. The dark red and clear specimens are translucent. A single yellow bead is too fragmentary to reveal its size and shape but it would appear to have been a rather large example of type a.

Two unique beads are of particular interest. One belongs to the type d shape, is $1.1 \mathrm{~cm}$. in length, and is grayish milk-white in color with a pink and white wavy line painted around the middle. The other is hexagonal (type e) and may be a fragment of what was once a long, thin bead or bead separator. The glass is clear but the inside seems to be covered with gold paint or some similar material and thus the bead appears to be a yellowish-gold color.

The only bead type in the collection that has any diagnostic value at all is the form known to the trade as "Cornaline d'Aleppo," so named because it was associated in the Italian export business with the city of Aleppo in Syria. This type of bead is found widely distributed throughout the North American continent and in fact became known as the "Hudson's Bay bead" in regions covered by that company (Orchard, 1929, p. 87). The dark brown-lined red "Cornaline d'Aleppo" is apparently the earliest type and occurs extensively on sites of the seventeenth and eighteenth centuries in the eastern United States and Canada (Woodward, 1965, pp.19-20). The whitelined red form is thought to be a more recent type and at least one authority believes that beads of this kind were confined to the northwestern trade (Orchard, 1929, p. 87). It seems likely, however, that both forms of "Cornaline d'Aleppo" bead were introduced into Alaska after extensive use elsewhere in North America, but the exact time of the introduction cannot, at present, be determined. As for the rest of the beads in the collection, they presumably represent a late nineteenth century assemblage of European and Syrian made trade beads, and they too were doubtless used extensively in the North American trade before being introduced into Alaska. 


\section{Clay}

The only artifact in the entire collection that can definitely be associated with a smoking complex is a fragment of a white kaolin pipe stem $2.5 \mathrm{~cm}$. in length.

\section{Textile}

The single textile fragment from the Tikchik site is a piece of oil cloth, approximately $5 \mathrm{~cm}$. long and $4 \mathrm{~cm}$. wide, in which were wrapped a large number of percussion caps and cartridge primers.

\section{Metal}

Objects of metal form the largest and most important category of imported goods from the Tikchik site. They suggest graphically the extent to which the Eskimos of this remote region had already become familiar with restricted aspects of Euro-American material culture. For guidance in analyzing these materials, particularly the nails and tin cans, I have relied heavily on the chapter concerning metal artifacts in Johnny Ward's Ranch: A Study in Historic Archaeology by B. J. Fontana and J. C. Greenleaf.

Considering the abundance of metal objects in the collection, surprisingly few nails were recovered. There are only 11 specimens, two of which are square-cut nails partially prepared for a secondary use and another three of the square-cut variety have been utilized as hooks in antler fishing lure-hooks; all five of these have previously been described. Of the remaining six, two are modern wire nails, the common variety in use at the present time. The others are of the square-cut type, three being $6 \mathrm{~d}$ and one $10 \mathrm{~d}$ in size (Fontana, 1965) (PI. 8,14); two are heavily corroded. All the squarecut nails belong to the form called common-cut. Common-cut nails, used more than any other form of square-cut nail, were made in sizes $2 \mathrm{~d}$ to $60 \mathrm{~d}$. All specimens, regardless of size, have beveled shanks and all shanks are rectangular at the point. Common-cut nails were used in boxes and crates (Fontana and Greenleaf, 1962, p. 57). In addition to the square-cut nails just described, there is also a small wrought boat spike in the collection (PI. 8,15$)$ as well as a previously described spike that has been partially prepared for a secondary use.

It is perhaps worth noting that the three square-cut nails used for fish hooks have all been sharply bent and yet show no signs of rupture. This indicates that they have been annealed as a part of the manufacturing process, a development which took place about 1870 
(Fontana and Greenleaf, 1962, p. 55). Thus these nails are at least post-1870 and it is highly probable that the other nails in the collection are too.

Although can fragments were found extensively throughout the Tikchik site, the quantity and variety of recovered identifiable cans is very small. It will be remembered, however, that can metal was used in the manufacture of artifacts.

Five types of cans are identifiable with some degree of certainty. None of them has the dimensions of the modern double-seamed cans, nor is it possible to refer any of them to a specific size of the earlier soldered hole-in-top can. Nevertheless, they give some idea of the kinds of canned products available to the Eskimos.

Type 1-A single round soldered hole-in-top can $10 \mathrm{~cm}$. in diameter and $12 \mathrm{~cm}$. in height.

Type 2-The lid or bottom of what was probably a baking powder can. The specimen, which has no trade name on it, measures $7.5 \mathrm{~cm}$. in diameter and probably fitted over a cardboard container.

Type 3-This type is represented by the single lid of a canned milk container with the words "Borden's Condensed Milk Company" running around the outer edge. This specimen has the characteristic "match stick" size filler closed by one drop of solder.

Type 4-A large, single-seamed, pail-like can, fragmentary and badly corroded, may have been a lard container. In addition to this specimen, there are three lids that appear to have come from a similar type of pail. They are $15,19.5$, and $20 \mathrm{~cm}$. in diameter, respectively, and all have clutch-type rims for pressing over the rim of the can. The largest of these has a series of letters, presumably spelling one or more words, appearing in a circle in the very center. Unfortunately, this lid is heavily corroded and only the letters "CLAD" can be determined with certainty. It is possible, however, that the inscription is "IRON CLAD."

Type 5-The most numerous type of can in the Tikchik collection is ovate in shape. There are four fragmentary specimens, two of the double-seamed variety and two single-seamed. The only example complete enough to indicate size is $9 \mathrm{~cm}$. in height and apparently had a lid which fitted snugly over the outside of the rim (Pl. 9,1). In addition to these can fragments there are 11 tops or bottoms, slightly curved in cross-section, which would appear to have fitted cans of this type. Five of these have a single hole, approximately 
$1.5 \mathrm{~cm}$. in diameter, directly in the middle (Pl. 8,12). An informant suggested that cans of this type may originally have held gun powder.

As previously mentioned, worked can fragments were found extensively throughout the site indicating the importance of this material for secondary working into artifacts of various types. Most of these were badly corroded and too fragmentary to indicate the size, shape, or method of manufacture of the cans.

The badly corroded, fragmentary remains of two buckets or pails were recovered, both of which were round with slightly flaring sides and loop handles. Although they appear to be of vastly different sizes, it is impossible to determine the actual dimensions of either of them.

There are six fragments of cast iron kettles, only two of which give any indication of the shape of the vessel. The largest of these represents a basal section of what must have been a round, squat kettle slightly inverted toward the rim and sitting on three short legs; one of the legs is present on the recovered fragment. Another fragment is from the rim of a more straight-sided vessel with a pronounced, slightly everted lip (Pl. 9,5). Also recovered were two segments of a brass kettle, but the shape of this vessel cannot be determined.

A relatively heavy, iron handle is virtually square in cross-section and may have been used with a small kettle of the same material (Pl. 8,11).

Four well-made planing adze blades have been constructed from rectangular iron bars. Three are flat across the proximal end (Pl. 9,8), while one shows signs of having been roughly rounded by means of blows from a hammer (Pl. 9,7).

A single chisel blade is long, thin, and has a narrow groove running about three-quarters of its length which widens toward the distal end to form a convex working edge $(\mathrm{Pl} .9,12)$. Such a blade was intended for insertion into an antler or wooden handle.

There is one single-bitted axe head with a fragment of cottonwood handle still in place. It is made of iron and has all the earmarks of having been hand forged. The working edge is so blunt as to suggest that the implement could not have been serving the purpose for which it was intended at the time it was lost or abandoned. Since the proximal surface is badly battered, the implement may have been used as a wedge. An examination of both sides of the haft opening reveals narrow lines that suggest the metal initially was in two pieces which were forged together (Pl. 9,4). 

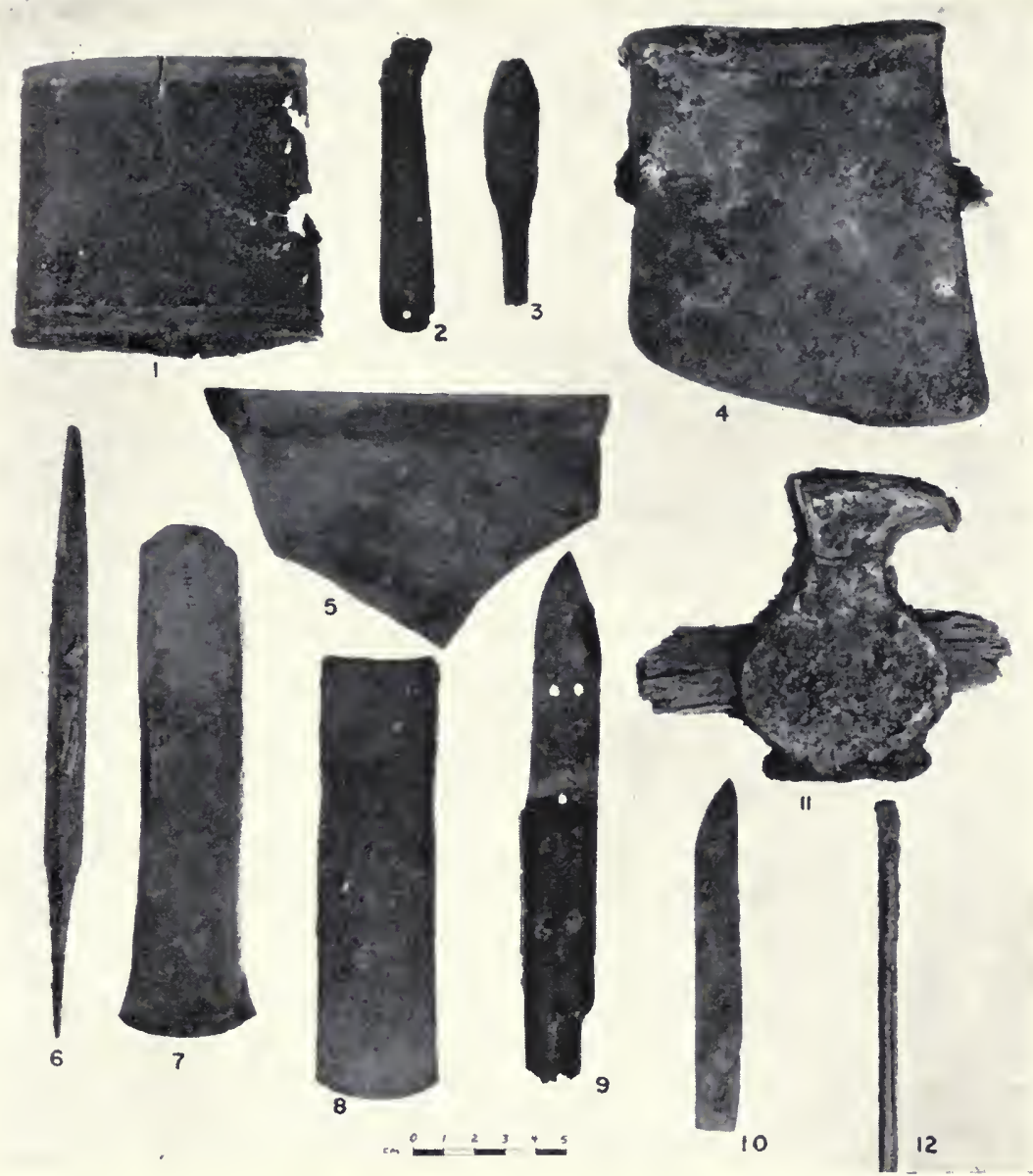

Plate 9. Metal Artifacts. 1. Ovate-shaped can, p. 297; 2. Jack knife fragment, p. $300 ; 3$. End bladed knife blade, p. $300 ; 4$. Axe head, p. $298 ; 5$. Cast iron kettle fragment, p. 298; 6. File, p. 300; 7. Planing adze blade, p. 298; 8. Planing adze blade, p. 298; 9. End bladed knife, p. 300; 10. End bladed knife blade, p. $300 ; 11$. Hammer, p. $300 ; 12$. Chisel blade, p. 298. 
A most unusual implement is a hammer with a claw at one end and a flat but extremely narrow hammering surface at the other. The haft opening, in which a section of cottonwood handle is still in place, is so located that the claw end extends well above the handle but the hammering surface is only a few centimeters below it $(\mathrm{Pl} .9,11)$. Such an implement must have been rather awkward to use. A rattailed file, triangular in cross-section, was also recovered (Pl. 9,6).

An end bladed knife has a commercially made, two-piece wooden handle which is held to the proximal end of the blade by a series of rivets $(\mathrm{Pl} .9,9)$. Five end bladed knife blades are difficult to distinguish from those that were described under the heading of locally manufactured goods. However, these are constructed from heavier metal and are generally so well made as to suggest that they were imported to the site as finished knives with wooden handles similar to the specimen just described. Four are long thin blades that are flat along the upper surface and then taper toward the sharp cutting edge $(\mathrm{Pl} .9,10)$. The fifth is spatulate in shape and may have been made in the village by hammering out one end of a short, rectangular fragment $(\mathrm{Pl} .9,3)$. A handle fragment of a folding or jack knife was also recovered (Pl. 9,2).

The badly corroded, fragmentary remains of two large tea kettles represent specimens which were round and tapered toward the rim. The spouts were separate pieces held in place by rivets. These have disappeared and only a triangular pattern of small holes remains to indicate their position. The collection of household equipment also includes a single kettle lid which was at one time fitted with a small wooden knob, a complete teaspoon (Pl. 10,9), and fragments of six others, a battered enameled pie tin, a scissors handle fragment (Pl. 10,4), two badly corroded scissors blade fragments, a small brass thimble (Pl. 10,6), and a ferrule (Pl. 10,10) which possibly fitted over some kind of wooden handle, perhaps that of a broom.

Gun parts in the Tikchik collection are confined almost entirely to the metal fittings from what appear to be a single weapon. These consist of a nearly complete flintlock assemblage including the lock (Pl. 10,1) itself, trigger mechanism, decorative sideplate (Pl. 10,12), trigger guard (Pl. 10,13), and butt plate (Pl. 10,2). The lock has a rounded, gooseneck type hammer with reinforced pan. Stamped on the lock plate directly in front of the hammer and below the pan is a two-line marking, the top line of which is illegible. The second line contains the single word "ARTICULA." All the gun parts described above were found in a position which suggests that the wooden parts 


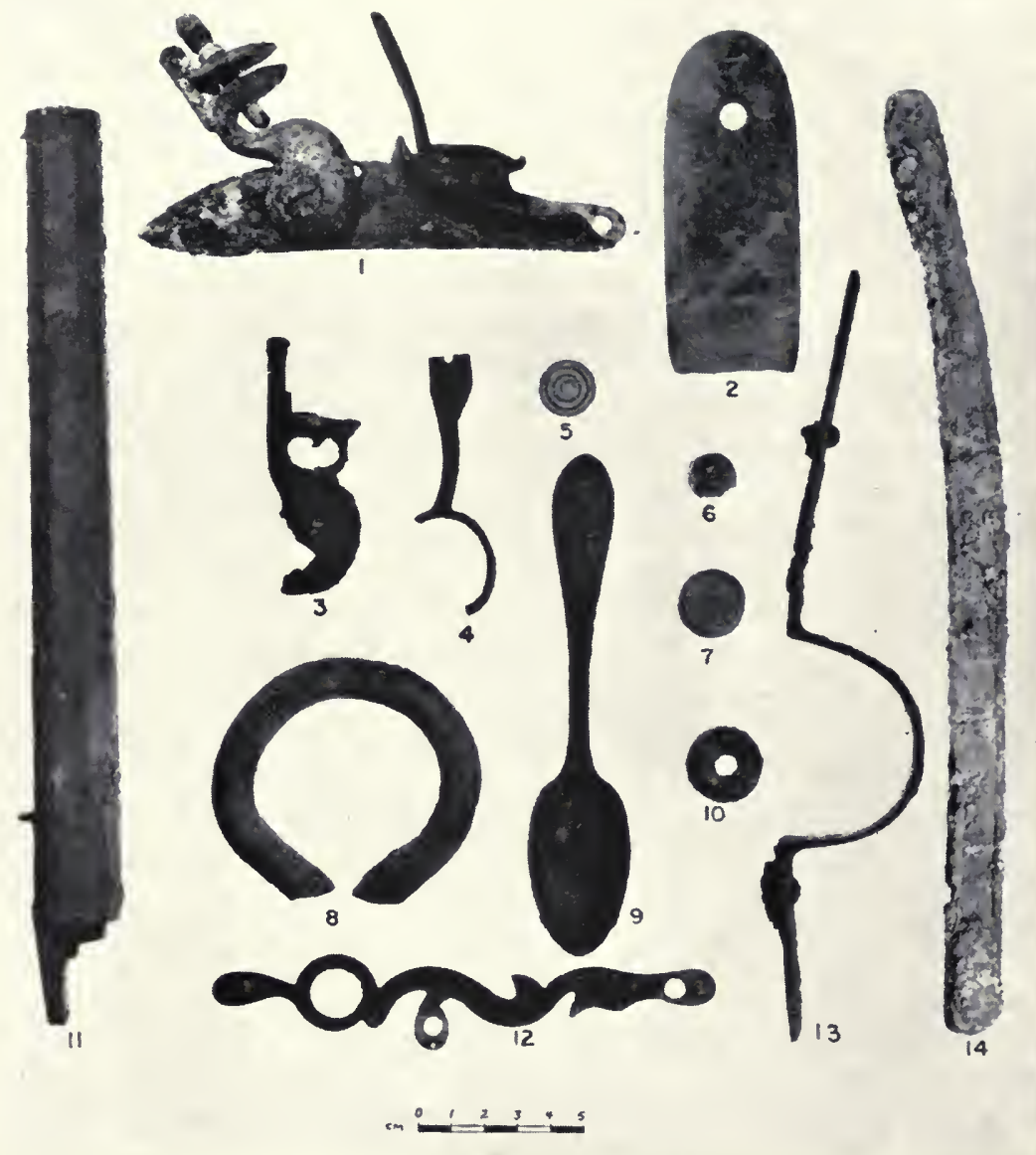

Plate 10. Metal Artifacts. 1. Flintlock plate and hammer, p. 300; 2. Butt plate, p. 300; 3. Flintlock hammer, p. 302; 4. Scissors handle fragment p. 300 ; 5. Spiral screw cap, p. $305 ; 6$. Thimble, p. $300 ; 7$. Spiral screw cap, p. $305 ;$ 8. Iron ring, p. $305 ; 9$. Teaspoon, p. $300 ; 10$. Ferule, p. $300 ; 11$. Pistol barrel, p. $302 ; 12$. Sideplate, p. $300 ; 13$. Trigger guard, p. 300; 14 . Bar of lead, p. 304. 
of a single weapon had simply rotted away. The barrel, however, was not recovered. It seems certain that this weapon belongs to the category of "trade gun" or "Northwest gun," a specific type of firearm supplied to native peoples in North America by traders from 1775 to the beginning of the twentieth century. The trade gun was manufactured in many different factories in Europe and the United States but regardless of its point of origin, certain characteristics can be noted. First of all, such a weapon was usually light in weight with a short barrel and cheaply constructed. Commonly, it was gauged to shoot a one-ounce ball, although some were smaller. The type was full-stocked with a flat brass butt plate similar to the illustrated specimen, and the light iron trigger guard was nearly always large enough to allow for a person to pull the trigger while wearing a glove or mitten. As one authority has pointed out, it was definitely a gun made for the north country (Russell, 1962, p. 104). A nearly universal characteristic of trade guns was the cast-bronze "dragon ornament" which was used by makers as a sideplate. Early dragon sideplates were thin in cross-section and engraved. Later ones, like the illustrated specimen, were thick and cast in relief design from iron molds (Hansen, 1955, p. 39). It has been suggested that such an ornament probably had no particular significance when it was first used on guns destined for the Indian trade, but Indians receiving the weapons in the early days of the American frontier may have come to feel that a weapon was not genuine without it (Russell, 1962, p. 127).

As with trade beads, it seems likely that the trade guns sold or traded to the Eskimos of southwestern Alaska by American traders were of a type used much earlier in areas to the south. There is nothing to indicate that the weapon described above was traded by the Russians and it should be kept in mind that flintlock muskets were used in Alaska until almost the beginning of the twentieth century because of a ban on the sale of breech-loading weapons to the Indians and Eskimos. This ban was in effect until 1896.

In addition to the gun parts just described, a hexagonal flintlock pistol barrel (Pl. 10,11) and a single fragmentary military style doublenecked fintlock hammer (Pl. 10,3), probably from a U. S. flintlock musket, Model 1816, were also recovered. The pistol barrel is unusual for two reasons. First of all, it represents a type of weapon that one would not expect to find at the site and, secondly, it has no visible proof marks. The testing of all pistol and musket barrels was a government requirement in most countries and a successfully tested 
barrel would be required to show proof marks. It is possible, however, that guns intended for the Indian trade would not be so tested.

A curious and somewhat unusual assemblage of artifacts recovered from the site were 13 musket percussion caps and 65 centerfire cartridge primers found together wrapped in a small piece of oil cloth in house 7. A percussion cap is a small cylinder of copper adapted to fit over the nipple of a gun and having a flake of fulminating powder inside. This is exploded by the fall of the hammer on the nipple which communicates fire through the latter to the charge in the gun. The percussion gun was not introduced in the United States military services until 1842, although the process had been invented in England in 1807 (Knight, 1876, vol. II, pp. 1664-1665). Musket percussion caps differ from those used with pistols and revolvers in being larger and having a narrow flange around the distal end. These caps are the only indication of the use of percussion firearms by the Tikchik Eskimos.

The method of firing a weapon using a percussion cap and nipple affixed to the proximal end of the barrel was replaced during the second half of the nineteenth century by the capped metallic cartridge in which the fulminate was applied inside the base of the shell, forming a ring in rimfire cartridges or a cap in the center of centerfire cartridges. The case of a centerfire cartridge is worked through a series of dies in order to draw the brass to the desired shape. This method results in a finished case which has a thin wall and a thick, strong base into which a hole is bored to accommodate the primer. A blow from the firing pin of the weapon ignites the fulminate in the primer. This produces a flame which passes through a small hole, or vent, and ignites the powder in the body of the cartridge case. Rimfire cartridges were invented just before the Civil War and the externally primed centerfire cartridge was introduced in 1866 (Knight, 1876, vol. II, pp. 1664-1665; Datig, 1956-58, vol. 1, pp. 13-15). The cartridge primers from the Tikchik site are unused and were presumably obtained by the Eskimos for reloading used metallic cases.

Since the Tikchik Eskimos appear to have had an interest in and the equipment for the reloading of cartridges, it might be expected that hunters would have recovered and saved used cases. Therefore, it is surprising that only six spent cartridge cases were found, although it is in keeping with the relatively few indications of the use of firearms at the site. Three of these cases have been made into blunt arrowheads while a fourth was strung with beads in a necklace; as artifacts, these specimens have already been described. There are 
two centerfire cartridge cases with the letters "W.R.A. Co." and "44 W.C.F." on the head which were doubtless used in a Winchester lever action rifle. The 44-40 centerfire caliber was first used in the famous Model 1873 which was listed in Winchester catalogues from 1875 to 1920 (Bowman, 1958, pp. 83-84; Williamson, 1952, p. 424). A third centerfire cartridge case appears to be of the same caliber but there are no manufacturer's marks.

There are two 44 caliber long rimfire cartridge cases without manufacturer's marks, presumably for use in Henry's Repeating Rifle. This efficient rimfire rifle was patented in 1860 and manufactured in Winchester's New Haven Arms Company in New Haven, Connecticut. One of the most common of all rimfire cartridges, the 44 long was also chambered to many other models until well into the twentieth century (Datig, 1956-58, vol. II, p. 153; Smith, 1960, p. 239; Fontana and Greenleaf, 1962, p. 81).

The sixth and last cartridge case has the letters "W.R.A. Co." and "45-60 W.C.F." on the head. This centerfire cartridge, manufactured by the Winchester Repeating Arms Co., was first loaded in 1879 for use in the Model 1876 rifle, a weapon that was listed in Winchester catalogues between 1878 and October, 1893 (Williamson, 1952 , pp. 425,454$)$. In addition to the cartridge cases just described, the collection also contains a single No. 6 shotgun pellet.

All the cartridge cases described here would have been used in high-powered rifles for the hunting of caribou and other big game. It would seem that the rifles represented are late nineteenth century prototypes of models in use at the present time.

Also associated with firearms is a single, narrow, rectangular bar of lead (Pl. 10,14) which appears to represent the manner in which this material was received by the Eskimos from the trader for manufacture into bullets for muzzle-loading weapons. There is raised lettering on one surface of the bar, but the specimen is badly corroded and the inscription, possibly a maker's name, cannot be read. In addition to the metal bar, a small piece of melted lead was also recovered.

In the sod layer covering kashgee 1 was found a steel spring trap of the type used extensively for taking fur-bearing animals throughout the area today. The maker's name is clearly visible on the pan. Across the top is the word "Victor" and around the bottom half of the pan run the words "Oneida Community, N.Y." and "made in U.S.A." There are two patent dates inscribed on the pan, but it is possible to read only one of these-1907. The trap is a size two, the 
size normally used for beaver by present-day Nushagak River Eskimos. Although it is certain that steel traps were in use at Tikchik before the site was abandoned, this particular specimen with its late patent date is clearly not contemporary with the other artifacts in the collection. Very likely it was set in the kashgee 1 pit by a trapper who never recovered it. A small beaver toe bone and piece of beaver fur were still in the jaws when the trap was excavated.

Four lead alloy spiral screw caps were recovered. These are presumed to fit the lids of the type 5 gun powder cans. Three are plain (Pl. 10,5), but the fourth has the words "Hazard's Powder" on the top (Pl. 10,7). A thin fragment of steel plate has the word "set" and an arrow near a small circular hole. This was doubtless part of the back plate of a small alarm clock. It is known that at the turn of the century such clocks formed part of the inventory of trade goods dispensed by the Alaska Commercial Company post at Nushagak (Moser, 1902, pp. 185-187).

There are, as might be expected, a large number of unidentifiable metal fragments. Many of these objects could doubtless be identified were they not so fragmentary, but others would probably defy identification even if complete. Among the more interesting are three possible ax head fragments and a large iron ring (Pl. 10,8). 


\section{Continuity and Innovation}

It can be stated at the outset that the Tikchik collection of traditional Eskimo artifacts, in spite of certain special characteristics, is well within the tradition of coastal Yuk culture; the inhabitants of the village possessed a material culture not radically different from that of their coastal relatives. This fact is clearly illustrated when the Tikchik traditional artifacts are compared with the following important collections: ethnographic materials collected by Nelson (1899) in the central Bering Sea coastal region near the turn of the century; an historic and recent-prehistoric archaeological collection from Hooper Bay Village south of the Yukon Delta (Oswalt, 1952a); a recent-prehistoric archaeological assemblage from the Togiak site at the mouth of the river of that name (Kowta, n.d.), and an historic archaeological collection from Crow Village on the middle Kuskokwim River (Oswalt and VanStone, 1967). Very briefly, such a comparison reveals that an overwhelming majority of the traditional artifacts in all categories can be duplicated in one of these four collections. Resemblance between the Tikchik collection and those of Nelson and Kowta are particularly striking and would doubtless be even more so if wooden artifacts had been preserved at Tikchik.

The nineteenth century inhabitants of the Bering Sea coast possessed a cultural inventory which was not only well adapted to sea mammal hunting and hunting and trapping on land, but also to the taking of fish. Thus they were able to adjust economically to any environmental situation that was compatible with their varied technology. It has been noted that when these people entered the Kuskokwim River system, fishing and land hunting methods were emphasized while the sea mammal hunting technology withered away and was forgotten (Oswalt and VanStone, 1967, p. 2). The same can be said for the Nushagak River system and, although little is known concerning the Yuk movement inland in this region, it seems clear that close ties have always been maintained with the coastal peoples here as well as along the Kuskokwim.

Although no exhaustive comparative analysis of the Tikchik artifacts will be attempted, it is certain that even within the context of 
historical contact, there is obvious and specific evidence of continuity with the past and it seems necessary that at least some aspects of this continuity be dealt with in detail. With reference to house construction, one of the most consistent cultural features at Tikchik, it is known that the house with four-post-center construction, a central fireplace, and lateral sleeping places is widely distributed throughout Alaska. The earliest occurrence is in the Old Whaling culture at Cape Krusenstern (Giddings, 1961, p. 166), and the type is also known from the early historic period on Hotham Inlet (Simpson, 1875 , p. 255), at Metlatavik near Wales on Seward Peninsula (Collins, 1937, pp. 261-264), and on Nunivak Island (Collins, 1937, pp. 258-260; Lantis, 1946, p. 157). Of particular interest here, however, is the fact that this type of house construction seems to have been particularly characteristic of the inland regions. It is found in all the culture phases (1250-1750 A.D.) along the Kobuk River (Giddings, 1952, pp. 11-19), at the Crow Village site (1840-1906), and has been reported for the late aboriginal period along the lower Kuskokwim (Oswalt and VanStone, 1967, p. 12; Oswalt, 1963, pp. 29-30, 119). My examination of other archaeological sites of the historic period in the Nushagak River region has led me to believe that the house form at Tikchik was characteristic of the entire area up to the time when old style houses were entirely abandoned in the early 1930's.

Traditional Eskimo stone working continued and the emphasis is such that some discussion is called for. Most surprising of all, perhaps, is the presence of a sizeable number of small flint implements which indicates that the residents of Tikchik possessed a high degree of skill in working this material. Of all the artifacts in the assemblage, they are the ones which are represented the least satisfactorily in the comparative collections mentioned at the beginning of this chapter, and indeed, one type - the small hand drills, is not represented at all. It is probably true that if most of this material had been found in another context, it would have been attributed to a much earlier cultural manifestation. In fact, the Tikchik planoconvex scrapers, hand drills, and small projectile points most closely resemble those from the Norton Culture at Cape Denbigh (Giddings, 1964, Pl. 53,13,16,20; Pls. 47 and 48; Pl. 55,1-5; Pl. 56) which seems to have flourished between approximately 400 B.C. and the beginning of the Christian era (Giddings, 1964, p. 244). However, these forms were widespread in Alaska and have frequently been encountered in those sites where polished slate predominated. On the Kobuk River flint working persisted well into the historic period, and side and end 
scrapers of flinty material were recovered from the historic Crow Village site (Oswalt and VanStone, 1967, pp. 26-27). In the Chagvan Bay area a sizeable and varied assemblage of flint implements was recovered from a house dated by the radiocarbon method at $1693-$ 1773 A.D. (Ackerman, 1964, p. 29). It appears virtually certain that the flint artifacts from Tikchik are indigenous and contemporary with the rest of the collection, since large numbers of flint chips were found on the floors of several houses. Side scrapers are the most common form and it is obvious that these and other types continued to fill a need that could not be met by the Russian and Anglo-American technology available to the villagers. It is tempting to suggest that skillful flint working may be present into the historic period in many areas of Alaska and that failure to recognize this is simply due to the small number of excavated sites of the period and the general lack of interest in historic archaeology on the part of most Alaskan archaeologists.

Further evidence for continuity in stone technology can be noted in the polished stone artifacts for working wood and skin. Of course, the flint scrapers and drills were wood-working tools also and their presence suggests that no trade equivalent was satisfactory for fine work. The presence of numerous polished stone adzes along with some of iron, however, would seem to indicate that the latter could not be obtained in sufficient quantity to satisfy the needs of the community. Adzes of the two materials are very similar in size and form and must have been roughly equal in efficiency. The stone specimens, however, would require a great deal of work in their manufacture and it seems certain that those of metal would quickly have replaced the older type had they been available. A similar assumption concerning availability can be noted with reference to the continued presence of stone skin-scraping tools. Whetstones, on the other hand, presumably owed their continuity to the fact that they doubtless functioned equally well for sharpening either stone or metal. These implements are also present in large numbers in the artifact assemblage from Crow Village and for a similar reason (Oswalt and VanStone, 1967, p. 27).

One of the most significant features of the excavations was the relative scarcity of raw bone and antler from both the houses and midden. A table of bone occurrences (Table 4) is interesting not so much from the standpoint of bulk of material recovered as for the few species that are represented. It is also significant that very few bones were recovered from the test trenches. A similar situation at 
Crow Village was explained by informants as being due to the fact that animal bones were thrown into the river to prevent the dogs from chewing them, thus offending the spirit of the animal involved and making the species difficult to take in the future (Oswalt and VanStone, 1967, p. 70).

Caribou bones occur with greater frequency than those of any other animal and this is not surprising since, according to informants, the animal was plentiful in the area and hunted extensively by Nushagak River residents as well as those of Tikchik. Moose bones, although considerably less plentiful than those of caribou, nevertheless occur and are widely distributed throughout the site. Informants reported that moose were rare throughout the Nushagak River region until 25 or 30 years ago. With reference to the presence of moose bones in the Crow Village site, another area where the animal is supposed to have been absent or scarce during the early contact period, it was suggested that they must represent animals hunted, perhaps by fur trappers, at a considerable distance upstream from the settlement (Oswalt and VanStone, 1967, p. 72). Since the people of Tikchik also hunted and trapped at some distance from their village, a similar explanation may be in order. Although it is probably true that the animal bones recovered from the site give an attenuated picture of the species taken, there can be no doubt that the caribou was the most important animal available for food and that much time and effort was directed toward taking this animal.

The bone list offers an equal distortion with regard to the taking of fur-bearing animals. Only beaver bones were recovered and these in no great numbers. From the 1830's until near the end of the century, beaver, muskrat, land otter, lynx, and various types of fox were the most important fur-bearing animals in the Nushagak River region (Russian-American Company Records: Communications Sent, vol. 9 , no. 321 , folios $482-487$; Elliott, 1875 , p. 40 ). It was only by exchanging pelts for trade goods that the Eskimos could obtain those exotic items which they desired and which are represented in the collection. The Tikchik people unquestionably were participants in the fur trade and yet there is little evidence of the species that were taken. And the collection contains no artifacts associated with trapping if one excepts the single metal trap which, as pointed out elsewhere, is probably not contemporaneous with the occupation of the site. Zagoskin (1967, p. 221) mentions that although metal traps were introduced for the trapping of beaver along the Kuskokwim River, traditional trapping methods continued to be preferred. What 


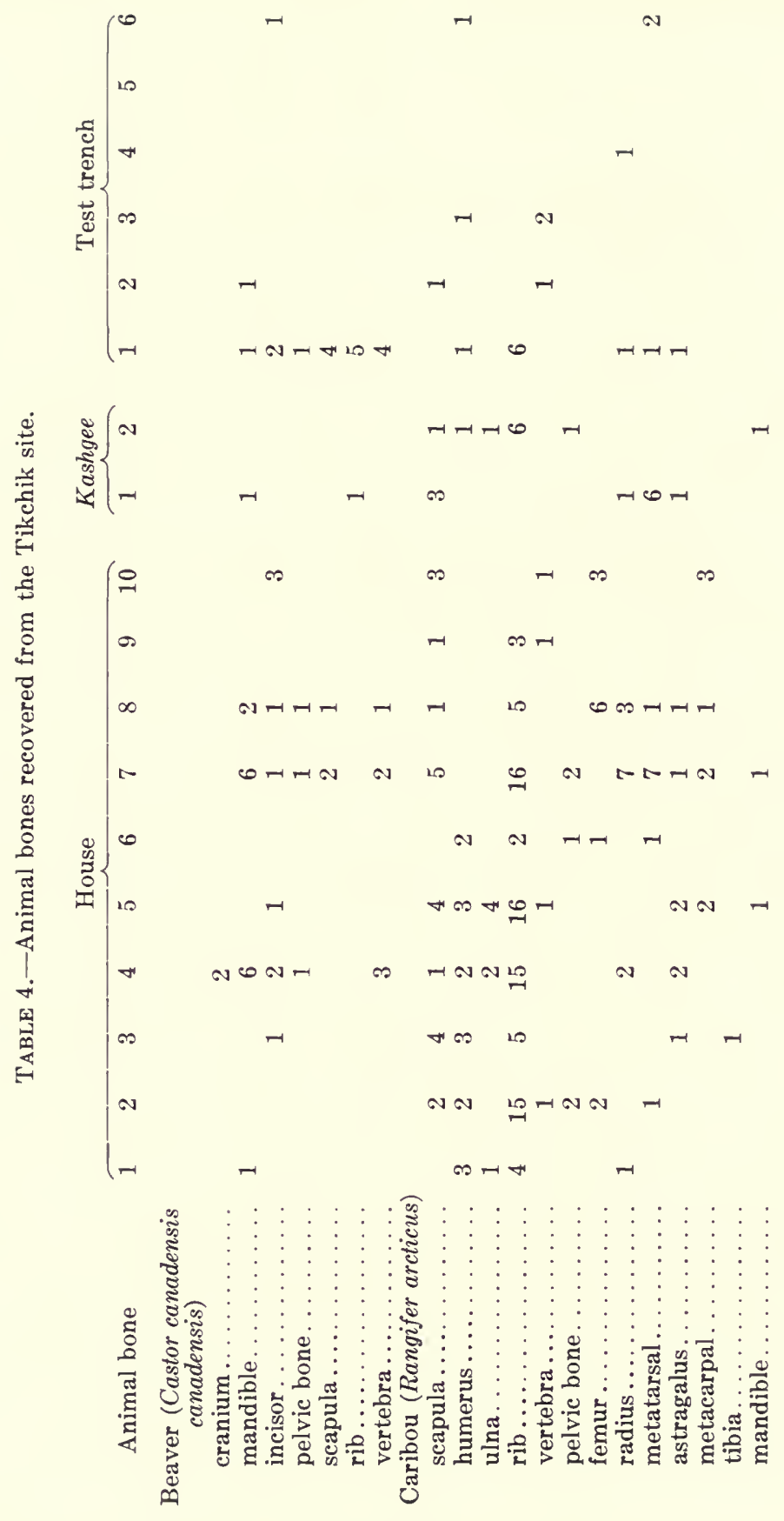




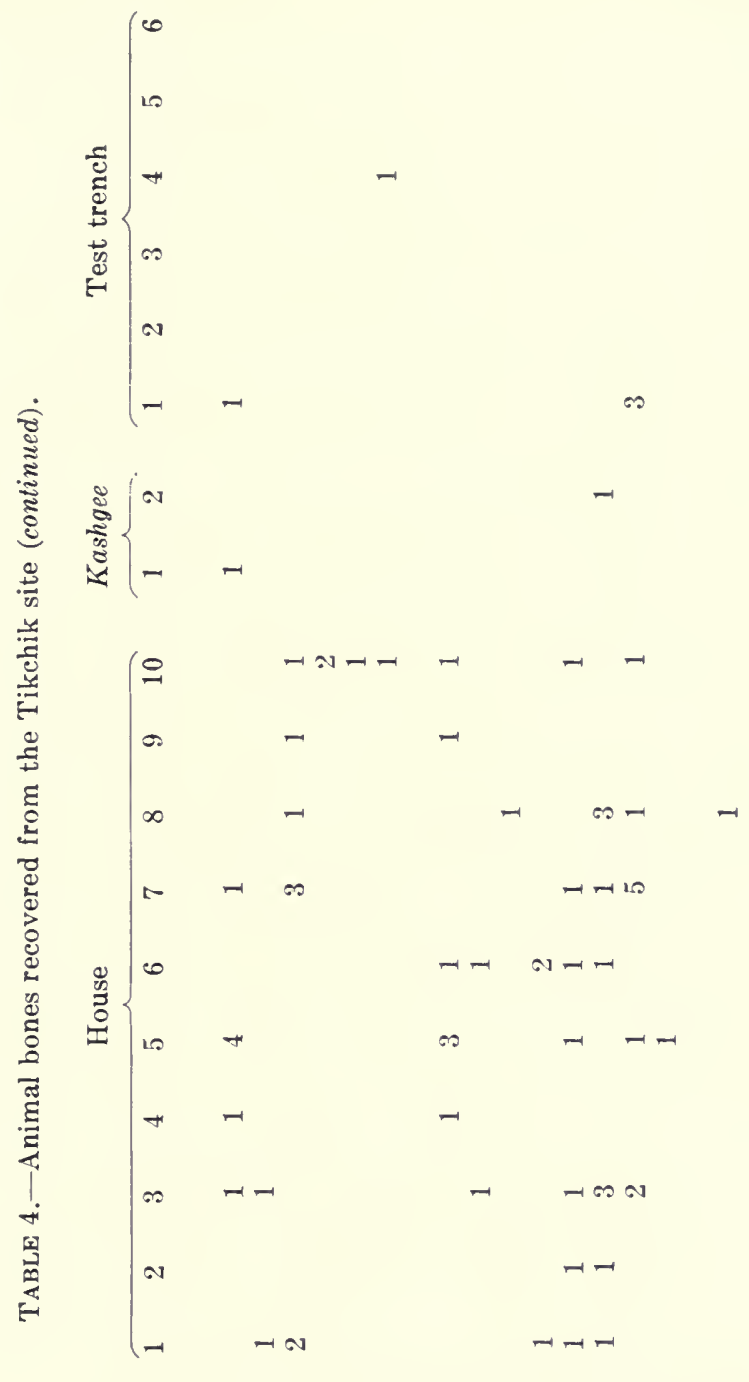

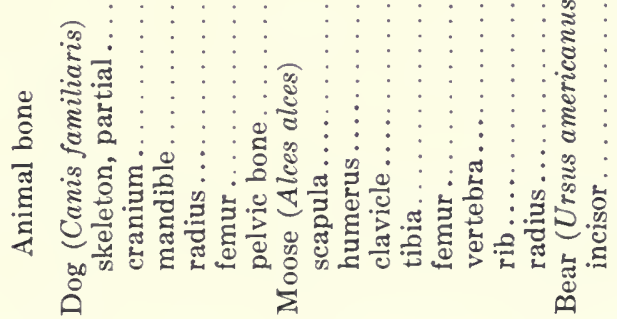


was true for the Kuskokwim was doubtless also true for the Nushagak area and it should be kept in mind that locally made snares, nets, and deadfalls would leave no trace in the archaeological record. Both these and metal traps would be set some distance from the village. The latter might frequently be hung in trees between trapping seasons and never brought back to the village. A similar absence of artifacts associated with trapping was noted at Crow Village (Oswalt and VanStone, 1967, p. 73), but this does not indicate a lack of intrest in this activity in either community.

The use of bone in the manufacture of artifacts is extremely rare at Tikchik as it is in most Eskimo sites where antler was available. Only five artifact types (salmon harpoon socket piece, splitting wedge, caribou scapula scraper, bark peeler, awl) made from locally available bone were recovered, while the whale bone out of which sled shoe sections were made was received in trade from the coast. Antler artifacts, on the other hand, are plentiful although conditions for their preservation were not particularly favorable. Here continuity with the past and with coastal Eskimos is also very clear. In fact, it would appear as though fishing was carried out at Tikchik almost exclusively by aboriginal methods; fish spears, salmon harpoons, nets with bark floats and antler sinkers, and line hooks. The latter have metal barbs, but the type is essentially aboriginal. The prevalence of antler awls and wedges may suggest a selective factor in the acquisition of trade goods. Both of these implements can be made easily and would be virtually as satisfactory as any trade substitutes that might be obtained. Thus the old forms are retained and the Eskimos' interests center on more exotic imports. A final point that might be made with regard to the use of antler concerns the 139 fragments of cut antler which were recovered. Of these, 78 were found in T-1, the midden directly in front of kashgee 2 , suggesting that, as might be expected, much of the antler working was done by men in the kashgee.

It seems virtually certain that the tradition of pottery making is seen in its last stages at Tikchik. The fragments of imported pottery and those of the locally-made ware are just about equal in number. It is interesting to note that the use of clay cooking pots was declining even more rapidly at the Crow Village site (Oswalt and VanStone, 1967, p. 74) which was abandoned about ten years later than Tikchik. Thus it would seem that pottery making, at least as far as cooking and storage pots were concerned, came to an end in interior southwestern Alaska during the first decade of the twentieth century. At both sites the Yukon Line Dot form of decoration was present (Os- 
walt, 1955, p. 37). Since no substitutes for clay lamps were found at either Crow Village or Tikchik (Oswalt and VanStone, 1967, p. 45), it is likely that this form continued to be useful, possibly because of the scarcity of imported fuel.

In addition to decorated sherds of the Yukon Line Dot type, 12 sherds with check stamped impressions were recovered at Tikchik. Since the occurrence of this style of surface treatment in sites of the contact period has not previously been reported in this general area, it is necessary to deal with these sherds in some detail and to broaden our comparative scope. In his classification of Alaskan pottery types Oswalt (1955) has recognized two categories of pottery decorated by exterior stamping in the form of checks; Nunivak Check Stamped and Norton Check Stamped. The latter is characterized by small checks 2 to $5 \mathrm{~mm}$. in width, and is generally early in Alaska. It is found at the Norton culture type site at Cape Denbigh in levels with radiocarbon dates of approximately 255 B.C. and 770 B.C. where it is predominantly fiber and sand tempered (Griffin, 1953; Griffin and Wilmeth, 1964, pp. 271-273; Dumond, 1965, p. 1244). The type also occurs in the Naknek drainage where it is tempered with sand and hair and has been recovered from levels dated by radiocarbon at approximately 160 B.C. and 50 A.D. (Dumond, 1965, p. 1244), and in sites at Chagvan Bay dated 150-300, 423-923, and 573-693 A.D. (Ackerman, 1964, p. 28). The latter ware is predominately hair tempered. Larsen (1950, pp. 181-183) also reports Norton Check Stamped ware from Chagvan Bay. At all these sites the ware is thin and well fired except at Chagvan Beach I where two kinds of check stamped sherds have been identified, one of which is thick and poorly fired (Ackerman, 1964, p. 28). The only late occurrence of the Norton form of check stamping, aside from the Tikchik site, is from deposits of the late pre-contact or post-contact age on Nunivak Island. Here the ware is predominately grass or sand and grass tempered (VanStone, 1954, pp. 182, 188).

Nunivak Check Stamped pottery, which tends to be later, is characterized by checks of large size that are square to rectangular in shape, up to $6 \mathrm{~mm}$. in width, and often impressed on a thick, poorly fired ware. This style of surface treatment was first described by Collins from sherds found a foot below the surface near the ruins of old houses on Nunivak Island (Collins, 1928, pp. 254-256); the ware has a "coarse rock temper and tends to exfoliate" (deLaguna, 1947, p. 229). Additional pottery, similar except for a finer gravel and sand temper, was also recovered from late sites on Nunivak (Van- 


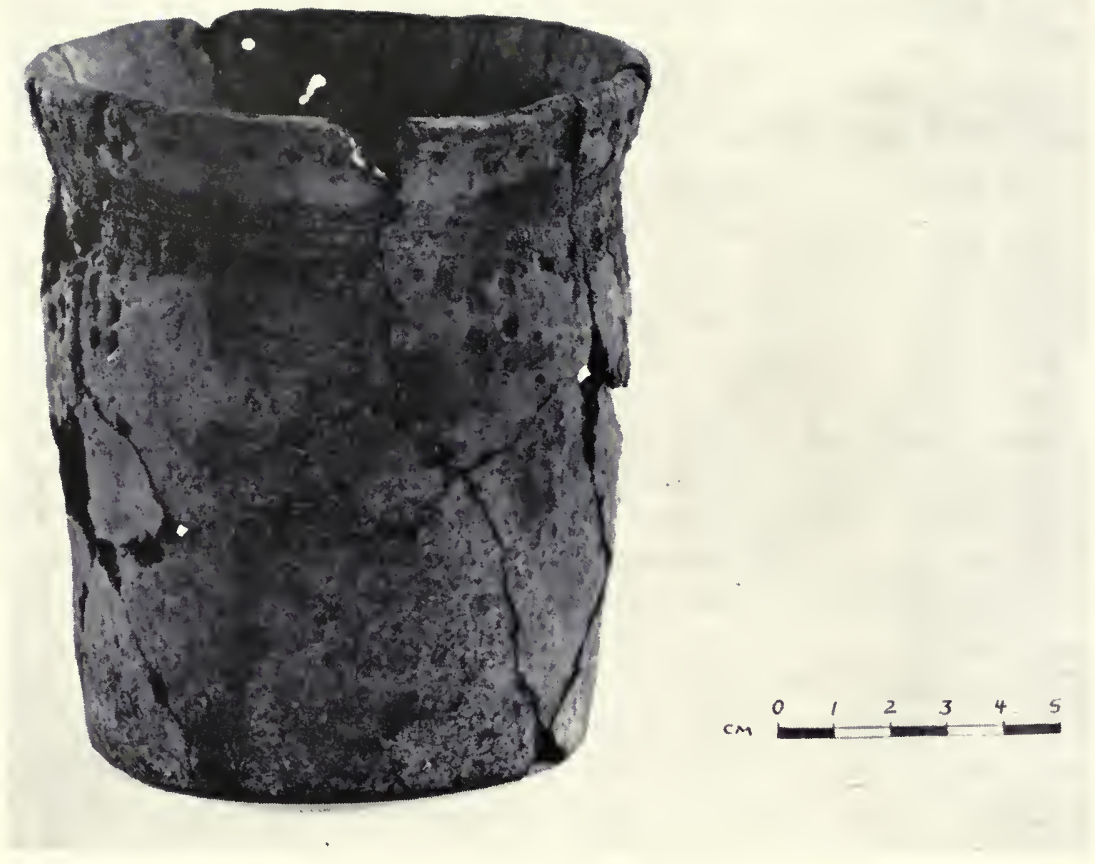

Plate 11a. Locally-made Pottery. Situla-shaped vessel with Yukon Line Dot surface treatment, p. 280. 


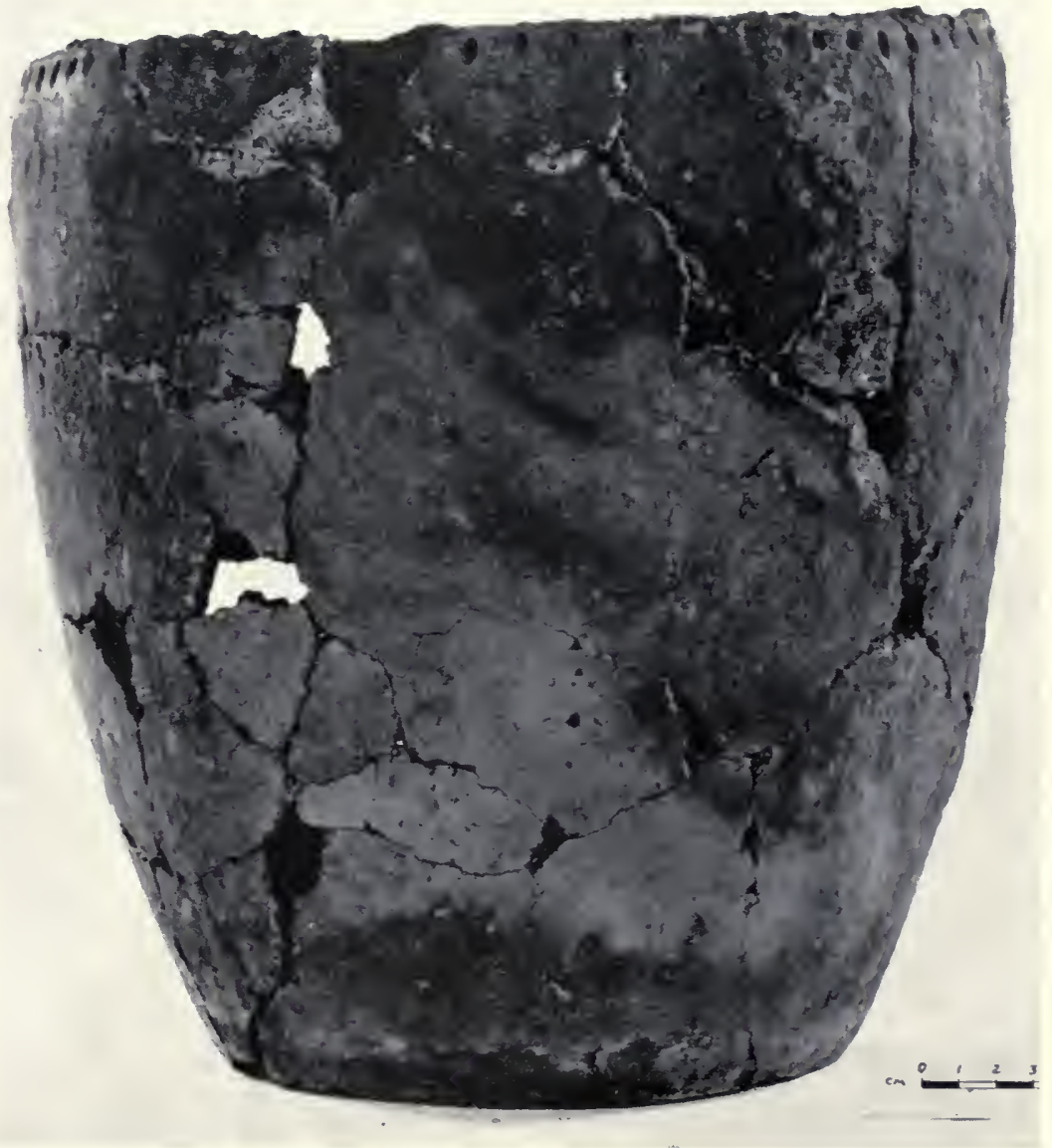

Plate 11b. Locally-made Pottery. Large, flat-bottomed vessel broken below the rim, p. 280. 


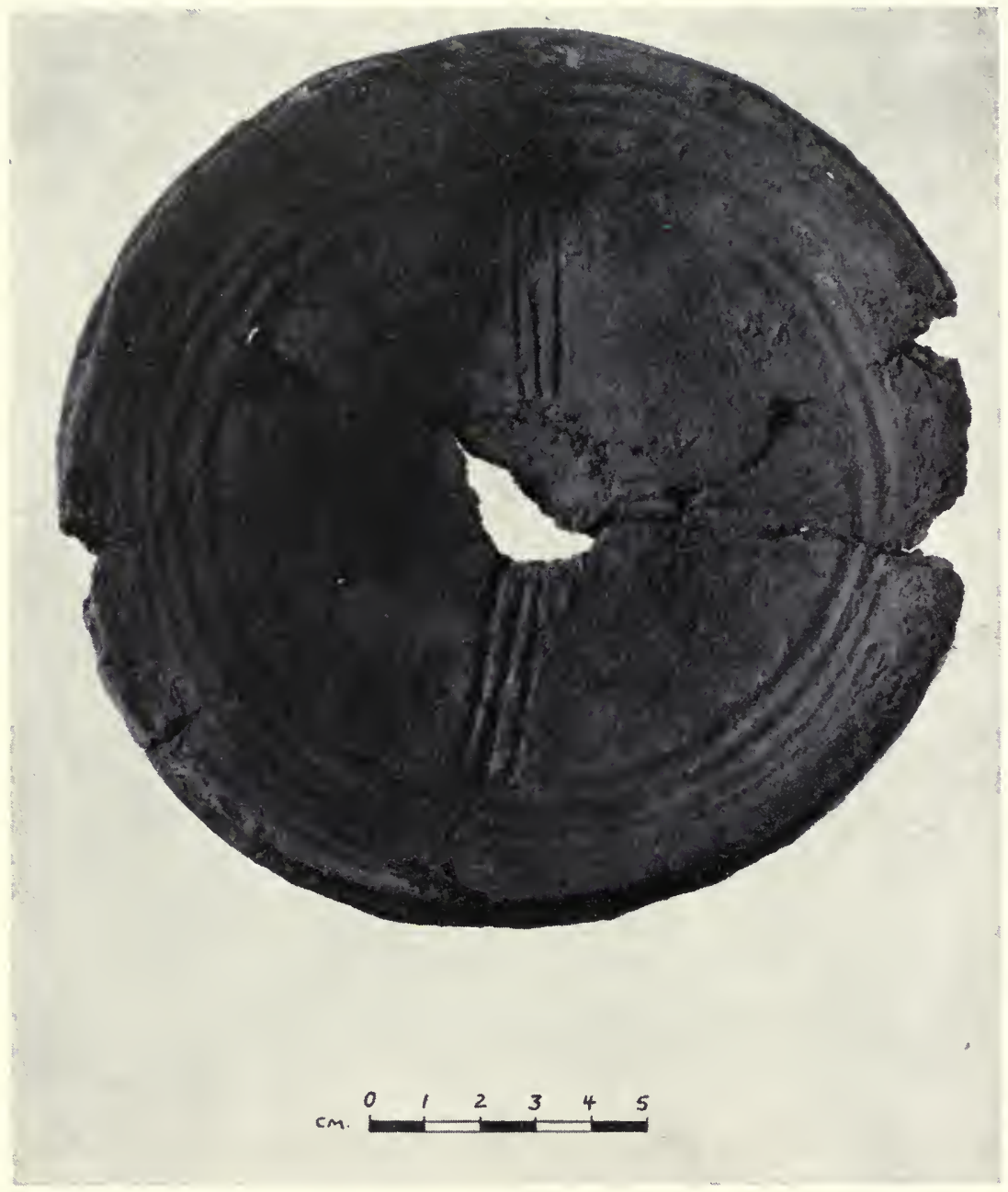

Plate 11c. Locally-made Pottery. "Killed" lamp from burial showing series of encircling lines and central cross motif, p. 283. 
Stone, 1954 , p. 182). Check stamped sherds of this type are widely distributed in Alaska in both time and space. In the Naknek drainage, checks larger than $5 \mathrm{~mm}$. on a predominately hair tempered ware occur in an occupation dating from 300 A.D. until around 800 A.D. (Dumond, 1962, fig. 4; 1965, p. 1244; personal communication). Single sherds with similar decoration were recovered from a Tigara phase burial at Point Hope undoubtedly later than 1500 A.D. (Larsen and Rainey, 1948, p. 177, Pl. 91, fig. 11), a house at Kotzebue dated by dendrochronology at about 1450 A.D. (VanStone, 1955, p. 122), picked up on the beach at Cape Nome (Collins, 1928, p. 254), and found on the surface of the midden at Meyowagh on St. Lawrence Island (Collins, 1937, p. 169). In addition, six such sherds were recovered from the Okvik site on the Punuk Islands (Rainey, 1941, pp. 536, $550)$. Two small collections of Nunivak Check Stamped sherds in the University of Alaska museum are worthy of note. The first consists of an undetermined number of sherds from a reputedly late site on Nelson Island, some of which have the Yukon Line Dot type of decoration (VanStone, 1954, p. 190). The other includes 12 check stamped sherds from a Deering house abandoned in 1902. These are tempered with crushed rock and have an average thickness of $11 \mathrm{~mm}$. (Oswalt, 1952b, p. 28).

On the basis of surface decoration and provenience alone, it seems clear that Nunivak Check Stamped ware occurs no earlier than 300 A.D. and probably continues well into the contact period, keeping in mind the late occurrences on Nunivak Island and at Tikchik, the sherds from the Deering house abandoned in 1902 and particularly a gravel tempered check stamped vessel of unknown provenience but mended with iron staples which was cited by deLaguna (1947, p. $229 ; 1940$, Pl. II, 3). Norton Check Stamped pottery, on the other hand, occurs at least as early as half a millennium B.c. but may also have lasted into the contact period. It must be admitted, however, that this latter supposition rests on evidence that is flimsy at best and runs counter to the findings of most Alaskan pottery specialists.

Since it seems difficult, if not impossible, to verify the persistence of check stamped ware on the basis of surface treatment and provenience alone, it will be worthwhile to consider the question on the basis of other aspects of pottery manufacture. In describing and analyzing the ceramic collection from the Norton and Nukleet phases at Cape Denbigh, Griffin and Wilmuth (1964, pp. 280, 297) were able to determine that on the basis of temper and thickness, check stamped 
and linear stamped sherds fell into one group, while the curvilinear stamped and incised and punctated fell into another. In other words, the basic division was between the Norton wares which were considered early and the Barrow and Yukon wares which were late. Speaking generally, then, these authors conclude that "from the time of manufacture of Norton ware to the historic period, there is a trend toward increasing vessel wall thickness, increasing coarseness of paste, and increasing size and abundance of sand pebble temper" (Griffin and Wilmuth, 1964, p. 287).

The analysis of a long ceramic sequence in the Naknek River drainage has led Dumond (1962, Fig. 4; personal communication) to make a similar division of his sherds into two groups based on temper and thickness. In this area ware 1 apparently began sometime around 500 B.C., is characterized by the presence of hair temper, and is very thin in cross-section. By 500 A.D., the paste had become much thicker but hair temper continued to predominate sometimes accompanied by inclusions of sand and rock. As ware 1 approached the year 1100 A.D. it became thicker and at about that time level, sherds were recovered which were transitional to ware 2 , tempered with hair and pebbles, and very thick. All pottery in the Naknek drainage after 1100 A.D. belongs to ware 2. Pebbles predominate as a tempering agent with occasional grass and hair inclusions, and the sherds grow thinner as they approach the historic period.

It will be immediately apparent that Griffin and Wilmuth and Dumond are in complete agreement as far as the basic changes in pottery types are concerned, although the trend toward increasing vessel wall thickness noted by the former authors apparently does not apply in the Naknek drainage. The long sequence in this area coupled with the impressively detailed analysis carried out by $\mathrm{Du}-$ mond, only a small part of which has been presented here, goes a long way toward convincing me that the answer to many, if not most, of the current questions regarding Alaskan pottery sequences will eventually be found within this framework. To begin with, it is clear that all the Norton Check Stamped ware from the Norton site, the Naknek drainage, and Chagvan Bay belongs to ware 1. In addition, the Nunivak Check Stamped ware from the Naknek drainage also belongs there. It seems equally clear, to me at least, that the Nunivak Check Stamped pottery from Nunivak Island and the above mentioned Deering house belongs to ware 2 and it appears likely that all other reported occurrences of this type of surface treatment do too, although the samples are disappointingly small, and much relevant data concerning paste and shape is lacking. 
Much more difficult, however, is the problem of correctly placing the Norton Check Stamped ware recovered from late sites on Nunivak Island and from the site being described in this report. In both cases the collections are so small that the features of the sherds, aside from surface treatment, are rendered inconclusive. On the other hand, I am reasonably certain of the stratigraphic position of the Nunivak sherds and completely certain of the position of those found at Tikchik. Dumond has convincingly demonstrated that in the Naknek drainage ware 1 in any form was not manufactured after about 1100 A.D. Therefore, it is inconceivable to him, and to me, that this ware could have survived until the late nineteenth century at Tikchik only about 220 kilometers to the northwest. As for the Norton Check Stamped sherds from Nunivak, the answer here would seem to depend on the time at which ware 2 replaced ware 1 throughout Alaska. Since ware 1 seems to include all the Choris and Near Ipiutak pottery as well as Norton, it is a widespread manifestation and future excavations may very well show that it was replaced by ware 2 throughout Alaska at about the same time as this took place in the Naknek drainage. If the Tikchik and Nunivak sherds with small checks belong to ware 1 , and this is by no means certain, then they are unquestionably intrusive into the deposits from which they were recovered. If, on the other hand, additional finds should show that they belong to ware 2 , then it would appear that the relationship of surface treatment to temper, thickness, and shape is not as clear or significant as had previously been supposed.

Both Dumond (1965, p. 1244) and Oswalt (1955, p. 39) have suggested that large check stamp decoration may be a lineal descendent of the small check stamping and the presence of Nunivak Check Stamped sherds in the Naknek drainage sequence chronologically later than those of the Norton type but still belonging to ware $1 \mathrm{dem}-$ onstrates the ability of this style of surface treatment to survive a basic change in paste characteristics. In other words, it now appears virtually certain that large checks are characteristic of both wares 1 and 2. This being the case, it seems altogether possible that future excavations will show that Norton check stamping was equally persistent and equally capable of making the transition from one ware to the other. If this should be the case, then it would definitely be questionable whether fine check stamping, or for that matter any of the other forms of surface treatment now associated with ware 1 , are necessarily "the marks of recognition of pre-Ipiutak pottery on the western Alaskan mainland” (Giddings, 1964, p. 176). 
In concluding this brief discussion of check stamped pottery, it might be pointed out that perhaps too much importance has been attached by pottery specialists to the distinction between sherds with small checks and those with large. It may well be that we are dealing with a single tradition of surface treatment in which the small checks tend to be early and the large ones late, but in which there is a great deal of blending and overlap, and in which occasionally the large are found relatively early and the small extremely late. Positive proof of a single continuous check stamping tradition in Alaska south of the Seward Peninsula will not be achieved, however, until excavations produce an undeniable association between Norton Check Stamped surface treatment and ware 2.

Having considered those features of Tikchik culture in which continuity with the past can, to a greater or lesser degree, be demonstrated, we now turn to examples of change induced by the contact situation. In dealing with the manner in which imported materials were adapted to local needs it seems advisable to adhere closely to the organization of a similar section in the report on Crow Village (Oswalt and VanStone, 1967) since this report describes the only comparable collection of trade materials from an Alaskan Eskimo site.

At Tikchik, as at Crow Village, the stimulus toward innovation that was provided by the presence of imported materials is indeed impressive. It is this fact, rather than the actual number or variety of imported items that will be emphasized here. In approaching the problem of change induced as a result of contact at Crow Village, it was pointed out that innovations might be expected to occur in three ways: 1$)$ through the introduction of exotic objects which are simply accepted and added to the cultural inventory; 2 ) as a result of the availability of new materials which permit changes in existing forms, and 3) through the construction of entirely new forms which are based on new models (Oswalt and VanStone, 1967, pp. 74-75). With regard to the first source of innovation, a reading of the artifact descriptions and a glance at the trait list will indicate the recovered items which were accepted into the cultural inventory without change. Although the number and variety are not great, there is room for doubt as to whether the collection is representative of the number of items that were available. Unfortunately, detailed inventories of the Russian-American Company and Alaska Commercial Company post at Nushagak have not, thus far, proved to be traceable, but I have examined such inventories for the Alaska Commercial Company store at Tyonek on Cook Inlet and they show that at the turn of the 
century a surprisingly large number of trade goods of all kinds were available to the people of that area. These included a wide variety of dry goods, clothing-including boots, shoes and rubber goods, notions, hardware, dried and canned foods, arms and ammunition, paints, patent medicines, candy, and even furniture. There is no reason to think that the store at Nushagak was not, to some extent at least, similarly stocked. Of course, the supply of trade goods at this time was doubtless much greater than it was throughout most of the period when Tikchik was occupied, but the fact still remains that the archaeological record would seem to give only a partial indication of the number of exotic objects potentially available to the villagers. Much, of course, has been lost through the poor preservation at the site. A strong conservatism on the part of these inland dwellers who probably saw Nushagak no more than once a year may also have been a factor.

The second source of innovation is of particular interest and significance because it concerns the introduction of new raw materials and their effect on the manufacture of traditional artifact types. Here we see clearly the persistence of old ideas in new mediums. The most notable examples are discussed below.

1) The use of a spent cartridge case to form the end of a blunt arrowhead represents only a slight modification of a traditional artifact. This change, which probably increased the durability and perhaps the efficiency of the point, has been noted from historic levels at Hooper Bay Village (Oswalt, 1952a, p. 53) and is represented in the Crow Village collection (Oswalt and VanStone, 1967, p. 76).

2) Ulu and end bladed knife blades made from can metal were doubtless easier to make and could be manufactured more quickly and in larger sizes than those made of slate. As has been pointed out for similar artifacts from Crow Village, however, these blades must have been far less functional than their stone counterparts due to the flexibility of the metal and its inability to hold a sharp cutting edge (Oswalt and VanStone, 1967, p. 75). This would also be true for a skin scraper blade of the same material, but in this case it was possible to strengthen the implement by folding the metal double.

3) Can metal folded into shallow dish-like containers was extremely common at Crow Village where they were thought to illustrate a marked conservatism with regard to the use of the new material because the containers were folded at the ends in the same manner 
as birch bark baskets (Oswalt and VanStone, 1967, p. 76). Although no comparable birch bark vessels were preserved at Tikchik, it seems certain that the can metal dishes from this site represent a similar continuity of container manufacture.

4) A rimfire cartridge case of undetermined caliber was perforated at the proximal end and a cord passed through the hole. The case was then strung as a bead separator to form a new type of necklace. Similar perforated cartridge cases were recovered at the Crow Village site (Oswalt and VanStone, 1967, p. 76) and it is likely that this form will eventually prove to be widespread in Alaskan historical sites.

5) It is not surprising that light metal, particularly from cans, which is bright and shiny when first obtained, should be attractive from the standpoint of personal adornment. Perforated can tops and circular cut pieces of light metal in the Tikchik collection were almost certainly pendants or parts of necklaces and as such were used traditionally in the same way that local materials were used.

6) Scrapers made from bottle glass resemble those of flinty materials and this use for an imported material was doubtless common throughout Alaska (Ackerman, 1965, p. 46; Oswalt and VanStone, 1967, p. 75), as well as in other parts of North America (Schaeffer, 1961, pp. 275-276).

It should be kept in mind that some trade goods which were acquired and accepted by the people of Tikchik without apparent modification may actually have been used in a manner far different from that intended by the manufacturer of the artifact, a manner which might, if evidence were available, further illustrate the persistence of old ideas. For example, Eskimos at the village of Point Hope along the coast of northwest Alaska informed me that when their fathers or grandfathers had first acquired bread in the form of hard tack, they drilled holes in it and wore the seemingly indestructible round biscuits as pendants. That the people of Tikchik were essentially conservative in their attitudes toward trade goods seems certain. A New Koliganek informant whose grandfather lived at Tikchik reported that when his relative first had an opportunity to purchase a breech-loading rifle to replace his muzzle-loader, he refused to do so because he doubted the ability of the new and unfamiliar weapon to kill game. If a strong conservatism applied to such a demonstrable improvement as a breech-loading rifle, it is easy to see 
how people might react to other innovations, the advantages of which were less readily apparent.

Turning to the third category of innovation mentioned above, that of new forms based on new models, there are, unfortunately, no examples from the Tikchik site. It would seem, therefore, that it was seldom if ever necessary for the Eskimos to improvise in order to maintain and continue to use the imported implements in their possession. An interesting example of an attempt by Eskimos to reproduce a non-Eskimo artifact locally was half of a sandstone bullet mold recovered at Crow Village (Oswalt and VanStone, 1967, p. 76).

The various specifics of innovation that have been discussed here are interesting because they provide a certain amount of information about Eskimo response to the new items of material culture that were available to them. The people of Tikchik doubtless had a cautious approach to things new, but like their contemporaries at Crow Village, seem to have been interested in experimenting with new materials. Neither the archaeological record nor written historical data allows us to elaborate on the selection factor and trade materials, but it is likely that the inventory of goods traded in the Nushagak River region was small at the beginning of the Russian period and gradually grew until at the time the site was abandoned the people presumably had access to a sizeable number and variety of trade items. In spite of this, however, the Tikchik collection indicates the same continuity with emphasis on the retention of traditional forms that was noted for Crow Village (Oswalt and VanStone, 1967, p. 77). 


\section{Time and Change}

The span of occupation at the Tikchik site would seem to encompass all or most of the nineteenth century. Trade goods were found in all the dwellings, the kashgee and in the test trenches, so it is safe to say that there was at least indirect historic contact during the earliest stages of occupancy. It may have been that the inhabitants had access to Russian trade goods before the actual appearance of the Russians in the Nushagak River region, and certainly opportunities for acquiring such goods increased greatly after the establishment of Alexandrovski Redoubt in 1818. However, the collections clearly show that it was American influence after 1867 that left its mark on the material culture of the villagers and continued to influence village life, both directly and indirectly, until the site was abandoned after the "great sickness" of 1899-1900. We have already noted that historical source material referring directly to Tikchik is scanty. Therefore it will be necessary to rely on such data for the Nushagak River region as a whole in order to specify particular spans of time that were significant to the history of the Eskimo inhabitants of Tikchik.

\section{$1829-1866$}

An exploring party under the direction of I. F. Vasiliev ascended the Nushagak and Nuyakuk rivers in 1829 and explored one or more lakes in the Tikchik Lakes system, probably making direct contact with the inhabitants of Tikchik. The following year Vasiliev again ascended the Nushagak and this time passed over to the Kuskokwim which he explored in the interest of expanding the fur trade into the interior of southwestern Alaska. In 1832 a trading post was established at the mouth of the Holitna River and was eventually moved twice until Kolmakovski Redoubt was founded in 1841 and became the center of the interior Kuskokwim trade until the end of the Russian period. From 1841 communications were maintained between Kolmakovski and Alexandrovski Redoubt and presumably the people of Tikchik occasionally encountered Russians along the river. They also are certain to have made trips to the mouth of the Nushagak 
River at least once a year where they had ample opportunity to acquire whatever trade goods were available. As far as can be determined, however, the Russians did not establish any out stations or subsidiary posts in the Nushagak River region with the exception of an odinochka near the mouth of the King Salmon River on the upper Nushagak which was a trans-shipment point between Kolmakovski and Alexandrovski and not a post in itself. Thus the Tikchik Eskimos were never actually close to the source of trade goods and therefore may have lagged behind the residents of some Nushagak River villages in their willingness to try out and eventually accept new ideas and new items of material culture.

In an earlier analysis of the imported manufactured goods from Tikchik an attempt was made to date the various trade items or at least to suggest their chronological significance to the collection as a whole. This proved to be extremely difficult and it is not possible to go beyond the general statement that the trade materials, taken as a whole, appear to belong to the latter part of the nineteenth century. Since Tikchik was presumably occupied during a considerable part of the Russian period, it was expected that materials clearly recognizable as belonging to this period would occur in the collection. Unfortunately, no clear dichotomy emerged, either stratigraphically or in terms of the artifacts recovered. Therefore, it is necessary to make some attempt to determine, if possible, which trade goods are of Russian origin and which were obtained from American traders.

In order to make a reasonable attempt at answering this question, it is necessary to turn to whatever historical sources are available that might give some insight into specific types of trade goods which the Russians introduced to the Nushagak River region and surrounding areas. In 1841 the manager of the Russian-American Company office at Kodiak visited Alexandrovski Redoubt to settle a dispute about the prices paid for furs and his orders from the general manager contain a few references to specific trade goods. He was instructed not to raise the prices paid in tobacco, beads, cloth and other so-called luxury items used by the Eskimos. On the other hand, if the payments were to be made in blankets, heavy cloth, canvas tent cloth and other materials which could be used for garments, then the price could be raised (Russian-American Company Records: Communications Sent, vol. 20, no. 43, folios 51-56).

It is apparent that although guns and metal traps were introduced by the Russians soon after they expanded their activities into southwestern Alaska, these items were never readily available in 
quantity to the Eskimos of the region. As late as 1839, Fedor Kolmakov was forbidden by the general manager of the Russian-American Company to sell guns to the Eskimos. Only a few of the most trustworthy men were allowed to borrow firearms and Kolmakov was ordered to keep a careful record in writing of those to whom weapons had been loaned. In the same year Alexandrovski Redoubt received only five metal traps for trading purposes. In fact, Zagoskin noted that in the Yukon and Kuskokwim villages in 1842-1844 the trappers, not interested in changing their traditional methods, would acquire metal traps only for the purpose of immediately converting the parts into knives, axes, rings, and other useful items (Zagoskin, 1967, p. 221; Russian-American Company Records: Communications Sent, vol. 16, no. 377, folios 106-108; vol. 17, no. 387, folio 370 ; no. 513 , folio 505 ).

At the time of Tikhmenev's study of the Russian-American Company in the period around 1860, Alexandrovski Redoubt had already lost much of its importance but still maintained an active trade with the people in the immediate Nushagak area. At that time the most favored trade goods at the post were tobacco, various kinds of dry goods, and cast iron kettles. Beads had formerly been preferred by the Eskimos of the region, particularly large red, black, and white ones, but these had fallen from favor and were bartered only in small quantities (Tikhmenev, 1939-1940, pt. II, p. 334). Other goods bartered by the Russians in western Alaska which were likely to have been included in the Alexandrovski trading inventories were blue beads, knives, iron for striking a fire, needles, combs, pipes, large cups, copper jugs, mirrors, copper rings, earrings, bracelets of copper and iron, leather pouches, mortars and pestles, small bells, navy buttons, Aleutian axes, flannel blankets, calico shirts, caps, cloth dresses, and other items of European clothing. At Nulato on the Yukon River beads were handled in strings and in 1843 a total of 3,360 strings one sazhen $(2.1 \mathrm{~m}$.) in length were traded to the Indians at the post and in the surrounding area (Zagoskin, 1967, pp. 148, 161, $170,184,185,246-247)$.

It is regretable that nothing more detailed is known concerning inventories of Russian trade goods and it is rather discouraging to know that nothing more is likely to come to light unless some sources are discovered that are presently unknown. A recent examination of the many folios of Russian-American Company records deposited in the National Archives has confirmed a suspicion that very little of this type of information is on file there. But it is clear from the 
list just given that there are at least a few identifiable Russian trade items in the Tikchik collection. Of particular interest in this regard are the beads. An earlier analysis of the Tikchik beads stressed the general nineteenth century character of the assemblage, but very little was said about the possible origin of the various forms of beads. Although it is undoubtedly true that various shapes, colors, and sizes of beads were traded at specific times, information simply does not exist that would make it possible to present a chronology of bead types. In the winter of 1965 I examined a number of Aleut hats decorated with beads in the collection of the Academy of Sciences Museum of Anthropology and Ethnography in Leningrad. These hats all dated from the early nineteenth century and had been collected by Russian explorers. Thus it can be assumed that the beads on them were, for the most part, traded to the Aleuts by Russians, although it should be kept in mind that American and British ships did occasionally trade in the area at the time. Virtually all the bead sizes and colors in the Tikchik collection were observed on these hats. Large, translucent, deep marine blue beads were particularly common, but small white and light blue types were also plentiful. Translucent beads were represented in blue, green, and various shades of red, and the so-called "Cornaline d'Aleppo" type was also present. Bead-decorated items of nineteenth century material culture from the Koryak and Chukchee peoples of Siberia were also examined and again one would expect that the beads were acquired through Russian sources. Prominent among these beads were small white-lined red types, beads with painted decoration similar to a single specimen from Tikchik, large light blue and translucent deep marine blue beads. These colors and sizes resemble in all respects those beads recovered from both the Tikchik and Crow Village sites. It would thus seem that any of the beads from Tikchik could be Russian trade items. On the other hand, they could all be later, too, since beads have been sold or traded to the Nushagak area Eskimos right down to the present time. Since some of the bead types from Tikchik are common in historic sites from other parts of North America, it is fairly obvious that there is no particular color, size, or style of bead that can, with confidence, be called Russian. Any bead manufactured in Europe or the middle east could have been and doubtless was obtained by the Russians for their Alaskan trade. It perhaps sounds overly pessimistic to say so, but I doubt whether an accurate chronology of bead types applicable to historic sites in Alaska could ever be achieved. 
Other objects in the Tikchik collection that could be considered as being of Russian origin are the fragment of kaolin pipe stem, the cast iron kettle fragments, a copper ring, and perhaps the brass kettle fragments. There may be others, but it is clear that the bulk of the imported manufactured goods from the site belong to the American period and were, for the most part, obtained from the traders who succeeded the Russian-American Company at the mouth of the Nushagak River. It would seem, then, that the Russian influence at Tikchik, at least in terms of material culture, was not great. This is perhaps not as difficult to understand as might at first appear. The period of Russian influence was, after all, relatively short and there are indications that it lacked intensity. In a discussion of a similar situation along the Kuskokwim River at the same time, it has been pointed out that since the Russians came into the interior of southwestern Alaska for the purpose of expanding their fur trade, they were always few in number and very circumspect about their dealings with the people. They had no force to back up their position such as they possessed decades earlier when establishing themselves in the Aleutian Islands and along the coast of southeastern Alaska. Seldom in southwestern Alaska did they settle in an occupied village and it seems certain that they made little or no attempt to interfere in the affairs of the various villages where they maintained contact for purposes of trade (Oswalt, 1963, pp. 106-107).

It should be emphasized once again that Tikchik was one of the most remote villages of the Nushagak River region and was probably visited only seldom by Russians, either traders or missionaries. In fact, it is altogether likely that Alexandrovski Redoubt may have been in existence for more than 20 years before the Tikchik residents began to visit it with any degree of regularity. If that were indeed the case, then the total period of even moderate Russian influence on the community would have been no more than 25 years. Thus it is perhaps not surprising that whatever Russian influence might have been noticeable in the material culture was easily swamped out by the succeeding 40 years of more intensive contact with American traders, cannery workers, prospectors, etc.

An extremely significant, but less tangible, result of the Russian presence in the Nushagak River region was the introduction of Christianity to the peoples of the area. Furthermore, the Russian Orthodox Church played a role at least equal to that of the Russian-American Company in opening up the country and in exposing the people to outside influences. Christianity was introduced to the Nushagak 
River region at the time of the construction of Alexandrovski Redoubt and there is evidence that during the next ten years Fedor Kolmakov baptized a small number of Eskimos who were employees in the service of the Company at the redoubt (Barsukov, 1886-1888, vol. 2, p. 36). Father Ivan Veniaminov, one of the first Orthodox missionaries in Alaska, visited the redoubt in 1829 from Unalaska and baptized 13 individuals, the first Eskimos north of the Alaska Peninsula to receive baptism. He returned in 1832 and ordered the construction of a small chapel. Between 1832 and 1838 Kolmakov continued to baptize people and in the latter year Gregory Golovin, Veniaminov's successor at Unalaska, visited the redoubt, administered the sacraments to 53 of those baptized by Kolmakov and baptized 52 new converts (Barsukov, 1886-1888, vol. 2, pp. 37-38).

In 1840 Veniaminov was named bishop of the Diocese of Kamchatka, the Aleutian and Kurile Islands and one of his first acts was to request permission from the Holy Synod to establish a mission at Alexandrovski. This was authorized and in 1841 Deacon I. Petelin, Veniaminov's son-in-law, was ordained a priest and appointed to take charge of the Nushagak mission (DRHA, vol. 1, pp. 385-386). The number of Christians at Nushagak in 1842 was about 200 and during the next three years as many as 400 additional Eskimos may have been baptized (Tikhmenev, 1939-1940, pt. II, pp. 297-298). Father Petelin also seems to have widened the scope of his activities to include the region north of the redoubt. It is likely that he ascended the Nushagak on several occasions and it is known that he visited the Kuskokwim for the first time in 1843 and received many Eskimos into the church (Zagoskin, 1967, p. 285).

We have already noted that the first reference to Tikchik in the vital statistics of the church at Alexandrovski Redoubt occurs in 1847 when two middle-aged men presumably visited the redoubt and were baptized. Unfortunately, it is impossible to say with certainty when a missionary first visited the village but there are indications in the vital statistics that this may have taken place as early as 1850 , in which case it would have been Hieromonk Nikolai from Nikolaevski Redoubt on Cook Inlet who first established direct contact with Tikchik. He included the Nushagak in his area of jurisdiction in 1847 when Father Petelin left the mission following the reduction of Alexandrovski to an odinochka in 1846 . Hieromonk Nikolai resided at Alexandrovski for a year in 1850-1851 (Barsukov, 1897-1901, vol. 1, p. 371; DRHA, vol. 1, p. 247). Tikchik continues to be mentioned more or less regularly in the statistics until 1882 but it seems virtu- 
ally certain that missionaries did not visit the settlement with any degree of regularity. Throughout the 1850's and 1860's the missionaries at Alexandrovski were seldom able to visit the villages along the Nushagak River more than twice a year and it is doubtless true that some of the more remote communities, of which Tikchik was certainly one, were visited less frequently than that. By 1864, all the Eskimos in villages which the missionary was able to visit had been baptized (DRHA, vol. 1, p. 149), but it is doubtful if Tikchik was included in this number. More likely it was only those settlements close to the redoubt that were strongly influenced by Christian teaching. Inhabitants of the remote settlements, like Tikchik, would probably seldom encounter a priest except when they made their periodic trips to the redoubt. The fact that no artifacts associated with Christian ritual and practice were recovered from the site would seem to further reinforce the impression that the residents were only marginal participants in the newly introduced faith, a condition that probably persisted as long as the settlement was occupied.

Information about the number of people living in the upper Nushagak River region during the Russian period is very inadequate and initially it will be necessary to consider a somewhat wider area in order to learn something about the nature of settlement patterns in the vicinity of Tikchik. The first estimate for the Kiatagmiut as a whole was made by Vasiliev in 1829 , and he set the number at 400 (reported by Zagoskin, 1967, p. 308). Shortly after Vasiliev's explorations the small pox epidemic of 1837-1838 swept the Kuskokwim and Nushagak River regions infecting more than 500 people of which 200 died (Tikhmenev, 1939-1940, pt. II, pp. 366, 368). Although epidemics similar to this one may have been relatively rare, there is every indication that once European diseases had been introduced, they took a yearly toll that may not have been great in terms of numbers of dead, but which greatly weakened the resistance of the survivors. It seems certain that the population of Tikchik would have been affected by the increasing prevalence of illness. Zagoskin believed that Vasiliev's population figures were too high and was inclined to reduce the latter's estimate by almost half (1967, p. 308).

During the summer of 1964 I conducted an archaeological survey of Nushagak Bay, the Nushagak River and its tributaries for the express purpose of locating settlements that had been occupied during the nineteenth and early twentieth centuries. In many cases the names, sizes, and approximate locations of the sites had been extracted from historical sources prior to the field work. It was determined as a re- 
sult of this survey that between 1800 and 1860 there were four and possibly six occupied settlements in the general vicinity of Tikchik including that village itself. There was Agivavik south of the present community of New Stuyahok, and Akulivikchuck and Kokwok just below the present village of Ekwok. Old Koliganek near the mouth of the Nuyakuk River was doubtless in existence, at least toward the end of this period, and there was a small settlement, the name of which could not be learned, north of Tikchik at the mouth of the Allen River. Although no population figures exist for these villages at this period, it seems likely on the basis of their present-day appearance that the total population of the region between 1800 and 1860 may have been between 300 and 500, figures that correspond roughly to the data obtained by Vasiliev in 1829 .

\section{$1867-1900$}

We have noted that the Alaska Commercial Company quickly emerged as successor to the Russian-American Company at Nushagak and maintained a moderately flourishing trade with the people of the area throughout the period under consideration here. Although some changes of policy may have taken place, it is likely that the basic relationship between the Eskimos of Tikchik and the traders did not change. At various times during the decade between 1880 and 1890 the Nushagak post may have maintained minor stations at points on the Nushagak River, placed in such a manner as to more effectively control the trapping activities of the Eskimos. Each of these stations was under the direction of native traders who, at certain seasons of the year, brought the furs they had purchased to Nushagak. One of the out stations appears to have been located at the mouth of the Mulchatna River. It was in existence somewhat prior to 1896 and was called Middle Station (Jackson, 1886, p. 55; Report of the Governor of Alaska, 1891, pub. 1891, p. 25; Baker, 1902, p. 284).

Although there is no way of knowing for sure, the people of Tikchik may have dealt with the trader at Middle Station in order to have easier and more frequent access to trade goods. It is also possible that a trader from this or one of the other out stations along the Nushagak River may have visited the settlement occasionally to obtain furs. It is certain, however, that there was no trading activity in the area other than that under the control of the Alaska Commercial Company until after the time when the Tikchik site had been abandoned. 
As was the case with the Russian period, precisely what the traders had to offer the people in terms of material goods is not known in detail. Merchandise inventories for the Nushagak post have not turned up in any of the archival depositories where records of the Alaska Commercial Company are known to exist and it seems fairly certain that these records were destroyed in the San Francisco earthquake and fire. From scattered sources, however, it is possible to piece together an uncertain picture of popular trade items in southwestern Alaska as a whole during the early phases of the American period. E. W. Nelson mentions that when he traveled from St. Michael to the mouth of the Kuskokwim River in 1878 he took along "leaf tobacco, ammunition, beads, brass jewelry, needles and other small wares" in order to purchase ethnographic specimens (Nelson, 1882 , p. 661 ). In the 1880 's the Moravian missionary W. H. Weinland listed tobacco, tea, drilling, needles, powder, lead, knives, axes, hardtack, twine for fish nets, sugar, flour, cooking utensils, old army muskets, and sheet iron tea kettles as the most popular trade items (Oswalt, 1963, pp. 110-111). We have previously noted the extensive inventory of the Alaska Commercial Company post at Tyonek in 1902, but it is doubtful if Nushagak had a similar inventory early in the American period. During the 1870's and 1880's it seems certain that the people of Tikchik and other villages in the area possessed the material apparatus of aboriginal Eskimos with the addition of relatively few trade items.

One possible source of trade goods for all the Nushagak River Eskimos was from the prospectors and miners who searched for gold along the river and its tributaries. Actually the Nushagak River never played an important part in the mining history of Alaska. No major stampedes were ever recorded for the river and the Nushagak was never an access route to any important gold fields. And yet, as early as 1887 prospectors were making their way up the river and concentrating their activities along the Mulchatna. Undoubtedly, some of these prospected along the Nuyakuk and may have visited Tikchik. But they were very few in number and probably had little to offer the Eskimos in the way of trade goods. The very fact that a few miners may have reached the village and perhaps traded some of their possessions for meat and fish merely emphasizes the rarity of contact between Eskimos and whites in this area up to the turn of the century.

Of far greater impact on all the peoples of the Nushagak River region was the commercial fishing industry that began to develop in 
Bristol Bay during the ninth decade of the last century. This remarkable industry, one of the most significant commercial developments in the entire history of Alaska, from its very inception brought significant and far-reaching changes to the area. In the last two decades of the nineteenth century it was responsible for bringing about major seasonal fluctuations of population which brought the Eskimos of even the remotest villages into first-hand contact with many different races and nationalities.

There are five species of Pacific salmon; the king or chinook, the red or sockeye, the pink or humpback, the chum or dog, and the silver or coho. All these salmon make spawning runs into the rivers of Bristol Bay, but it is the red salmon that is the most important from a commercial standpoint. The rivers flowing into the bay are the greatest red salmon spawning grounds in the world because these fish spawn only in lakes or in streams that flow into or out of lakes. It so happens that most of the rivers flowing into Bristol Bay have numerous lakes at their headwaters.

The earliest fishing by Euro-Americans in Nushagak Bay was for salting purposes and was carried out by the Alaska Commercial Company (Petroff, 1884, p. 16). It was the invention of the canning process, however, that provided a means by which the Alaska salmon runs could be utilized more fully, and between 1883 and 1903 ten canneries were constructed at various points on Nushagak Bay (Moser, 1899, pp. 173-174; Cobb, 1931, pp. 462-463; Hawkins and Daugherty, 1958, p. 17).

From the beginning there appears to have been little or no effort made to utilize the local labor supply in the salmon canning industry. Most of the actual fishing was done by Euro-Americans, while work in the canneries was done by Chinese laborers. As might be expected, however, large numbers of Eskimos were attracted to Nushagak Bay during the fishing seasons and tent settlements sprang up near the canneries every summer (Gregory and Barnes, 1939, p. 27). Gradually, though, some Eskimos were able to obtain employment in the canneries even during the earliest years of the industry in spite of what was obviously considerable prejudice against them and their abilities as workers. In the early 1890's, for example, Eskimo cannery workers in Nushagak Bay were averaging $\$ 48.50$ per month during an average period of operation of 63 days (Porter, 1893, p. 218) and in 1900 the two canneries at Nushagak village employed 70 local people as opposed to 193 Chinese (Moser, 1902, pp. 203-204). The fact is that even when Chinese contract labor was readily available, 
the canneries in Nushagak Bay could not get along without hiring some Eskimos, particularly at the peak of the salmon runs.

This is not the place for a detailed discussion of the effect of the salmon canneries on settlement patterns and other aspects of Nushagak River Eskimo life. It is sufficient to note that the presence of the exotic canneries and the possibility of employment and interaction with the foreign fishermen and cannery workers drew people to the bay area from all over southwestern Alaska. The inhabitants of the Nushagak River region, already accustomed to making summer trips to Nushagak to trade their furs, tended to prolong these visits once the canneries provided an added attraction. The residents of Tikchik were doubtless no different from those of other villages in this respect, although Ivan Ishnook insisted that members of his family never worked for the canneries and had very little direct association with the workers. Perhaps the people of Tikchik were too conservative and unfamiliar with outsiders to join actively the large number of cannery "hangers on." Nevertheless, the canneries with their exotic personnel and new and strange material culture must have acted as effective agents of change into the orbit of which even the most retiring Tikchik resident must have been drawn. It would be very surprising indeed if the villagers did not return to their settlement each summer with a store of new ideas, impressions, and perhaps a few material items not obtainable at the post, but available through trade with a friendly fisherman from San Francisco or a homesick cannery worker from Hong Kong. It is known, for example, that the canneries frequently distributed food to the Eskimos, and the people of Tikchik may have first become acquainted with American foods in this manner, foods that would not, toward the end of the century, have been stocked by the Alaska Commercial Company post at Nushagak.

Turning once again to a consideration of Christianity in the Nushagak River region, we note that after the purchase of Alaska by the United States there was a decline in mission activity. The priest at Nushagak was withdrawn in 1868 and the mission was left in the care of a lay reader. This move seems to have been prompted by a fear that it would be impossible for the Nushagak and also the Yukon parishes to exist without the logistic support of the Russian-American Company. For a while the Nushagak area converts to the Russian Orthodox Church had little contact with their priests. It would seem, however, that the church authorities gradually reconciled themselves to working out satisfactory relations with the Alaska Com- 
mercial Company and by 1878 there was once again a priest at Nushagak. At this time, too, the first chapels in the Nushagak region were constructed. The locations are not known, but it is likely that there was one on the Nushagak River, perhaps at Kokwok (DRHA, vol. 1, p. 329). Nevertheless, the influence of the missionaries in the 1870's and 1880's was not great. Petroff (1884, pp. 135136) noted that although all Eskimos were carried on the register of the Orthodox Chuch, it was rarely that the outlying settlements received even an annual visit from the priest at Nushagak. This was certainly true of Tikchik and it is doubtful if, during this period, villagers had any contact with the priest at all except when they came to the post.

In 1886 the Moravian Church established a mission and school at the mouth of the Nushagak River just a few miles from Nushagak. Although the new missionaries worked hard to extend their influence throughout the area and eventually maintained two small chapels on the middle Nushagak River, they were unable to make much headway against the opposition of their Orthodox counterparts and the venture was abandoned in 1905 . There is no indication at all that the Moravians made any converts among the Eskimos of Tikchik, although the people may have visited the new mission and school on their trips to the bay (Hamilton, 1892; Schwalbe, 1951, pp. 51-64).

In evaluating his work during the 1880's the Orthodox priest at Nushagak noted that most of the river Eskimos, living as they did far from the church, retained many of their old beliefs and practices. He saw little hope of any improvement until these people could be visited at least two times a year (DRHA, vol. 2, p. 144). These statements seem to sum up very well the extent of Christian influence at Tikchik, the most remote of the Nushagak area villages. It may well have been that many, perhaps even most, of the villagers were nominal members of the Orthodox Church. As infants they may have been baptized and perhaps some couples were married when they visited the mission. But there appears to have been no real understanding of Christianity and no practice of Christian ritual in the settlement itself. At the time the village was abandoned, the residents were virtually as pagan as they had ever been in spite of more than 60 years of at least peripheral exposure to Orthodox teachings. This fact alone suggests the nature of isolation in the interior at the time when the bay area was rapidly becoming a cosmopolitan and highly acculturated center. 
Realistic population statistics for Tikchik and villages in the surrounding area are difficult to obtain for the period between 1860 and 1900 , partly because the seasonal movements of people made them difficult to count but also because during this period people from other areas were continually moving in to the Nushagak River region. It is likely, however, that much of this influx would eventually find its way to the bay area. Probably the most reliable figures are those based on official Orthodox Church sources, and they show that in 1895-1896 there were 384 Kiatagmiut, while in 1898-1899 the figure was 398. Most of these would appear to have lived in middle and upper river villages. Between 1860 and 1890 a number of new settlements came into existence in this area to replace in degree of importance earlier ones. However, the basic continuity of upriver and middle river population centers was not greatly altered. Tikchik, it will be recalled, had a population of 31 in 1879 (Bailey, 1880, pp. 2627 ) and it is likely that Old Koliganek replaced it as the major upriver settlement. This rapidly growing community had a population of 30 in 1879 (Bailey, 1880, pp. 26-27), 91 in 1880 (Petroff, 1884, p. 17) and 114 in 1898 (Elliott, 1900, p. 740). In the middle river region, three new villages appeared: Ahkokpak, Elilakok, and Tunravik. The only population listing for any of these settlements is a figure of nine for Ahkokpak in 1890 (Porter, 1893, p. 164) and it is doubtful if more than 100 persons ever occupied the three villages. In the Kokwok-Akulivikchuk area we can note important shifts in population. Agivavik, with a population of 47 in 1879 (Bailey, 1880, pp. 26-27), 52 in 1880 (Petroff, 1884, p. 17), and 30 in 1890 (Porter, 1893 , pp. 5,164 ) was probably abandoned sometime during the first decade of the present century, perhaps at the same time as Tikchik and for the same reason. Also abandoned about this time was Akulivikchuk which had 72 inhabitants in 1880 (Petroff, 1884, p. 17) and 61 in 1890 (Porter, 1893, p. 164). The last residents are said to have moved down to Kokwok, which itself was about to go into a decline in the first two decades of the twentieth century. During our period of interest Kokwok had a population of 83 in 1879 (Bailey, 1880 , pp. 26-27), 104 in 1880 (Petroff, 1884, p. 17), 145 in 1881 (DRHA, vol. 2, p. 144), 46 in 1890 (Porter, 1893, pp. 5, 164), and 106 in 1898 (Elliott, 1900, p. 740). Ekwok, with 79 inhabitants in 1898 (Elliott, 1900, p. 740), began to emerge as the major settlement for this section of the middle river and has continued to maintain this position down to the present time. On the basis of these population figures and an examination of the sites in question, it is possible to 
estimate an overall population of 300 to 400 people for the area between Tikchik and the middle river during this period.

The most critical dates for Tikchik Village itself were 1899-1900, for it was at this time that a major epidemic of influenza and measles struck the area. The people tended to blame it on the Twelf th Federal Census, statistics for which were being collected at the time and it is this epidemic that old time residents of the Kuskokwim and Nushagak regions refer to today as the "great sickness." The Orthodox Church reported 111 deaths among its parishioners in 1899, about four times the usual number, while at the Moravian mission at Carmel every child under the age of two died (Schwalbe, 1951, p. 60; DRHA, vol. 2, p. 331). As we have noted, the abandonment of Tikchik was directly attributable to this epidemic, the results of which were aggravated by a famine that followed in its wake. The people were too weak during the summer months to gather food supplies for winter.

In concluding this section on time and change it seems worthwhile to turn our attention briefly to a reconstruction of the seasonal round of subsistence activities at Tikchik near the turn of the century, or just before the settlement was abandoned. Much of the information to be presented was obtained from Ivan Ishnook, but data from other sources pertaining to the Nushagak River region as a whole will be drawn upon in order to round out the picture. It should be kept in mind that this information applies to the period between 1880 and 1900 , and the picture of seasonal activities that is presented is, in many ways, certain to be different from that which prevailed during the late prehistoric period.

Unlike the Nushagak River villages, Tikchik appears to have been a year-round community, although supporting data for this statement is not as conclusive as one would wish. The Nushagak River people spent the winter months in their villages along the river and in spring moved to temporary camps along streams in the mountainous country of the interior. There they hunted and trapped, returning to the river in early summer to fish for salmon. In the late summer the men alone moved to the interior, this time leaving the women to watch over the full fish caches. Interior hunting and trapping would continue until the first snowfall in October at which time the return trip to the winter villages would be made once more. At Tikchik, on the other hand, the hunters and trappers appear to have left their families in the village at all times, except perhaps at the time of the annual trip to Nushagak Bay, and returned frequently. 


\section{Fall and winter}

Trapping in the Tikchik area appears to have begun in the early fall and continued more or less continuously throughout the winter. Marten were very plentiful in the vicinity of the village and deadfalls were set for them. Tikchik men trapped farther up the Tikchik River. They had a few steel traps but most of the fox and beaver were taken with snares and deadfalls. Caribou were hunted along the Nuyakuk River and to the north in the area between the Tikchik Lakes and the upper Nushagak River. This was relatively high, open country and caribou were usually plentiful within a day's journey of the settlement. Moose, on the other hand, were comparatively scarce, although Ivan Ishnook noted that the residents of Tikchik saw these animals more frequently than did those people who lived along the Nushagak.

When ice began to form on the river about the end of October or early in November, traps for whitefish were placed under it and grayling were taken with hooks through holes. Later on in mid-winter when the ice on Tikchik Lake was solid, fishing through the ice for trout became a relatively important activity. A small bone fishing lure was used to attract the large fish close to the hole where it would be harpooned with a harpoon dart. Spruce hens are plentiful in the forested area around the site today and doubtless these birds supplemented a diet of fish and meat in winter. Further inland at the foot of Tikchik Mountain, ptarmigan were plentiful and were taken with snares.

The major winter activities in the villages of the Nushagak River were dances and dance festivals that began in late December or early January and lasted until February. Unfortunately, the winter ceremonies of this area were never described in detail by contemporary observers. Some of them appear to have been purely secular, while others doubtless had supernatural implications and seem to have centered around the propitiation of the dead and possibly the magical revival of game animals. The center of these winter festivities was the kashgee and frequently residents of other settlements would be invited and the singing and dancing in the kashgee would continue for many days (Porter, 1893, pp. 93-94). It was doubtless through this cycle of festivals and ceremonies that the people of Tikchik maintained social contacts and friendly relations with the inhabitants of other settlements in the upper Nushagak region and also gave expression to their religious beliefs. 


\section{Spring and summer}

In late February or early March trapping would begin again with the taking of beaver, bear, land otter, and other fur-bearing animals. It appears that beaver were taken mainly by digging them out of their houses (DRHA, vol. 1, p. 329). Caribou were again hunted extensively in the open country to the north and east of the village. The ice would go out of the Tikchik River in early May, but it might be the middle of June before the lake was completely free of ice. At this time the Tikchik families would begin to prepare for salmon fishing even though it would be some time before the runs of salmon reached the village. Traps constructed of split spruce strips were repaired so that they could be used effectively when the fish began to run. At the rapids on the upper Nuyakuk not far from the village salmon were taken with spears and dip nets (Cobb, 1907, p. 32Bower, 1926, pp. 108-110). Today waterfowl are plentiful around the site and various kinds of ducks and geese nest in the marshy bank area just to the northwest of the settlement. The taking of these birds must have been an important activity in the late spring and early summer.

We have already noted that in early summer not long after the river ice broke up, the residents of Tikchik would go down the Nuyakuk and Nushagak rivers to the Alaska Commercial Company post at Nushagak to trade their furs, thus following a pattern that had doubtless been established shortly after the founding of Alexandrovski Redoubt. It was at this time that trade goods were obtained and contacts made with the Eskimos of Nushagak Bay and other coastal points. It is likely that they did not stay long on the coast because of the necessity of getting back to the village in time to put up a winter's supply of fish. The return trip, as previously noted, was made by way of the Wood River and the lakes in order to avoid an arduous, time-consuming upriver paddle.

Today the red salmon appear in the Tikchik River opposite the site about the 15th of July and the run continues sporadically for about two weeks. Other species follow and it is likely that some salmon could be taken right up until freeze up. The river is relatively deep near the settlement since the bank is cutting at this point; it would be an ideal location for the setting of nets and traps. Most of the fishing at Tikchik, then, would take place in the late summer or early fall and it would be necessary for the villagers not to prolong their stay at the post if they wanted to be certain of taking full advantage of the red salmon run. It was this necessity of returning to the settle- 
ment in mid-summer that doubtless prevented the Tikchik people from a more intensive exposure to the influences of the salmon canneries in Nushagak Bay. Fish taken in the late summer were dried on racks with the heads sometime being buried and allowed to rot slightly before being eaten. Occasionally whole fish were buried in this manner. Fish eggs were put up in seal oil obtained in trade from the coastal Eskimo and these eggs were considered a delicacy to be eaten during the winter festivals.

Salmon fishing lasted much longer at Tikchik than it did in the Nushagak River villages, but in the early fall the attention of the men once more turned to caribou hunting because it was at this time of the year that many skins could be secured for winter clothing. In mid-September the fur of the beaver was again in prime condition and these animals were taken, as previously noted, in wooden deadfalls and by breaking their dams and allowing the water to run out exposing the beaver. Thus, fall activities would be well underway and the seasonal round completed. 


\section{Interpretations and Conclusions}

The primary disappointment and handicap in the Tikchik excavations was the absence of a recognizable division between the Russian and American periods of influence. This situation was not totally unexpected since I had participated in the excavation of another historic site in southwestern Alaska in which short term exotic influences could not be isolated in an archaeological context. One is forced to conclude that there may be few, if any, sites in Alaska in which such dimensions can be determined on a strong stratigraphic basis. The total period of time involved is simply too short and the various external influences on the Eskimo settlements apparently lacked sufficient intensity at specific points in time. It is obvious, then, that archaeology alone cannot solve the many problems of interpreting change among nineteenth century Eskimos. However, a satisfactory attempt at interpretation can be made, as has been noted elsewhere (Oswalt and VanStone, 1967), by integrating archaeological data with informants' statements and historical source material. It should be noted, however, that this is much more easily said than done. Eskimo informants who have even the vaguest remembrance of events at the end of the nineteenth century are virtually nonexistent. Even when one is encountered, it is unlikely that he will be able to remember cultural details sufficiently to be a major source of information to the ethnographer. In fact, the latter will probably consider himself fortunate if his informants can provide him with even the grossest information about the settlement pattern, approximate time of abandonment of sites, etc. After all, it is the scarcity of informants for this period that has made it necessary to add archaeology to the research tools of history and ethnography for the study of nineteenth century culture change.

Having noted the limitations of both ethnography and archaeology in this connection, we can now turn to a consideration of the third research tool, historical source materials. It will be obvious to the reader by this time that history has provided much of the background material against which the description of the Tikchik site and collections has been set, and that at the same time history has pro- 
vided relatively little specific information about the site itself. This situation can be said to be characteristic of the historical source material for all southwestern Alaska at all periods of time. There is much general impressionistic data but when it comes to specific, narrow studies in depth, this type of data is wanting. Of course, virtually none of the historical material utilized in this study was collected, organized, and written by a professional historian and none at all by an anthropologist. It was collected by individuals who found themselves in the Nushagak River region in the performance of their duties as priests, government officials, school teachers, cannery workers, etc., and their reports, naturally enough, are oriented around their jobs. Thus a Russian Orthodox priest will describe a trip up the Nushagak River, note the fact that baptisms and other religious rites were performed in several villages and give no other information at all. In this case, the ethnohistorian will consider himself fortunate if the priest actually gives the names of the villages he visited. At least then it is possible to say that such-and-such a village was occupied at such-and-such a time. It is certain that these problems are familiar to all ethnohistorians regardless of the area in which they have worked. They are mentioned here only to illustrate the fact that, in its own way, historical source material is not a much more satisfactory research tool for the study of cultural change in nineteenth century southwestern Alaska than archaeology and ethnography. All three are necessary if anything remotely approaching a complete picture is going to be achieved. The question might be asked, however, whether we are using these three research tools in a manner so as to extract the maximum amount of data from them.

As far as archaeology and the use of informants is concerned, it is difficult, at the present time, to see how refined techniques could produce more information. If there is no stratigraphic distinction between Russian and American levels in a site, for example, not even the most refined excavation technique will create one. It is true, of course, that a more skillful handling of aged informants might produce more data and I have discovered that as my own information increases, my more sophisticated questions elicit increasingly sophisticated answers. But it is perhaps in the area of historical sources that we have the most to learn as far as maximum usefulness is concerned. It is becoming increasingly necessary that we go not only beyond published sources but even beyond the standard archival repositories. And even in this latter field there is still a great deal to do. The records of the Russian-American Company, handed over to the 
United States government at the time of cession and currently deposited in the National Archives, are just beginning to be used by ethnographically oriented historians and the vast Alaska Church Collection in the Library of Congress, which records the activities of the Russian Orthodox Church throughout Alaska, has hardly been touched. Beyond these standard but little known sources, the diaries of missionaries, school teachers, traders, and others must be sought out and studied. Inventories of trade goods covering a long period of time at a particular trading post may yield data on material culture persistence and change which archaeological excavation has not produced. A study of nineteenth century trade materials in museum collections might be expected to provide similar useful information. The point is, that as far as the utilization of historical source material is concerned, we have just scatched the surface. There may be little more we can do at present to improve the quality and quantity of data obtained through archaeology and ethnography, but our work is just beginning as far as the use of written sources is concerned.

Allowing for the fact that more thorough work with historical sources is necessary, it is still possible to say that we already know a great deal about the Nushagak River and its population in the nineteenth century. I have presented this data in some detail elsewhere (VanStone, 1967) and it has been sketched in broad outline in the various chapters of this report. However, there is still much to be learned. A few elderly informants in communities along the river remain to be interviewed, but the main question concerns the extent and value of additional archaeological excavations. Just what can we expect to determine by digging more historic sites in the area? Will these be able to fill gaps that still exist because of various inadequacies in the Tikchik collections? Although it has become increasingly apparent from the excavations at Crow Village and at Tikchik that some of the major questions concerning culture change may not be answerable through archaeology, I nevertheless feel that we cannot be certain of this on the basis of one excavated site on the Kuskokwim River and another in the Nushagak region. In the latter area, for example, it would seem to be worthwhile to search for a site with preservation in order to give a more complete picture of traditional Eskimo material culture. It seems unlikely that such a site will be found on the river itself, but frozen sites have been reported in the area contiguous to Nushagak Bay (Larsen, 1950). At the same time, the excavation of one or more settlements on the Nushagak River itself might add to the number of known trade goods types for the 
area and perhaps also indicate whatever differences might exist between a strictly riverine settlement and one that conceivably could have had a stronger inland orientation and permanency of residence. In Nushagak Bay, the precise location of Alexandrovski Redoubt has not yet been determined with certainty. Should a further examination of the Nushagak site reveal the exact whereabouts of the post, it would almost certainly repay excavation and present a further opportunity to obtain, and possibly even isolate in a stratigraphic context, Russian trade goods. In short, it would seem that a fairly extended program of historical archaeology might be carried out in the Nushagak River region and increase our knowledge of a changing material culture to the point where certain generalities about the nature of change in the area could be advanced and supported with a reasonable amount of data.

Quite apart from the problems and difficulties presented by the whole concept of historical archaeology, ethnography, and history in the Nushagak River region, there are certain interpretive problems that arise specifically in connection with the Tikchik site and its inhabitants. One of the most puzzling of these concerns the precise identity of the people who inhabited the settlement from the time it was first established, presumably early in the nineteenth century, until it was finally abandoned in 1900 .

We have previously noted that Tikchik is located within the area that in late prehistoric times, at any rate, was thought to have been occupied by the Kiatagmiut, one of the subgroups of Yupik speakers. They were, it will be remembered, distinguished from the Aglegmiut who lived along the shore of Bristol Bay and southwest along the north shore of the Alaska Peninsula. This basic sub-cultural distinction between a coastal and inland people was recognized by the earliest explorers and today, in spite of many population changes, people are, in a general way, aware of the difference. Although the mixture of population in this area undoubtedly preceded the period of historic contact, we also know that the newly established Alexandrovski Redoubt served as an attraction to peoples both from the south and north (DRHA, vol. 4, pp. 243-244). In 1829, Father Veniaminov wrote that not only Aglegmiut, but also people from the Kuskokwim and various points on the Alaska Peninsula could be seen at the redoubt (Barsukov, 1897-1901, vol. 1, p. 14). Apparently Aleuts, too, occasionally visited Nushagak and in 1878, some of these, along with Kuskokwim Eskimos and Tanaina Indians, were living in the area under the jurisdiction of the Nushagak mission (DRHA, vol. 2, 
p. 230). Representatives of the same sub-cultural groups continue to be mentioned in the sources until the end of the century and it seems likely that although Kiatagmiut may have continued to be the most numerous subgroup living along the Nushagak River, Eskimos from the Kuskokwim and elsewhere already outnumbered Aglegmiut in the bay region. Ivan Petroff, in collecting data for the Tenth Federal Census, noted that many families from the Kuskokwim River, Yukon Delta, and Norton Sound were living in the vicinity of Nushagak (DRHA, vol. 2, pp. 146-147; Bailey, 1880, pp. 26-27; Elliott, 1900, p. 740; Petroff, 1884, p. 136).

It will be remembered that in 1829 Vasiliev visited the Kuskowagamiut village of "Tuksa," a settlement that we have identified as Tikchik, and that the only population listing for Tikchik in the historic sources indicates that 31 "Kuskaquims" were living there in 1879 (Russian-American Company Records: Communications Sent, vol. 6, no. 244, folio 478; Bailey, 1880 , pp. 26-27). With regard to the population figures, we have noted that they were taken from mission records at Nushagak and there is reason to believe that the sub-cultural designation is correct. That is, that the inhabitants of Tikchik at that time and earlier were not Kiatagmiut as might be expected, but rather people who had moved into the upper Nushagak River region from the Kuskokwim River. If this was the case in 1829 and 1879 , the question naturally arises whether Kiatagmiut ever lived at Tikchik or whether the settlement was established and then continuously inhabited by Kuskowagamiut.

Although it is likely that most Kuskokwim River people in the Nushagak River region generally and in Bristol Bay in particular, reached their new homes by way of the Bering Sea coast, there is no reason at all why some could not have come into the area by way of interior rivers and portages. The various routes between the middle Kuskokwim and the upper tributaries of the Nushagak must have been well known to the people of both areas even before the pioneer explorations of Vasiliev and Kolmakov. Although the KiatagmiutKuskowagamiut boundaries at the time of contact are usually drawn so as to include the Tikchik Lakes area in the territory of the former, it may very well have been that this region was uninhabited, or virtually so, at the time the Tikchik settlement was established. If, as at least seems possible, it was Kuskowagamiut who pushed into the area and established the settlement, then the boundaries should probably be redrawn so as to place this area within the territory of the Kuskowagamiut. One might well ask, however, whether people mov- 
ing from the middle Kuskokwim River would bring with them stone lamps and, at this time, a well-developed flint working technology. On the basis of present information, the answer would have to be no. But little is known of the archaeology of the middle Kuskokwim in the late prehistoric and early historic periods.

In the preceding descriptions and discussions, detailed comparisons with other Alaskan Eskimo sites have been avoided except with regard to the occurrence of check stamped pottery which presented a special interpretative problem. It is important, however, to draw some conclusions based on riverine archaeology elsewhere in Alaska. The only such archaeology is the Kobuk River excavations of J. L. Giddings (1952) and the Crow Village site on the middle Kuskokwim River (Oswalt and VanStone, 1967). During the 1940's Giddings excavated a series of sites along the Kobuk River and on adjacent Kotzebue Sound in northwest Alaska which range in time from 1250 1760 A.D. and provide greater continuity between the prehistoric and late prehistoric periods than is recorded anywhere else in Alaska. On the basis of these excavations, Giddings has described the Arctic Woodland Culture which is characterized "by a remarkable adaptation to an environment which includes clear streams, rugged mountains, forests, and a bay of the sea. It is a culture that draws freely upon all of the natural resources of these surroundings, and yet retains a core of basic traits in which may be demonstrated more than 700 years of continuity and stability. River fishing is hardly second to caribou hunting as a means of livelihood, and both of these stand well ahead of harbour sealing as bases of economy. Exchange of the resources of these endeavors as well as materials such as furs, tree barks and root fibers, and mineral substances, helps to minimize the special effects of local environment and makes possible the enrichment of the life of the individual without his having to move continually from one environment to another" (1952, p. 115). Giddings has further stated that the Arctic Woodland Culture, since it is a response to a particular set of environmental conditions-the river, forest, sea combination-should appear wherever these conditions exist (1952, p. 118).

In attempting to apply the Arctic Woodland Culture concept to the Kuskokwim River system, Oswalt and I noted that since the forest does not reach the sea in this area, the concept could not fit in its entirety. At the same time it was recognized that there were certain characteristics common to the two river systems, most notably the fact that both are western Alaskan rivers occupied by 
forest-dwelling Eskimos, both shared a diversity of economies with an emphasis on fishing, both had ties with the coast and with Athapascan Indians. The Kobuk River people, however, placed more emphasis on caribou hunting and probably maintained closer ties with coastal Eskimos. The Crow Village people, on the other hand, may have had closer ties with the Indians and certainly possessed greater economic stability due to the abundance of salmon. A comparison of Arctic Woodland Culture traits with the Crow Village collection tended to confirm the above pattern, particularly with regard to the greater intensity of coastal contacts found on the Kobuk (Oswalt and VanStone, 1967, pp. 106-108).

While questioning the usefulness of the Arctic Woodland Culture as a configuration applicable to the central Kuskokwim, Oswalt and I were nevertheless reluctant not to recognize that "riverine Eskimo cultures at the time of historic contact were in many ways distinct from their coastal neighbors" (1967, p. 109). We go on to suggest that "perhaps it might be useful to conceive of a configuration of Alaskan riverine Eskimo characteristics. The traits would include diverse fishing techniques for taking salmon and whitefish in particular. The use of trees, . . . is important, . . . The relative stability of physical settlement is a function of the productivity of the environment. ... There is also the trade with coastal Eskimos in which there is the exchange of forest-riverine products for those of the seacoast. It should be stressed also that like most Eskimos these people maintained a flexibility in their subsistence pursuits. They exploited land animals as well as fish, but their economic stability came from fishing" (1967, p. 109).

It is obvious, of course, that the Tikchik site exhibits all the characteristics of a riverine Eskimo configuration and one would hardly expect it to do otherwise. There are, however, certain features of life at Tikchik, as we have reconstructed it, that call for more detailed comment. To begin with, it seems likely that ties with the coast were somewhat stronger than at Crow Village but less than on the Kobuk River. The presence of the Nushagak post and later the salmon canneries served to draw the residents of Tikchik to Nushagak Bay at least once a year and we know that while they were there they traded for coastal products. However, coastal subsistence techniques are not reflected in the material culture at Tikchik and it is highly unlikely that the inhabitants engaged in subsistence activities during their visits, as did the Eskimos of the Kobuk River when they went to Hotham Inlet and Kotzebue Sound. 
Another point of interest on which we have already touched briefly is the possibility that the people of Tikchik were somewhat more sedentary than is usually the case with riverine peoples. We have suggested that the settlement may have been one of year-round occupation rather than one that was abandoned at certain times of the year when people moved inland to hunt, as was apparently the case with most Nushagak River villages during the nineteenth century. If such was indeed the case, the reasons can be found in the far inland location of Tikchik which made it convenient not only for the important summer salmon fishing, but also for caribou hunting and the trapping of fur-bearers. This possibility is strengthened by the statements of Ivan Ishnook who took care to point out that Tikchik was a year-round settlement and that hunters and trappers were seldom away from the community for more than two or three days at a time. There was good caribou hunting as well as trapping in the immediate vicinity of the village, particularly in the high country to the north and east and farther up the Tikchik River. This combined with the extensive salmon runs in the Tikchik in July and August and the good winter fishing for whitefish and trout in Tikchik Lake, allowed the residents to practice all the subsistence activities that were characteristic of riverine Eskimos without making long trips away from the village. There are indications that a similar stability of the physical settlement may also have characterized the middle Kuskokwim River but here we will only stress the fact that as far as the Nushagak River region as a whole was concerned, it is likely that for those settlements in the upper river area, and possibly in the Wood River Lakes region too, the settlement pattern was somewhat more stable than on the lower and middle Nushagak.

If Tikchik was indeed a year-round settlement, then it seems certain that it never could have been very large, and that all ten houses could not possibly have been inhabited at the same time. This also seems unlikely for other reasons that we will examine shortly, but it is clear that a community of at least 130 persons, which would be about its size if all the houses were occupied simultaneously, could not support itself by exploiting only that part of the environment within a two- or three-day trip from the settlement. It is much more probable that no more than three or four houses were occupied at a time throughout the total length of occupation and perhaps at times as few as two. This would permit the heads of perhaps six or seven nuclear families to utilize fully the adjacent environment for purposes of hunting and trapping. A much larger population 
could, of course, have been supported during the summer at the time of the salmon runs, but this larger number would then have had to disperse in order to carry out the subsistence activities characteristic of a woodland riverine environment.

It so happens that there are a number of indications evident in the Tikchik collections and in the physical settlement itself which suggest an age differential for the houses even within the relatively short span of total occupation. The following criteria were used as a means of determining tentatively the chronological relationship of the ten house pits to each other: 1) Distinctness of the house pit before removal of the sod. It was realized that a shallow, indistinct appearance is by no means an infallible indication of antiquity, but in combination with the other criteria, this seemed to be a reasonable characteristic of greater age at Tikchik;2) Wood preservation. Again this would not be a satisfactory criterion alone, particularly since so many of the houses had been robbed of at least some logs prior to collapse. Judgment here was based more on the condition of the wood rather than the amount. Generally speaking, those houses in which the wood present was pulpy and badly distintegrated were considered to be the oldest; 3 ) Prevalence of locally manufactured pottery. Those houses containing the most pottery were considered to be the oldest; 4) Prevalence of indications of flint working. Again, those dwellings with the most flint chips and tools were considered as oldest; 5) Prevalence of metal containers, tools, and worked fragments. Those dwellings containing the smallest amount of metal artifacts and rejectage were considered to be of the greatest age; 6) Depth of excavation. In combination with the other criteria, the depth of excavation of the dwellings appeared to be significant. A shallow excavation was thought to be an indication of age, while the more recent houses were built into fairly deep excavations. This is a relative matter, of course, since none of the structures on the site, with the exception of the kashgees, were really deeply excavated.

It will be noted that no attempt is made here to include a criterion involving relative age of the artifacts recovered from various houses. As stated previously, no artifacts could be identified as belonging solely to the period of Russian contact and those that do correspond to types mentioned in the Russian sources are too few in number and too widely distributed throughout the site to be significant as a possible indication of the age of any structure.

On the basis of the above mentioned criteria, it appears that houses 7 and 8 are the most recent on the site, with perhaps house 7 
being the more recent of the two. This would coincide with Ivan Ishnook's uncertain identification of house 7 as the dwelling in which he lived just before the village was abandoned. Houses 1, 2, and 4 seem to be the next oldest, although not necessarily in that order. House 5 is next and it is followed by another group of three, houses 3,6 , and 9 , with house 10 being considered the oldest. Of the two kashgees, number 1 is obviously the more recent since we know that it was in use at the time the site was abandoned.

Two points worthy of comment arise as a result of this chronological ordering of the Tikchik houses. First, it will be immediately apparent that the oldest houses are those without entryrooms, and second, the houses containing burials on the benches belong to the oldest group of structures. It is difficult to determine the significance of both these facts. Houses with entryrooms occur over a wide area of both time and space in Alaska and it may be simply fortuitous that those without entryrooms appear to be the earliest at this particular site. At other nineteenth century archaeological sites in the Nushagak River region examined by the author, both types are represented. On the other hand, the presence of entryrooms on the later houses at Tikchik could demonstrate greater permanence of residence and perhaps a more elaborate material culture. Houses 7 and 8 , for example, were the richest in the settlement from the standpoint of numbers of artifacts recovered.

The presence of burials on the benches of houses 3,5 , and 6 are equally difficult to explain satisfactorily except, as previously noted, it is virtually certain that following such a burial the house in question would be abandoned. Although this type of burial has been reported before for sites in southwestern Alaska (Larsen, 1950, pp. 180,181 ), it does not seem to be a common cultural trait and is probably a response to a crisis situation of some kind. That is, some occurrence that would force people to deviate from the usual method of burial. In this case it might have been a desire to depart from the settlement as quickly as possible.

On the basis of the house burials and the chronological order of occupation that has been discussed here, it is tempting to postulate two phases of occupation at Tikchik with perhaps a gap of a few years between them when the settlement was totally abandoned. The first phase would include houses $3,5,6,9$ and 10, not all of which, presumably, would have been occupied at the same time. Houses 6 and 9 in particular would seem to have been used for a very short period of time because of the very small number of artifacts recovered from 
them. Toward the end of this first occupation phase, some disaster, possibly the small pox epidemic of 1837-1838, overtook the residents and resulted in the deaths of several persons. In their haste to abandon this unlucky spot, the survivors buried on the benches of the houses those who were the last to die and quickly departed. Now perhaps there was a period of a few years during which no one at all lived at Tikchik; not long, probably, but long enough so that people would forget why the place had been abandoned. Then the second occupation phase would begin, this time involving houses $1,2,4,7$, and 8 , again with probably no more than two or three occupied at the same time. At the close of the century, illness once more visited Tikchik, this time resulting in the gradual abandonment of the occupied houses until perhaps only those living in house 7 remained and then they, too, departed. Admittedly, this sequence, and particularly the supposed gap between the two occupations, rests on very thin evidence. A glance at the site map (Fig. 3) will show that the houses belonging to phase one and those to phase two do not occur spatially in any suggestive groupings except that the earlier houses do appear, for the most part, to be located around the peripheries of the site and, with one exception, well back from the river bank. The population of 31 at the settlement in 1879 doubtless suggests the optimum number of persons who could have been living at Tikchik at any one time. Although the site as it appears today is one of the largest in the Nushagak River region, it seems certain that at no time was it ever as large as a number of villages on the Nushagak Rivel itself where greater mobility throughout the year would permit a larger concentration of population in the home village during the summer months. 


\section{References}

Ackerman, R. E.

1964. Prehistory in the Kuskokwim-Bristol Bay region, southwestern Alaska. Washington State Univ. Lab. Anthro., Rept. of Investigations, no. 26.

1965. Archaeological survey, Glacier Bay National Monument, southeastern Alaska, pt. II. Washington State Univ. Lab. of Anthro., Rept. of Investigations, no. 36 .

Alaskan RUSSIAN CHURCH ARCHIVES, ACCESSION 12,766.

MS. Vital statistics, Nushagak, 1842-1931. The Library of Congress, Washington.

Albert, L. S. and Kent, K.

1949. The complete button book. Doubleday \& Company, New York.

BAILEY, G. W.

1860. Report upon Alaska and its people. The U. S. Senate, 46th Congress, 2nd session, Doc. 132 . Washington.

BAKER, M.

1902. Geographic dictionary of Alaska. U. S. Geol. Survey, Bull. 187. Washington.

BARSUKOV, I. (ed.)

1886-88. Tvoreniya Innokentiya Mitropolita Moskovskago. 3 vols. in 2. Moscow.

1897-1901. Pisma Innokentiya Mitropolita Moskovskago i Kolomenskago 18281878. 3 vols. St. Petersburg.

BERKH, V. N.

1823. Puteshestvie uchenika morekhodstva Andreya Ustyugova, i sluzhiteley Rossiykoy Amerikanskoy Kompanii Fedora Kolmakova i Petra Korsanovskago v 1819 godu. Sievernyi Arkhiv, pt. 4. St. Petersburg.

Bower, W. T.

1926. Alaska fishing and fur-seal industries in 1924. Rept. of the U. S. Commissioner of Fisheries for the fiscal year 1925 with appendices. Washington.

1927. Alaska fishery and fur-seal industries in 1926. Appendix IV to the report of the U. S. Commissioner of Fisheries for 1927. Bureau of Fisheries Doc. no. 1023 . Washington.

BOWMaN, H. W.

1958. Famous guns in the Winchester collection. Fawcett Publications, Inc., Greenwich.

Chernenko, M. B.

1967. Lavrentiy Alekseyevich Zagoskin. An account of his life and works. In Michael, Henry N., ed., Lieutenant Zagoskin's travels in Russian America, 1842-1844. Aretic Institute of North America, anthropology of the north, translations from Russian sources, no. 7, Toronto. 
Cовв, J. N.

1907. The fisheries of Alaska in 1906. Rept. of the Commissioner of Fisheries for the fiscal year 1906 and special papers. Washington.

1931. Pacific salmon fisheries. Rept. of the U. S. Commissioner of Fisheries for the fiscal year 1930 with appendices. Washington.

Collins, H. B., JR.

1928. Check stamped pottery from Alaska. Jour. Wash. Acad. Sci., 18, pp. $254-256$.

1937. Archeology of St. Lawrence Island, Alaska. Smithsonian Misc. Coll., 96, no. 1. Washington.

DAtig, F. A.

1956-58. Cartridges for collectors. 2 vols. Borden Publishing Company, Los Angeles.

DOCUMENTS RELATIVE TO THE HISTORY OF Alaska.

MS. Alaska History Research Project, 1936-1938. MS in the University of Alaska Library and the Library of Congress.

Dumond, D. E.

1962. Prehistory of the Naknek drainage: a preliminary statement. Dept. Anthrop., Univ. of Oregon.

1965. On Eskaleutian linguistics, archaeology and prehistory. Amer. Anthrop., 67, no. 5, pp. 1231-1257.

Elliot , C. P.

1900. Salmon fishing grounds and canneries. In Compilation of narratives of exploration in Alaska. Washington.

Elliott, H. W.

1875. Our arctic province. Alaska and the Seal Islands. Charles Scribner's Sons, New York.

Ferraro, P. and Ferraro, B.

1964. The past in glass. Western Printing and Publishing Company, Sparks, Nevada.

Fontana, B. L.

1965. The tale of a nail: on the ethnological interpretation of historic artifacts. Florida Anthro., 18, no. 3, pt. 2, pp. 85-96.

Fontana, B. L. and Greenleaf, J. C.

1962. Johnny Ward's ranch. The Kiva, 28, nos. 1-2.

Giddings, J. L.

1952. The Arctic Woodland Culture of the Kobuk River. University Museum, Univ. Penn., Philadelphia.

1961. Cultural continuities of Eskimos. Amer. Antiquity, 27, no. 2, pp. 155173.

1964. The archaeology of Cape Denbigh. Brown University Press.

Godden, G. A.

1964. Encyclopedia of British pottery and porcelain marks. Crown Publishers, Inc., New York.

Gregory, H. E. and Barnes, K.

1939. North Pacific fisheries with special reference to the Alaska salmon. Studies of the Pacific, no. 3. American Council, Institute of Pacific Relations. New York. 
GRIFFIN, J. B.

1953. A preliminary statement on the pottery from Cape Denbigh, Alaska. In Asia and North America-transpacific contacts. Memoirs of the Society for American Archaeology, no. 9, pp. 40-42.

Griffin, J. B. and Wilmuth, R. H., JR.

1964. The ceramic complexes at Iyatayet. In Giddings, J. L., The archaeology of Cape Denbigh. Brown University Press.

Hamilton, J. T.

1892. The Moravian mission in Alaska. Christian Literature, 5, pp. 351-357.

HAMMERICH, L. L.

1958. The western Eskimo dialects. Proc. 32nd Cong. Americanists, 1956. Copenhagen.

HaNson, C. E., JR.

1955. The northwest gun. Neb. Hist. Soc., Publ. Anthro., no. 2.

Hawkins, J. E. and Daugherty, E. A.

1958. The silver fleece. An economic study of the Bristol Bay region. Alaska Rural Development Board, Juneau.

HunT, C. B.

1959. Dating of mining camps with tin cans and bottles. Geo Times, 3 , no. 8, pp. 8-10, 34 .

JACKSON, S.

1886. Report on education in Alaska. Washington.

KNIGHT, E. H.

1876. Knight's American mechanical dictionary. 3 vols. Houghton, Mifflin and Company, Boston.

KowTA, M.

nd. Old Togiak in prehistory. Unpublished Ph.D. dissertation. Univ. Calif., Los Angeles.

DELAGUNA, F.

1934. The archaeology of Cook Inlet, Alaska. University Museum, Univ. Penn., Philadelphia.

1940. Eskimo lamps and pots. Jour. Roy. Anthro. Inst., 70, pt. 1, pp. 53-76.

1947. The prehistory of North America as seen from the Yukon. Memoirs of the Society for American Archaeology, no. 3.

1956. Chugach prehistory: The archaeology of Prince William Sound, Alaska. Univ. Wash. Publ. Anthro., no. 13.

LANTIS, M.

1946. The social culture of the Nunivak Eskimo. Trans. Amer. Philos. Soc., 35 , pt. III.

LARSEN, H.

1950. Archaeological investigations in southwestern Alaska. Amer. Antiquity, 15, no. 3, pp. 177-186.

LARSEN, H. and RAINEY, F.

1948. Ipiutak and the arctic whale hunting culture. Anthro. Papers of the Amer. Mus. of Nat. Hist., 42.

Moser, J. F.

1899. The salmon and salmon fisheries of Alaska. Bull. U. S. Fish Commission, 18, for 1898. Washington. 
1902. The salmon and salmon fisheries of Alaska. Rept. of the Alaskan salmon investigations of the U. S. Fish Commission steamer Albatross in 1900 and 1901. Washington.

NELSON, E. W.

1882. A sledge journey on the delta of the Yukon, northern Alaska. Proc. Roy. Geograph. Soc., n.s., 6, pp. 660-670.

1899. The Eskimo about Bering Strait. Eighteenth annual report of the Bureau of Amer. Ethnol. pt. I. Washington.

ORCHARD, W. C.

1929. Beads and beadwork of the American Indian. Contrib. no. 11, Mus. Amer. Indian, Heye Foundation. New York.

ORMSBEE, T. H.

1959. English china and its marks. Channel Press, New York.

OSWALT, W. H.

1952a. The archaeology of Hooper Bay Village, Alaska. Anthro. Papers of the Univ. of Alaska, 1, no. 1, pp. 47-91.

1952b. Pottery from Hooper Bay Village, Alaska. Amer. Antiquity, 18, no. 1, pp. 18-29.

1953. The saucer-shaped Eskimo lamp. Anthro. Papers of the Univ. of Alaska, 1, no. 2, pp. 15-24.

1955. Alaskan pottery: a classification and historical reconstruction. Amer. Antiquity, 21, no. 1, pp. 32-43.

1963. Mission of change in Alaska. Eskimos and Moravians on the Kuskokwim. The Henry E. Huntington Library and Art Gallery, San Marino.

1967. Alaskan Eskimos. Chandler Publishing Company, San Francisco.

Oswalt, W. H. and VanStone, J. W.

1967. The ethnoarcheology of Crow Village, Alaska. Bureau of Amer. Ethnol., Bull. 199. Washington.

Petroff, I.

1884. Report on population, industries and resources of Alaska. Washington.

Porter, R. P.

1893. Report on population and resources of Alaska at the eleventh census: 1890. Washington.

RAINEY, F. G.

1941. Eskimo prehistory: the Okvik site on the Punuk Islands. Anthro. Papers, Amer. Mus. Nat. Hist., 36, pp. 453-469.

RHEAD, G. W.

1910. British pottery marks. Scott, Greenwood \& Son, London.

Russell, C. P.

1962. Guns of the early frontiers. Univ. Calif. Press.

RUSSIAN-AMERICAN COMPANY RECORDS.

MS. Communications sent, vol. 6 , no. 244 , folio 478 .

vol. 7 , no. 257 , folio 269 .

vol. 8 , no. 322 , folio 247 .

vol. 9 , no. 321 , folios $482-487$.

vol. 9 , no. 460 , folio 350 .

vol. 16 , no. 377 , folios $106-108$. 


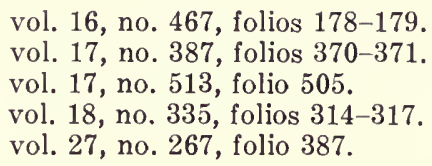

SCHAEFFER, B.

1961. Glass flake-scrapers. Plains Anthropologist, 6, no. 14, pp. 275-276.

SCHWALBE, A. B.

1951. Dayspring on the Kuskokwim. The story of Moravian missions in Alaska. Moravian Press. Bethlehem.

SimPSON, J.

1875. The western Eskimo. In A selection of papers on arctic geography and ethnology. John Murray, London.

SMiTh, C. S.

1960. Cartridges and bullets from Fort Stevenson, North Dakota. Appendix to River Basin Surveys paper no. 19. Bureau of Amer. Ethnol., Bull. 176, pp. 232-238.

Society of the United Brethren for Propagating the Gospel Among the HEATHEN.

1888. Proceedings of the one hundred and thirteenth general meeting of the Society of the United Brethren for Propagating the Gospel among the Heathen, held at Bethlehem, September 28, 1888. Bethlehem.

STEINBRing, J.

1966. The manufacture and use of bone defleshing tools. Amer. Antiquity, 31, no. 4, pp. 575-581.

SWINEFORD, A. P.

1898. Alaska, its history, climate and natural resources. Rand McNally \& Co., Chicago and New York.

Thorn, C. J.

1947. Handbook of old pottery and porcelain marks. Tudor Publishing Co., New York.

Tikhmenev, P. A.

1939-40. The historical review of the formation of the Russian-American Company and its activity up to the present time. 2 pts. St. Petersburg (translated by Dimitri Krenov, Works Progress Administration, Seattle, Washington).

\section{United States Department OF THE INTERIOR}

1891. Report of the Governor of Alaska for the fiscal year 1891. Washington.

VANSTONE, J. W.

1954. Pottery from Nunivak Island, Alaska. Anthro. Papers, Univ. Alaska, 2, pp. 181-194.

1955a. Archaeological excavations at Kotzebue, Alaska. Anthro. Papers, Univ. Alaska, 3, no. 2, pp. 75-155.

1955b. Exploring the Copper River country. Pacific Northwest Quart., 46, no. 4 , pp. $115-123$.

1959. Russian exploration in interior Alaska. An extract from the journal of Andrei Glazunov. Pacific Northwest Quart., 50, no. 2, pp. 37-47. 
1967. Eskimos of the Nushagak River: An ethnographic history. University of Washington Press.

1968. An annotated ethnohistorical bibliography of the Nushagak River region, Alaska. Fieldiana: Anthr., 54, no. 2, pp. 149-189.

Williamson, H. F.

1952. Winchester, the gun that won the west. A. S. Barnes and Company, Washington, D. C.

WOODWARD, A.

1965. Indian trade goods. Oregon Archaeol. Soc., publication no. 2. Portland.

ZAGoskin, L. A.

1967. Lieutenant Zagoskin's travels in Russian America, 1842-1844. The first ethnographic and geographic investigations in the Yukon and Kuskokwim valleys of Alaska. Edited by Henry M. Michael. Arctic Institute of North America, anthropology of the north, translations from Russian sources, no. 7. Toronto. 


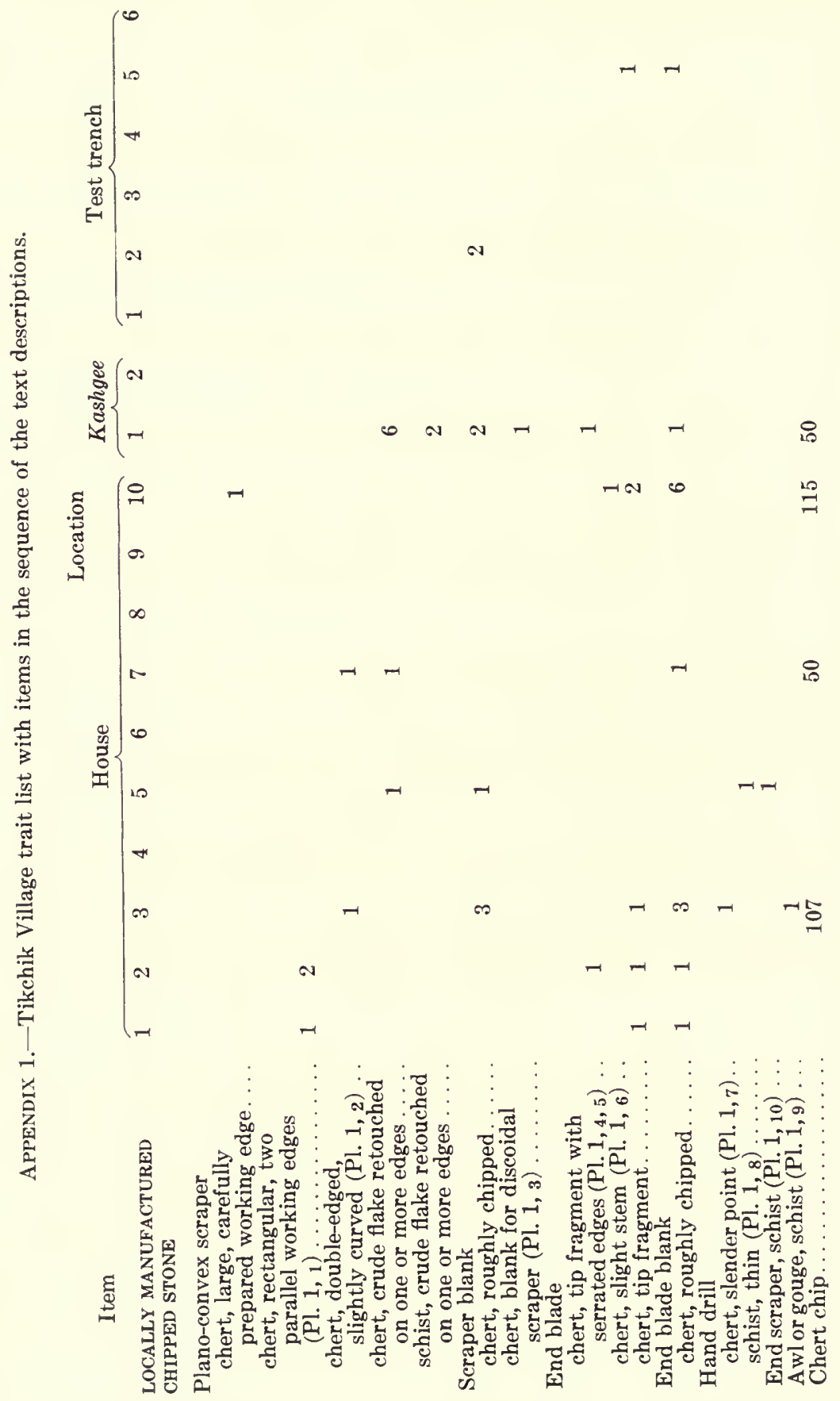




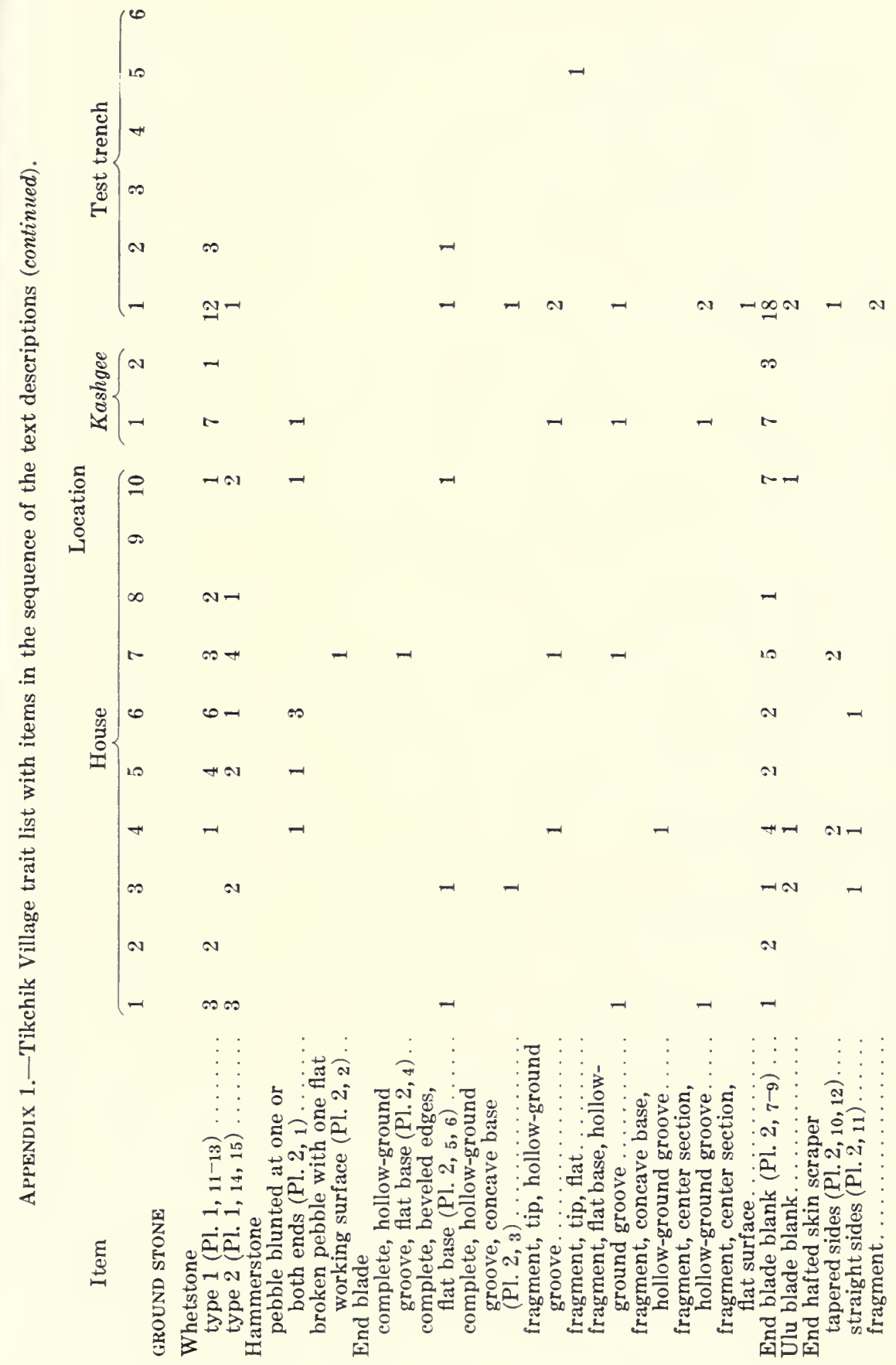




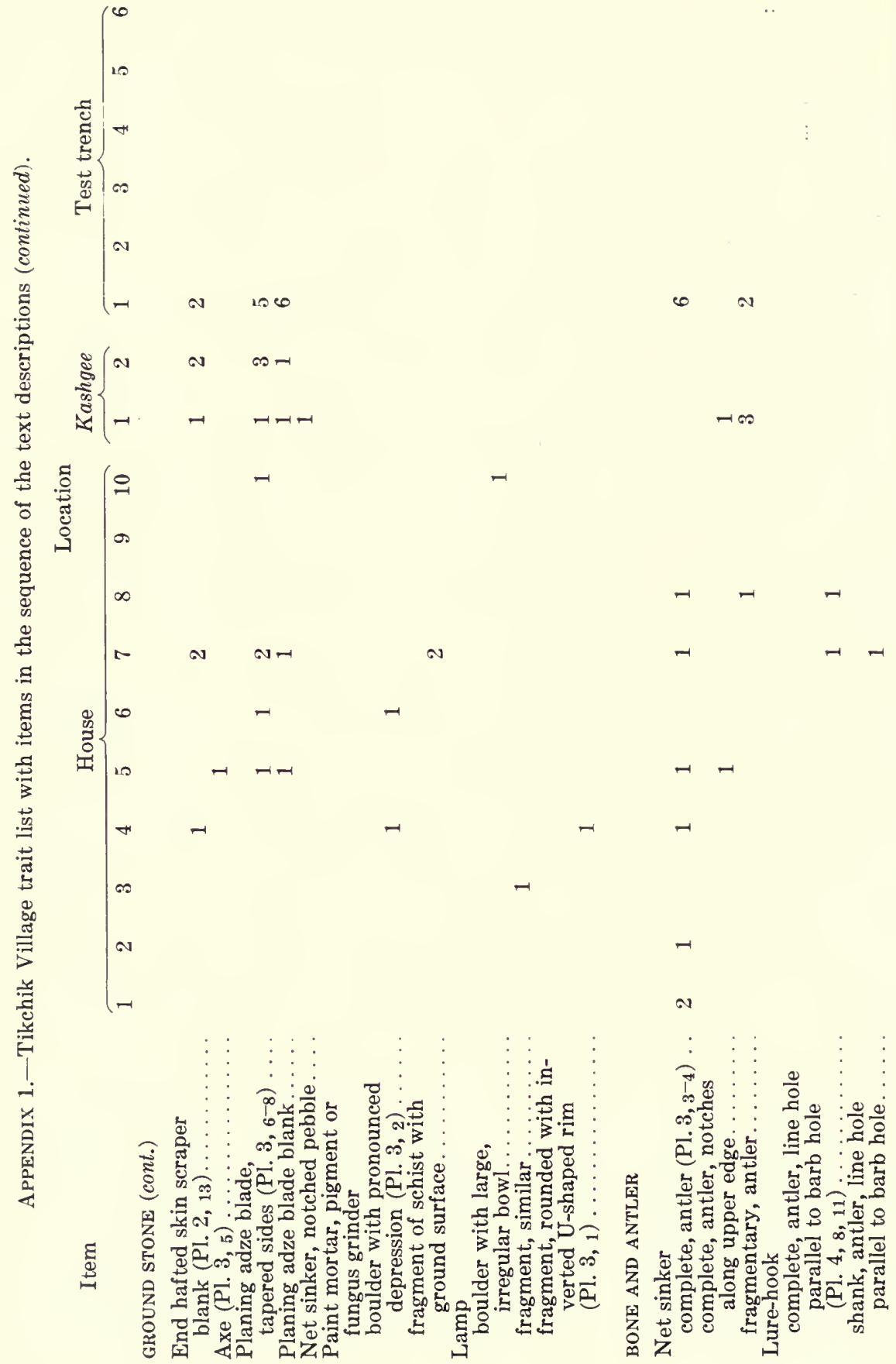




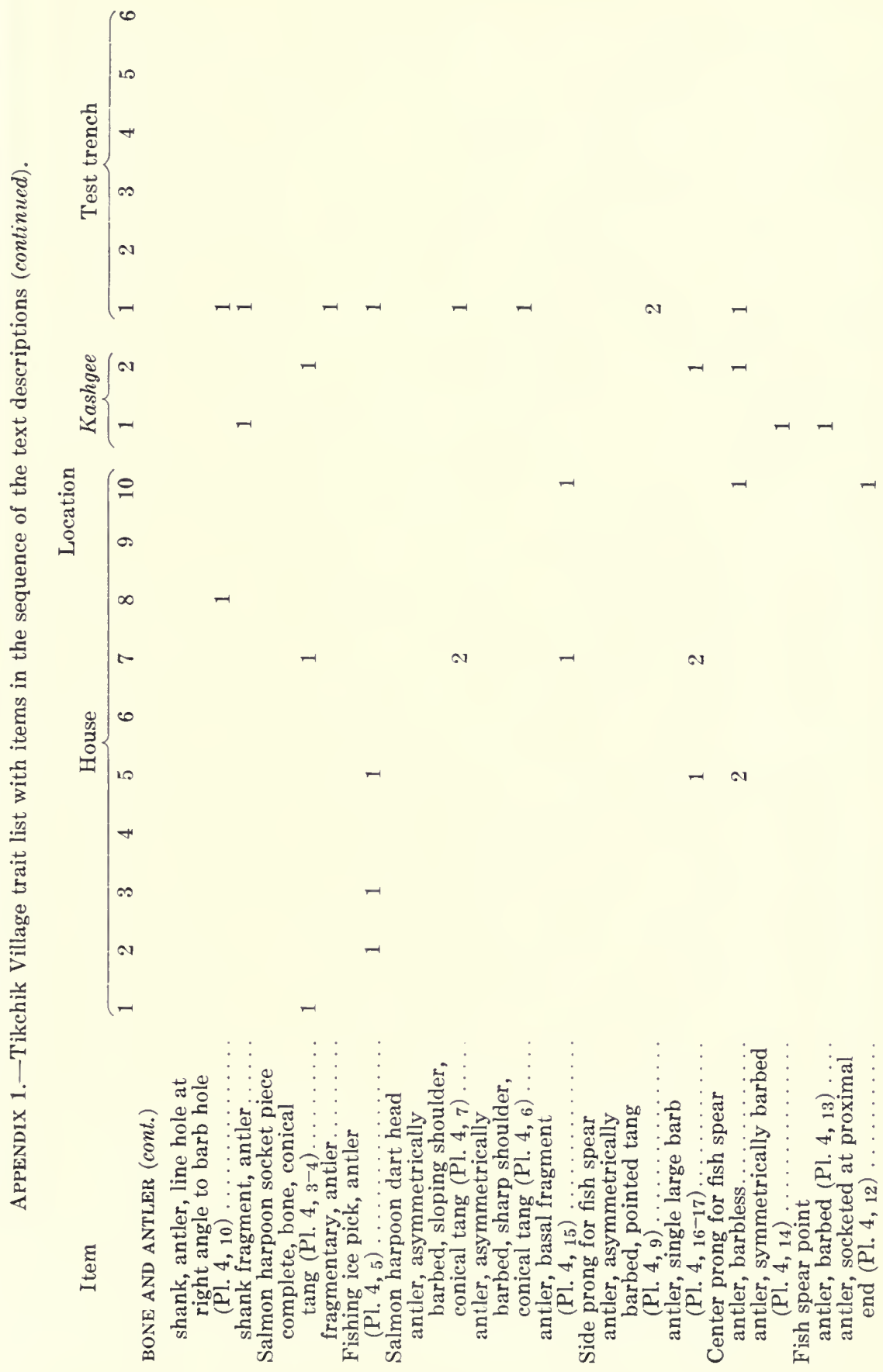




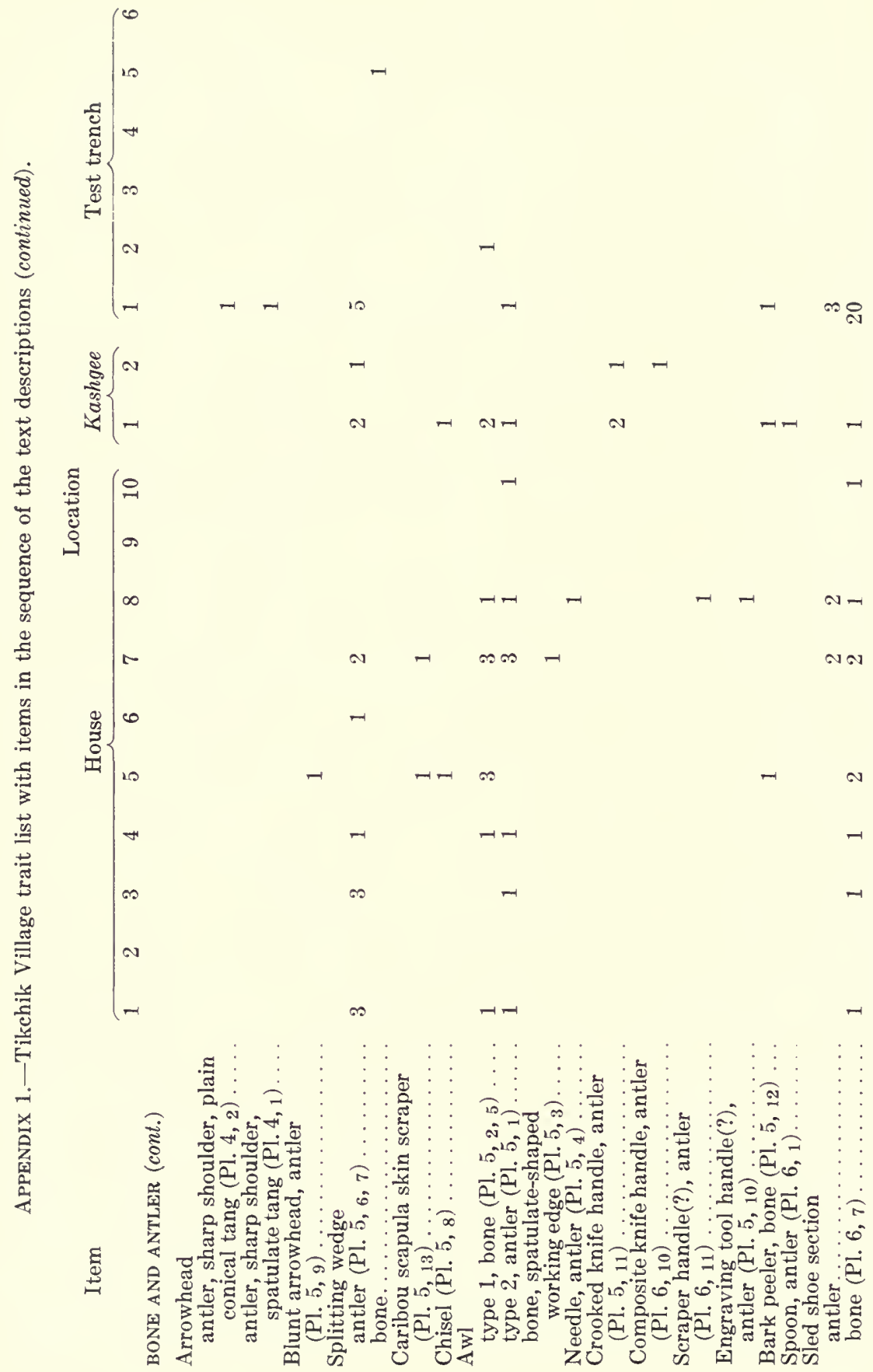




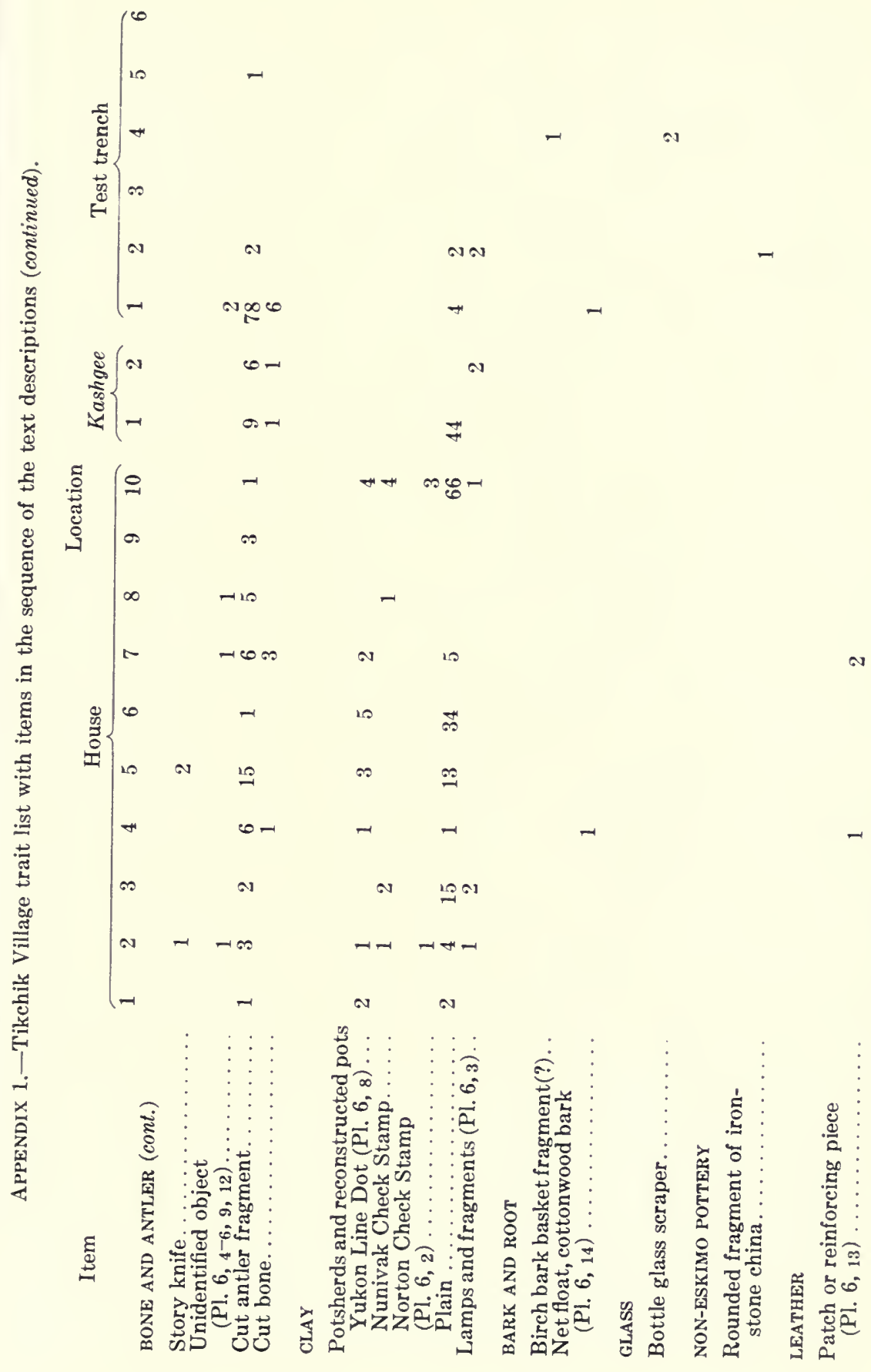




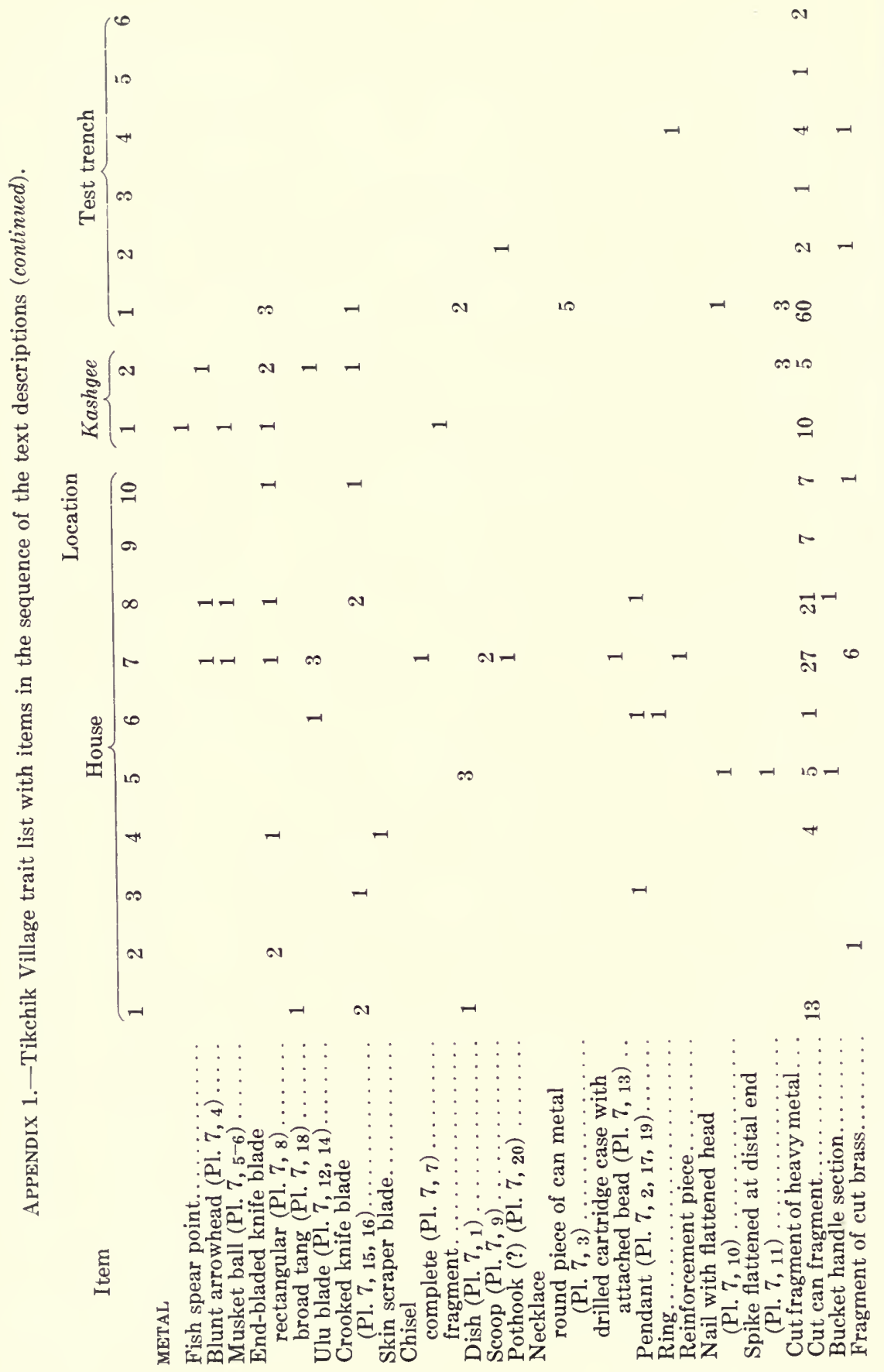




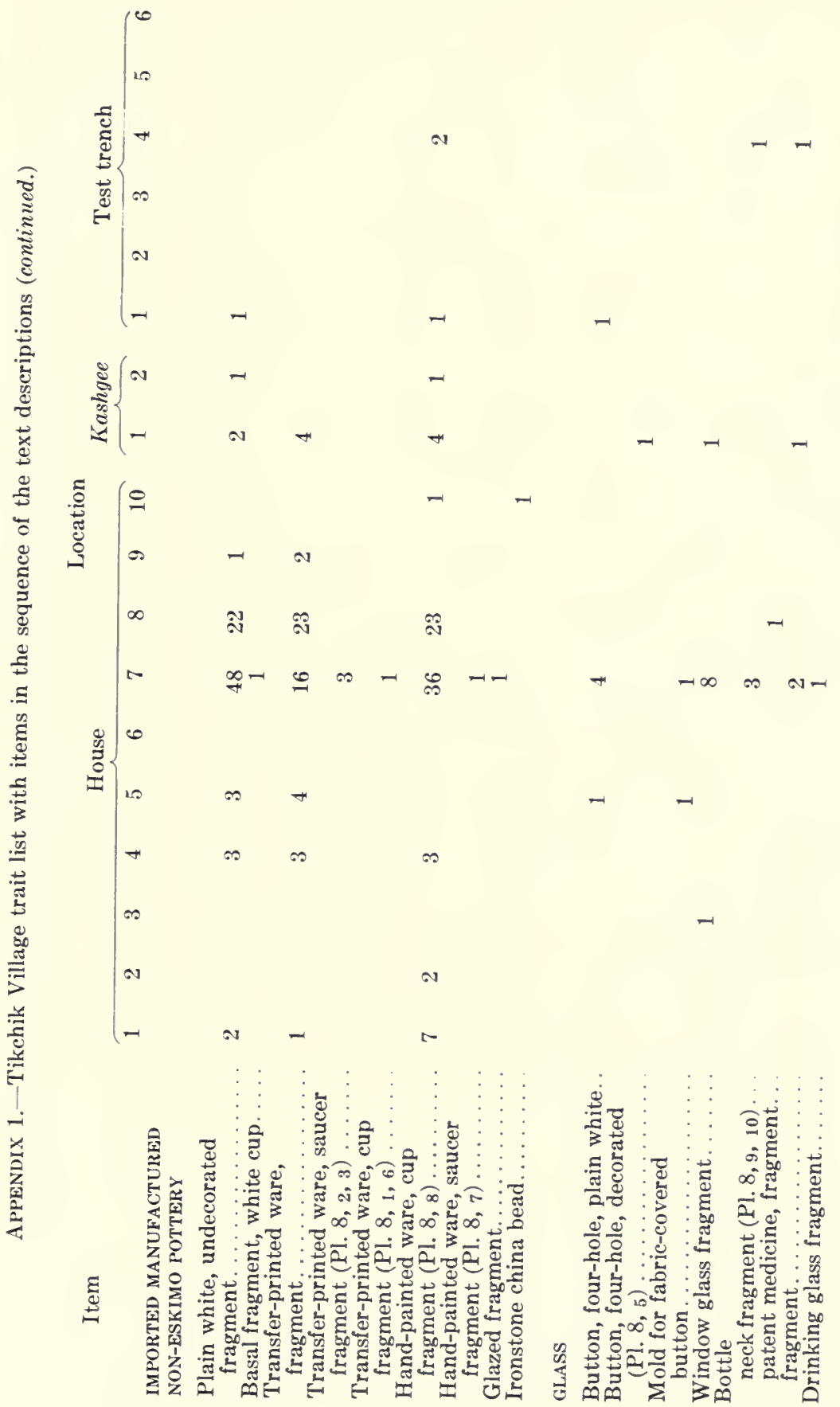




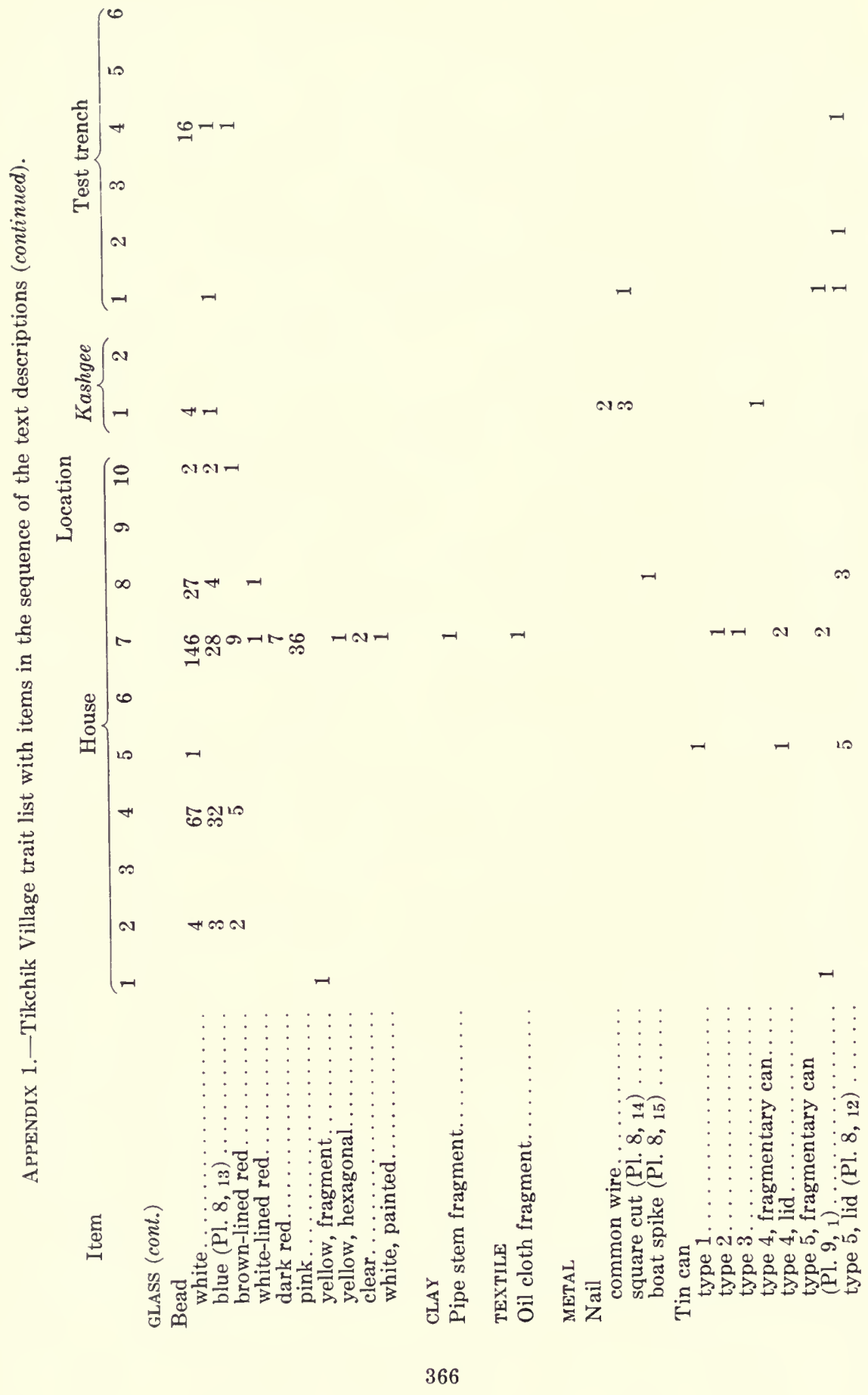




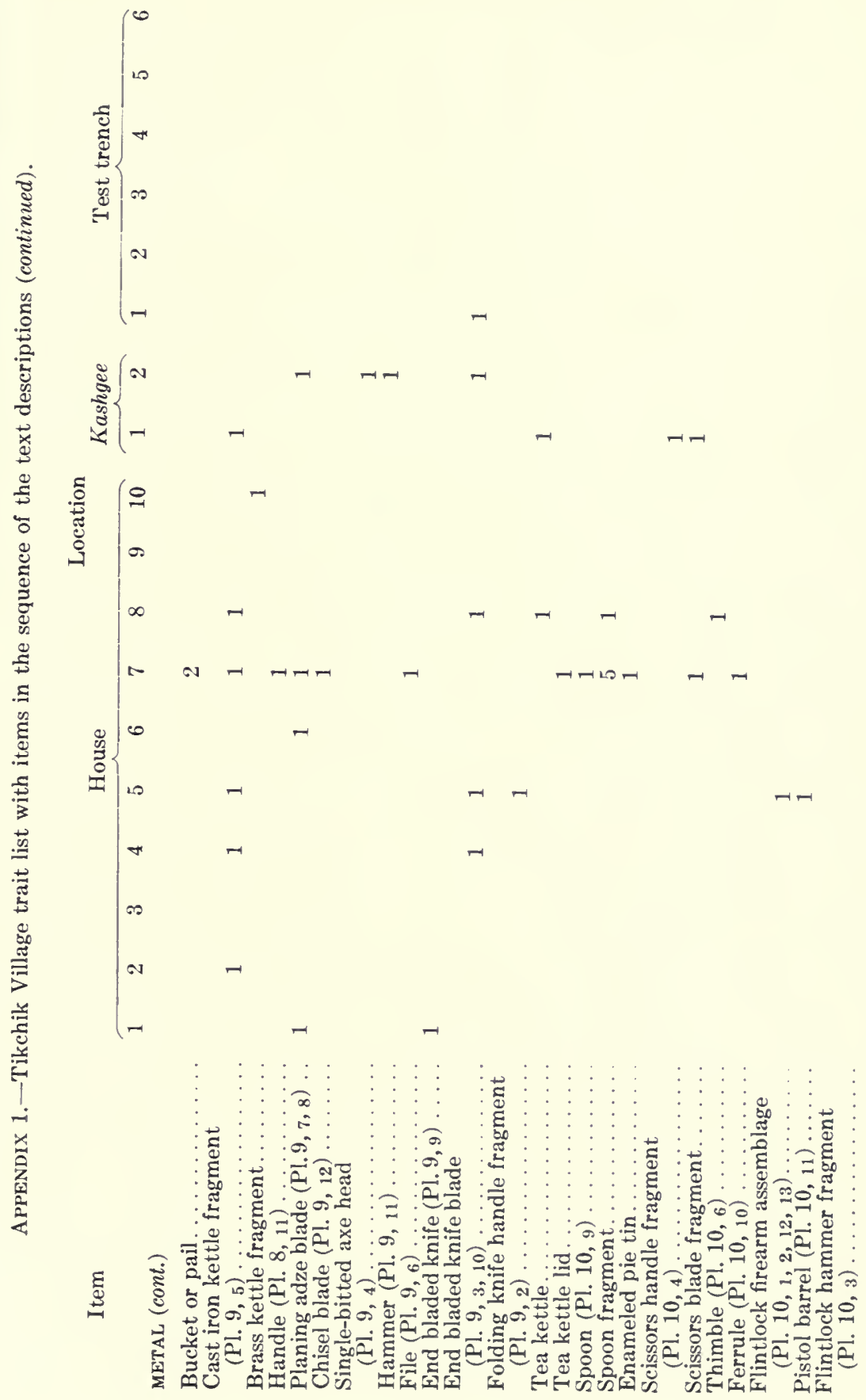




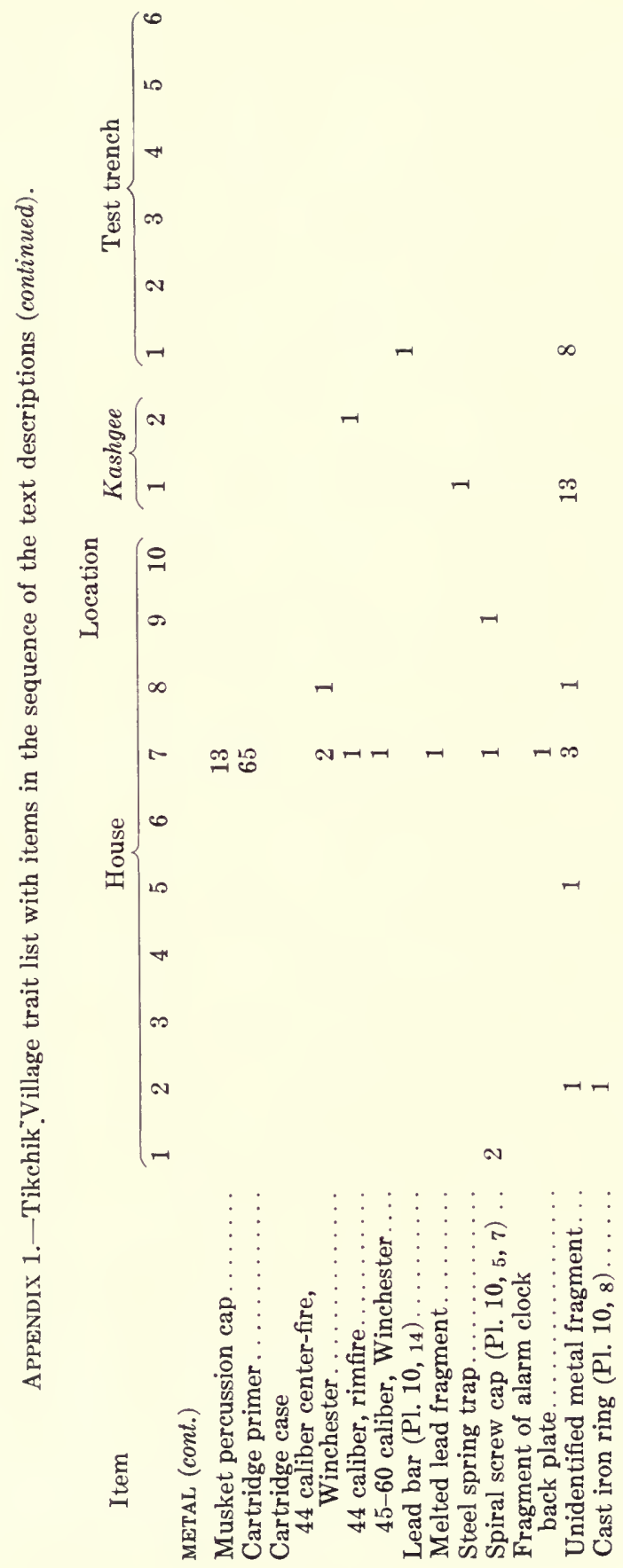




Publication 1057 





UNIVEASTY OF RLINOIS-URBANA

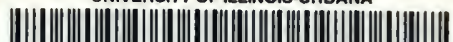

(1)

30112084204707 